\title{
Assessing the learning process in transdisciplinary research through a novel analytical approach
}

\author{
André Mascarenhas $^{1}$, Johannes Langemeyer $^{1,2}$, Dagmar Haase $^{1,3}$, Sara Borgström $^{4}$ and Erik Andersson $^{5,6}$
}

\begin{abstract}
Inter- and transdisciplinary research projects bring with them both challenges and opportunities for learning among all stakeholders involved. This is a particularly relevant aspect in social-ecological research projects, which deal with complex real-world systems and wicked problems involving various stakeholders' interests, needs, and views, while demanding expertise from a wide range of disciplines. Despite its importance in such research efforts, the learning process is often not the primary focus of investigation and therefore the knowledge about it remains limited. Here, we put forward an analytical framework that was developed to assess the learning process of both the research team and other participating stakeholders within the scope of an international transdisciplinary project dealing with urban green and blue infrastructure. The framework is structured around five dimensions of the learning process: "Why learn?" (the purpose of knowledge generation and sharing); "What to learn about?" (the types of knowledge involved); "Who to learn with?" (the actors involved); "How to learn?" (the methods and tools used); 'When to learn?' (the timing of different stages). We developed an interview protocol to operationalize the framework and tested our approach through interviews with project researchers. Based on our empirical results, we draw main lessons learned that can inform other transdisciplinary projects. These include capitalizing on what already exists, addressing trade-offs inherent to different types of knowledge, fostering inter- and transdisciplinarity, engaging stakeholders, supporting a learning environment and fostering reflexivity. Besides the empirical insights and the lessons we present, the main contribution of this research lies in the analytical framework we developed, accompanied by a protocol to apply it in practice. The framework can capture the learning process taking place in transdisciplinary research more comprehensively than similar existing frameworks. The five intertwined dimensions it covers are essential to understand and plan such learning processes.
\end{abstract}

Key Words: interdisciplinarity; knowledge; learning; reflexivity; stakeholders; transdisciplinarity

\section{INTRODUCTION}

Mutual learning and self-reflexivity are key for transdisciplinary knowledge production (Polk and Knutsson 2008, Jahn et al. 2012, Wittmayer and Schäpke 2014), which in turn is an important process underlying the resilience and sustainability of socialecological systems (Brandt et al. 2013, Clark et al. 2016, Hoffmann et al. 2017; Evely et al. 2012, unpublished manuscript, https:/citeseerx.ist.psu.edu/viewdoc/download?doi=10.1.1.459.2079\&rep= rep1\&type=pdf). Transdisciplinarity is, at its core, "both critical and self-reflexive: It not only systematically scrutinizes in which ways knowledge is produced and used by different societal actors in support of their concerns; it also methodically challenges how science itself deals with the tension between its constitutive pursuit of truth and the ever increasing societal demand for the usefulness of its results" (Jahn et al. 2012:9). A greater recognition of the different ways of understanding and working with knowledge is thus needed. So is moving away from merely technical approaches to knowledge exchange, limited to unidirectional, linear exchanges (Reed et al. 2014).

Knowledge that supports action toward sustainable development should be perceived by stakeholders as salient (relevant to their needs), credible (scientifically adequate), and legitimate (unbiased, fair, and respectful of stakeholders' divergent values and beliefs; Cash et al. 2003). Existing research suggests that the attributes of knowledge co-production processes - tightly linked with knowledge legitimacy - are important determinants of whether that knowledge leads to action (Posner et al. 2016).
Approaches to assess such attributes are therefore needed, in line with calls for monitoring, reflecting on, and continuously refining knowledge exchange as a flexible process (Reed et al. 2014). The learning process often refers to the production of knowledge as a joint process among stakeholders, including scientists (Walter et al. 2007, Vilsmaier et al. 2015), building on the notion of mutual learning, defined as "the basic process of exchange, generation, and integration of existing or newly developing knowledge in different parts of science and society" (Scholz 2001:118).

Despite its importance in transdisciplinary social-ecological research efforts, the learning process is often not the primary focus of investigation and therefore the knowledge about it remains limited. Literature presenting self-reflections by researchers on the learning taking place in transdisciplinary efforts is rare, while empirical studies of learning often remain implicit regarding who learns about what and why (van Mierlo et al. 2020). Empirical evidence from the different parties involved in transdisciplinary research is needed to improve the existing body of knowledge and better support guidance for knowledge exchange (Reed et al. 2014). Hence, several authors stress the need for more studies focusing on learning, for example in the context of sustainability transitions research (van Mierlo et al. 2020).

In this article we put forward an analytical framework that was developed to assess the learning process of both the research team and other participating stakeholders within the scope of an international transdisciplinary project dealing with urban green

${ }^{1}$ Humboldt-Universität zu Berlin, Department of Geography, Landscape Ecology Lab, Berlin, Germany, ${ }^{2}$ Institute of Environmental Science and Technology (ICTA), Universitat Autònoma de Barcelona, Barcelona, Spain, ${ }^{3}$ Helmholtz Centre for Environmental Research (UFZ), Department of Computational Landscape Ecology, Leipzig, Germany, ${ }^{4}$ Department of Sustainable Development, Environmental Science and Engineering, KTH Royal Institute of Technology, Stockholm, Sweden, ${ }^{5}$ Stockholm Resilience Centre, Stockholm University, Stockholm, Sweden, ${ }^{6}$ North-West University, Unit for Environmental Sciences, Potchefstroom, South Africa 
and blue infrastructure (GBI). Drawing from existing literature, the framework is structured around five dimensions of the learning process, covering (i) the purpose of knowledge generation and sharing, (ii) the actors involved in the learning process, (iii) the knowledge, insights, ideas, and perspectives involved in the learning process, (iv) the methods and tools used in the learning process, (v) the timing of different stages in the learning process. Because knowledge can be seen as contextdependent and strongly related to an individual's perceptions and worldview (Gibbons et al. 1994; Evely et al. 2012, unpublished manuscript), we developed an interview protocol to operationalize the framework and tested our approach through interviews with project researchers. Our empirical results from a multi-case study research project offer insights into a learning process taking place in different contexts but under a common overarching conceptual framework. Such an international perspective across local contexts is seen as increasingly important in urban research (Hurley et al. 2016). We conclude by drawing main lessons learned and take-home messages, which can inform other transdisciplinary projects.

\section{METHODS}

\section{Analytical framework}

Our approach covers the different components of a knowledge system (Posner et al. 2016): the knowledge co-production process, the participants in the process, and the resulting knowledge itself. However, we refer to the process as a "learning process" instead of knowledge co-production or knowledge exchange process (Enengel et al. 2012, Reed et al. 2014). This is in line with a shifting understanding of knowledge, from "knowledge as a thing" that can be produced, given, and received, toward "knowledge as a process" that is evolving and context-specific (Raymond et al. 2010, Reed et al. 2014; Evely et al. 2012, unpublished manuscript). It also aligns with our interest not only in knowledge sensu stricto (which can be interpreted in a more formal sense, related to education), but also on ideas, insights, or perspectives that the different participants in the learning process might gain. In this sense, we follow a definition of learning process from the transitions literature, as "the process of acquiring and generating new knowledge and insights, and of meaning-making of experiences in communicative interaction, in a reciprocal relationship with the social, (bio-)physical and institutional context. Moreover, it is a non-linear, iterative process in which ideas and possibilities for collaborative action are being developed, experimented with and pursued in a diversity of networks" (van Mierlo et al. 2020:253).

We drew on existing literature to develop our analytical framework for assessing the learning process taking place in transdisciplinary research. As noted by Hoffmann et al. (2017), various frameworks have been developed to structure evaluations (ex ante or ex post; formative or summative) of transdisciplinary research. However, most of them are unsuitable or too limited for our purpose. For example, very few differentiate types of actor involvement at different stages of the research (Hoffmann et al. 2017). Our framework draws more heavily on the works of Enengel et al. (2012), Hoffmann et al. (2017), and Roux et al. (2017). On a study about the specific challenges for implementing co-production of knowledge in doctoral studies, Enengel et al. (2012) developed an analytical framework to compare transdisciplinary case studies, consisting of the following elements: (1) typology of actor roles: Who?, (2) research phases: When?, (3) objectives and forms of actor integration: Why?, and (4) types of knowledge: What? Hoffmann et al. (2017) adapted the framework by Enengel and colleagues to compare transdisciplinary integration across four synthesis processes regarding different types of generated knowledge (what?), different types of involved actors (who?), and different levels of actor involvement (how?) at different stages of the processes (when?). The study by Roux et al. (2017) is the most aligned with our purpose because it focuses on mutual learning within transdisciplinary research, specifically on three aspects that could guide researchers in designing and facilitating such learning: "who to learn with," "what to learn about," and "how to learn." The development of the analytical framework was supported by joint reflections and feedback from all consortium researchers in internal workshops throughout the ENABLE project (described below).

Our analytical framework is structured around five dimensions of the learning process (Fig. 1):

Fig. 1. Analytical framework to assess the learning process in transdisciplinary research. Adapted from Enengel et al. (2012), Hoffmann et al. (2017), Roux et al. (2017).

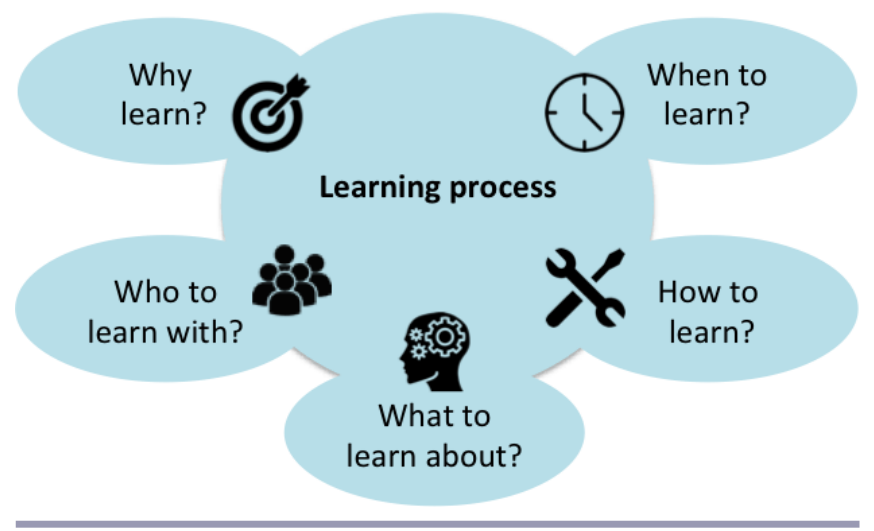

- Why learn? (the purpose of knowledge generation and sharing);

- What to learn about? (the knowledge, insights, ideas, and perspectives involved in the learning process);

- Who to learn with? (the actors involved in the learning process);

- How to learn? (the methods and tools used in the learning process);

- When to learn? (the timing of different stages in the learning process).

The purpose of knowledge generation and sharing (Why learn?) is linked to the applicability of knowledge. This can take various forms, but two general purposes are particularly relevant: (i) knowledge to develop policy options, strategies, decisions, practices (applicability for policy or society); (ii) knowledge to develop theories, methods, and models (applicability for science). These can be regarded as poles in a gradient, which reflect a life- 
world approach vs. an inner-scientific approach to transdisciplinary efforts (Jahn et al. 2012), linked with local or context-specific knowledge vs. generalized knowledge (Raymond et al. 2010, Enengel et al. 2012). This dimension differs from the "Why?" by Enengel et al. (2012), which was focused on different types of stakeholder involvement.

The knowledge, insights, ideas, and perspectives involved in the learning process (What to learn about?) can be limitless, so several authors have developed typologies of knowledge. We consider three mutually dependent types of knowledge inherent to transdisciplinary research as particularly relevant (Hadorn et al. 2008): (i) systems knowledge of empirical processes and interactions of factors, addressing questions about the origin, development, and interpretation of life-world problems; (ii) target knowledge concerning questions related to determining and explaining the need for change, desired goals, and better practices; (iii) transformation knowledge dealing with questions about technical, social, legal, cultural, and other means of action to transform existing practices and introduce desired ones. We were also interested in "knowledge on how to create knowledge," which refers to a reflection about the research approach (e.g., how different methods can be combined to generate knowledge on GBI-related issues in different case study cities; Dunford et al. 2018).

Regarding the participants of the learning process (Who to learn with?), we identified two main groups: (a) the research team; (b) other project stakeholders. These can be further detailed, following the five categories developed by Ritter et al. (2010) and adopted by Enengel et al. (2012): (i) core scientists: the main scientific actors throughout the course of a project; (ii) scientific consultants: academic experts who support the core group; (iii) professional practice experts: practitioners who are often very familiar with the practical and political aspects of the issues investigated, but not necessarily with the specific local case context; (iv) strategic case actors: practitioners at case level with a specific formal or informal responsibility, or professional competence; (v) local case actors: all other actors involved in the processes at the case level. It can be relevant to consider alternative ways of categorizing participants, for example according to the types of knowledge they represent (Roux et al. 2017) or to their level of interest and influence on the project (Reed 2008).

The methods and tools used in the learning process (How to learn?) will vary across projects and case studies, but two concepts are important here (Opdam et al. 2015, Roux et al. 2017): (i) boundary concepts: a special case of boundary objects (e.g. models, indicators, and maps). Co-production of these objects can establish shared interest and bridge understanding across multiple knowledge domains. Similarly, boundary concepts, which are non-material, can play a mediating and translating role in a transdisciplinary context, by creating a discursive space in settings with a common urgency, but without consensus or a common knowledge base; (ii) "third places": in a transdisciplinary sense, a third place represents a learning space at the interface between academia and practice, where academics and nonacademics can have an equal voice when they engage to find common ground regarding particular social-ecological issues. We consider that third places refer not only to physical spaces, but more widely to settings that can promote such a learning space (e.g., through a set of rules of engagement).

The timing of different stages in the learning process (When to learn?) can have several implications, like influencing the policy uptake of scientific knowledge, according to policy windows (Rose et al. 2020). The key stages of a knowledge co-creation process can be categorized as (1) problem history, (2) problem identification and structuring, (3) research design and selection of methods, (4) data collection, (5) data analysis and triangulation, (6) reflection/interpretation and synthesis, and (7) dissemination of results (Pohl and Hadorn 2007, Enengel et al. 2012).

The framework's dimensions do not necessarily follow a specific sequence; there can be different and multiple entry points, depending on the features of a specific application (like aims, scope, or time of assessment). For example, if applying the framework ex ante to support the design of a learning process, it might make sense to start with what motivates the learning process (why learn?), followed by who should be involved (who to learn with?) and what knowledge, insights, or perspectives are expected or wanted from participants (what to learn about?), and finally considering methods and tools to support the process (how to learn?), always keeping in mind the time dimension (when to learn?).

\section{The ENABLE project}

ENABLE was a research project funded under the 2015-2016 call from BiodivERsA, a network of national and regional funding organizations promoting pan-European research on biodiversity and ecosystem services. The project aimed at enabling GBI potential in complex social-ecological regions using a systems perspective and engaging local actors in five case studies: Barcelona (Spain), Halle (Germany), Łódź (Poland), Oslo (Norway), and Stockholm (Sweden). New York City (USA) was also included as an external node for benchmarking. The research reported in this article targeted the five European case studies.

As a transdisciplinary project, ENABLE represented an opportunity to foster learning among all participants, including members of the consortium and the different stakeholders who were engaged in the process, mainly in each case study. Project partners developed approaches tailored to each urban region to achieve that aim (as illustrated by many of the articles in this Special Feature) under ENABLE's common overarching conceptual framework (Andersson et al. 2019).

\section{Interviews}

We developed an interview protocol to operationalize (ex post) the analytical framework (Appendix 1). Joint reflections and feedback from all ENABLE researchers in internal workshops throughout the project supported the development of the interview protocol (in line with the analytical framework). Some questions differed depending on the main group of participants (the research team or the project stakeholders). To contextualize the results regarding the five dimensions of the framework, it was also important to gather information on what participants found interesting and useful about the process. This can be used to identify relevant aspects that influence learning (Restrepo et al. 2018). To capture that information we added questions drawing 
Table 1. Main topics emerging from the interviews for each dimension of the analytical framework. The contextualization and details given in the main body of text are essential to interpret the topics listed.

\begin{tabular}{|c|c|}
\hline Dimension & Main topics \\
\hline Why learn? & $\begin{array}{l}\text { To improve actionability and relevance for green and blue infrastructure planning and management } \\
\text { To build a shared systems understanding } \\
\text { To provide a platform for discussion among stakeholders } \\
\text { To actively enact the integration of transdisciplinary research } \\
\text { To guide future research } \\
\text { To expand the individual researchers' conceptual understanding or methodological toolbox }\end{array}$ \\
\hline What to learn about? & $\begin{array}{l}\text { How to work together with different stakeholders (benefits, challenges, limitations, needs) } \\
\text { How to apply different methods to specific issues or contexts } \\
\text { How to (co-)create knowledge (contextualized meaning and use of concepts, boundary concepts) } \\
\text { Opportunities to extend and amplify learning processes }\end{array}$ \\
\hline Who to learn with? & $\begin{array}{l}\text { Local authorities (especially planning, environmental, green space management, or similar departments) } \\
\text { Initiatives and organizations at sub-municipal scale (e.g., neighborhood) } \\
\text { Citizens in general } \\
\text { Colleagues in and outside research consortium } \\
\text { Private actors } \\
\text { Politicians } \\
\text { Marginalized groups } \\
\text { Grassroots groups }\end{array}$ \\
\hline How to learn? & $\begin{array}{l}\text { Workshops with local stakeholders } \\
\text { Participation in expert groups } \\
\text { Thematic meetings with individual stakeholders } \\
\text { Training events } \\
\text { Consortium workshops } \\
\text { Using boundary concepts } \\
\text { Devising "third places" }\end{array}$ \\
\hline When to learn? & $\begin{array}{l}\text { Project preparation phase } \\
\text { Temporal alignment with real ongoing processes } \\
\text { Follow-up on stakeholder engagement events } \\
\text { Dissemination and assessment of new knowledge }\end{array}$ \\
\hline
\end{tabular}

on the Most Significant Change technique (Serrat 2017), a storybased, qualitative method for uncovering most significant project impacts experienced by individuals. The main guiding question used to open a conversation through this technique was: "What did you find most interesting and useful from the project? What were the main "take-home messages"?" Two other questions included in this technique drew on the work by Cvitanovic et al. (2016), one on barriers preventing knowledge exchange and one on suggestions for improving knowledge exchange.

Ten members of ENABLE's research team were interviewed per online call toward the end of the project, between June 2019 and April 2020. We aimed for individual perspectives (as opposed, for example to having a spokesperson per case study) because we see them as most relevant in an inter- and transdisciplinary learning process, where researchers within the same team have had different roles. Because of practical constraints it was not possible to conduct the interviews with project stakeholders across case study cities. The first author of the present article conducted all the interviews and was not included as interviewee, whereas the remaining co-authors were. Interviews were conducted in English and lasted between 30 and 60 minutes. Interviewees signed an informed consent form (Appendix 2). The first author transcribed and manually coded the interviews supported by the software MAXQDA Plus 2020, release 20.0.8 (VERBI Software 2019). The remaining co-authors have verified the coding in a subsequent stage, to identify potential inconsistencies or deviations in interpretation. Interviews were transcribed, in a close way to what the interviewees said, but not fully verbatim, because it was the content of what was being said that was of interest and not the wording (Kuckartz and Rädiker 2019). We anonymize interviewees when presenting results in this article, using identifiers composed of the initials of the case study city (BAR: Barcelona; HAL: Halle; LOD: Łódź; OSL: Oslo; STO: Stockholm; CC: cross-case) followed by an ordinal number (e.g., BAR1). This retains the identification of different case studies and interviewees, which is relevant for the analysis of results.

\section{RESULTS AND DISCUSSION}

We present results according to, first, the different dimensions of our analytical framework (see Table 1 for a summary), and second, topics cutting across dimensions. Because the analytical dimensions are closely interrelated, we cross-reference dimensions along the text when pertinent, for example by flagging content that is relevant for other dimensions with " $\rightarrow$ [dimension's short designation]." Given the qualitative nature of this research, we have tried to highlight recurring topics from the interviews, while capturing the diversity of topics brought up by interviewees. However, it is not possible to cover all points raised by interviewees, so we refer readers to the coded interviews' transcriptions in Appendix 3.

\section{Why learn? Applicability for policy, society, and science}

Findings on the usefulness of the knowledge, insights, or perspectives resulting from ENABLE varied across case study cities while covering the applicability for policy, society, and science. In terms of applicability for policy and society, because of the scope of ENABLE, most of its outputs and outcomes were 
aiming to be relevant for GBI planning and management in the case study cities, or in other words, to be salient (Cash et al. 2003). Overall, the project has raised general awareness about GBI benefits, enhanced the focus on the social dimension (distributional issues) of GBI, and it provided planning authorities with data and analyses that they probably could not accomplish themselves because of time constraints or lack of technical capacities. For example, in Oslo, three tools were developed that are already being taken up in practice: a modelbased tool to prioritize where green roofs fill demand gaps most effectively, which supports planning and zoning decisions; a Nordic standard for tree valuation, which can equip Oslo's municipality with an up-to-date tree damage compensation assessment that includes ecosystem services; a blue-green factor standard that can be used as a policy instrument to integrate GBI in new property developments (Horvath et al. 2017). In Łódź, research on children's exposure to green spaces while walking to school and the production of a digital sociotope map (a map of social functions of public green spaces; Laszkiewicz et al. 2020) are among the outputs that have "started to inform the local authorities on different green space availability and accessibility standards" [LOD1]. In Stockholm, through the resilience assessment, researchers have promoted "more of a systems understanding" that GBI is not only about the infrastructure itself, "but very much a question of how you think about the city and its inhabitants, around those green and blue spaces" [STO1] (see Borgström et al. 2021; Andersson et al., in press). That process also raised stakeholders' awareness that GBI "will change and be impacted by change - demographic, economic, governance changes, climate change, environmental change" [STO2] (see Borgström et al. 2021). ENABLE has started a discussion (and provided supporting knowledge) about how to move beyond the dichotomy of conservation only in natural areas vs. densification only in urban areas. In Barcelona, among other efforts that are aligned with policy concerns, a direct contribution to the new municipal resilience strategy (De Luca et al. 2021) was highlighted as a relevant ENABLE outcome for the planning and management of GBI.

Both in the Stockholm and Barcelona cases the joint learning process itself was noted as useful instead of knowledge as such, which "is very intangible in a way, but we speak now the same language, we understand each other in these forums, and I understand the city's needs and they understand where we are heading, this is very critical and a fundamental way of bringing in new concepts, new critical ideas into the discussion" [BAR1]. The learning process provided a platform for stakeholders "to meet and discuss things that they normally do not have room for discussing in their daily work-life context" [STO2] $(\rightarrow$ How). This focus on the learning process itself supports the notion that knowledge is not a package that can simply be transferred from producers to users; instead it is better seen as "a process of interaction characterized by multiple changing meanings and interpretations about what the knowledge is about, and how relevant, challenging, or good it is considered to be" (Tuinstra et al. 2019:135). Related to this, we argue that the saliency of the knowledge produced, apparent in several of the ENABLE cases, was tightly linked to its legitimacy, i.e., respectful of stakeholders' values and beliefs in an unbiased and fair way (Cash et al. 2003), which in ENABLE was actively sought through its transdisciplinary approach $(\rightarrow$ How, $\rightarrow$ Who, $\rightarrow$ When). Nevertheless, we note the transitory nature of solutions to societal problems, inherent to transdisciplinary research (Jahn et al. 2012). It also became apparent that differences across ENABLE cases in terms of knowledge applicability for policy and society reflect the notion that actors in the learning process "enter a setting that has already been shaped by previous experts and past advisory practices, including formal and informal rules and codes of working, as well as a certain understanding of what counts as authoritative knowledge" (Tuinstra et al. 2019:128).

Concerning the applicability for science, across cities ENABLE was seen as useful for considerations of "how to build a comprehensive approach to both understanding and actively engaging with green and blue infrastructure and its functionalities and benefits" [STO1]. The mixed- and multi-methods approaches used within ENABLE (Andersson et al. 2021) "were quite useful to think about how can we look at and address a specific issue through multiple lenses and still combine the insights from them" [STO1]. Similarly, interviewees from Halle and Barcelona highlighted the thinking around filters through ENABLE's conceptual framework (Andersson et al. 2021), together with the concepts of availability, accessibility, and attractiveness of GBI (Biernacka and Kronenberg 2019) in relation to environmental justice (Langemeyer and Connolly 2020) as useful for science but also for policy and society, which underlines their potential to act as boundary concepts ( $\rightarrow$ How). All these insights speak to the notion of integration, considered to be the main cognitive challenge of transdisciplinarity and defined as "the cognitive operation that establishes a novel, hitherto non-existent connection between distinct entities of a given context" (Jahn et al. 2012:7). Considering the insights reported throughout this article (see also Andersson et al. 2021), it becomes apparent that the ENABLE learning process entailed the three levels of integration suggested by Jahn et al. (2012): epistemic (understanding the methods, notions, and concepts of other disciplines and recognizing and explicating the limits of one's own knowledge); social-organizational (explicating and connecting different interests or activities of participating researchers, subprojects, and larger organizational units); communicative (establishing some kind of common language that advances mutual understanding and agreement). In this regard, ENABLE's outcomes could be useful for funding bodies because they show "what interdisciplinary research can be about and what different parts are needed, ... other capacities than [ordinary] research projects" [STO2]. Finally, interviewees also noted that the learning from ENABLE can support the writing of new research proposals and how they conduct future similar research ("why it worked or why it didn't work" [CC1]), teaching and writing of scientific publications, work as experts in other processes, the ability to engage with emerging topics, like the role of GBI during the COVID-19 crisis (see Barton et al. 2020), or promoting further collaboration with local stakeholders.

Interviewees also reflected on the usefulness of knowledge for themselves. Most answers referred to expanding one's conceptual understanding or methodological toolbox, related to: the concept of filters, "quite useful ... for the way you engage with the benefits of green and blue infrastructure" [HAL2]; the framework (and assessment methods) of GBI availability, accessibility, and attractiveness; having "a more operational idea of the actual 
design of transdisciplinary science, ... what are the critical things that need to be integrated, how can they be integrated and how can I describe how to do that and the resources needed" [STO1]; a deeper understanding of preferences, values, and perceptions of citizens concerning the design of green infrastructure; the BlueGreen Factor assessment; or thinking about "the beneficial overlaps between different techniques and methods" [HAL2] $(\rightarrow$ What). Expanding one's conceptual understanding can support individuals in adapting mental models and promote double-loop learning (Fazey et al. 2005). These self-reflections can stimulate individual researchers to orient their work toward favoring learning over knowing, which is one of the ways to help build improved capacity for social learning in a sustainability context (Clark et al. 2016).

\section{What to learn about? Different types of knowledge}

The most recurring topic emerging from the interviews regarding this dimension was related to insights on working with stakeholders. These included (i) the benefits, challenges, and limitations implied ("For the first time we were doing this exercise with stakeholders ... and I think this is something that we learned is very useful and that we would like to do in the future as well" [LOD1]; "I was reminded of the challenges of working with stakeholders, in terms of problem understanding, the time budget and capacity in total" [HAL2]; "I see much more the limitations linked to that and the bias that the selection of stakeholders brings with it" [BAR1]); (ii) better understanding of stakeholders ("Knowing who the actors are, how they view the system, how they think about other actors" [STO1]); (iii) how to better align the research with stakeholders' needs ("Getting the research from the lab to the end-users and practitioners, that is definitely what we have learned a lot about" [BAR1]). These insights represent target knowledge as well as "knowledge on how to create knowledge." Related to the latter but also with systems knowledge, another topic that emerged was learning on applying different methods to specific issues or contexts, which is closely related to the scope and goals of the project ("How different aspects can be studied using different research methods and how manifold methods have been applied to different extents in the different cities and also with different outcomes" [CC1]; see also Andersson et al. 2021). A third emerging topic that links with different types of knowledge concerned governance issues with a spatial expression. In one case this had to do with a disconnect between the city-wide scale of planning and the problems at neighborhood scale (related to transformation knowledge and systems knowledge). The other case concerned the surprisingly large impact of formal administrative boundaries in how people talk about values (more related to target knowledge).

The researchers gained further trans- and interdisciplinary "knowledge on how to create knowledge" through ENABLE. They learned new terms, which can act as boundary concepts (Opdam et al. 2015; $\rightarrow$ How). These were mainly the concept of filters (infrastructural, perceptual, institutional) mediating the benefits flowing from GBI, put forward in ENABLE's conceptual framework (see Andersson et al. 2019, 2021); flows (of benefits) and barriers, both closely associated with the filters (Wolff, Mascarenhas, Haase, et al., unpublishedmanuscript); and the triad of availability, accessibility, and attractiveness to or of GBI (see Biernacka and Kronenberg 2019). Several interviewees stressed that it was not so much about learning new terms per se, rather trying to operationalize them and "having a deeper understanding of what the terms could mean" [STO1], particularly in the different contexts of each case study city. This happened for example with the concepts of environmental justice, nature-based solutions, sustainability, and resilience. In line with a process perspective of learning (Beers and van Mierlo 2017), several interviewees identified not only knowledge, ideas, insights, or perspectives as such, but referred to learning opportunities that the project offered them, often related with the conceptual approaches and different methods that were applied in the project $(\rightarrow$ How $)$. For example "approaching the green infrastructure planning and the benefits of green infrastructure under a framework of resilience and environmental justice" [BAR2], "looking more in-depth into the mapping of preferences and values ... try and test and adjust the Q-methodology for the first time on our own" [CC1], or more generally "learning by doing, learning by mistakes in trying to develop tools for discussing these things along the way" [STO2]. The latter challenges the fear to fail, one of the most critical shortcomings that transdisciplinary sustainability research has to navigate (Lang et al. 2012).

\section{Who to learn with? Diversity of perspectives}

ENABLE researchers engaged with various stakeholders throughout the project and drew different learning insights from that engagement. Because of the scope of ENABLE, focused on the benefits flowing from GBI in urban areas, partners engaged mainly with local authorities, especially their planning, environmental, green space management or similar departments. Engaging with those stakeholders was seen as particularly beneficial to learn about "what is going on in terms of policy" [BAR2], "how processes actually work, what are the real obstacles" [STO1], "the realities and challenges of planners" [BAR1]. Another type of stakeholder involved in several of the case study cities were initiatives or organizations at very local scale, e.g., of the neighborhood. This was considered useful to learn, for example, about the multiple perspectives of residents in a neighborhood facing several social challenges like unemployment or poor integration of migrants [HAL2]. In some cases, stakeholders also included citizens in general, who were "there on their free time just because they cared about the area or had a specific interest in the area" [STO2]. Engaging with stakeholders generally provided an opportunity for critical reflection among the researchers and gaining a better understanding of how to design participatory processes in a transdisciplinary research context (including insights on requirements or different degrees of inclusiveness) or how to apply methods coming from research to specific contexts, "so that it is still understandable and can also create meaningful results" [CC1] $(\rightarrow$ What, $\rightarrow$ Why).

Interactions with colleagues within the project consortium promoted learning on a more abstract level. This included conceptual development of aspects related to the ENABLE framework, like the notion of barriers (Wolff, Mascarenhas, Haase, et al., unpublished manuscript), learning how to conduct integrated research or work with different epistemologies, ontologies, and different researchers' backgrounds, or stimulating reflexivity to extract lessons from what worked or not in each city (see Andersson et al. 2021). Learning also took place through discussions with other scientists, e.g., in conferences or case study workshops, where insights and experiences from ENABLE can 
be compared with those from similar projects [STO1] ( $\rightarrow$ What). This provides support to the notion that mutual learning among the researchers during a research process needs to be actively established and learning processes beyond the boundaries of individual projects must take place for a comprehensive embedding of the own case and contributing to extant knowledge (Lang et al. 2012).

Interviewees identified stakeholders who could have been beneficial to the learning process, but who were not engaged. Private actors were mentioned several times, for example, "stakeholders from private housing companies ... who actually have quite decisive impact on GBI benefits" [HAL2]. Politicians were noted as a type of stakeholder with similarly high influence. Difficult-to-reach stakeholders were also mentioned, namely marginalized groups representing a specific kind of GBI users who influence "the functionality and perceptions of green and blue infrastructure" [STO1]. Other stakeholders included grassroots groups or neighborhood associations, as well as the general public, which included people who might be engaged in societal issues but not necessarily through organized groups. Insufficient contact with stakeholders (mainly decision makers and practitioners) from case study cities other than one's own was also noted. Related with this, "also maybe direct interaction between cities could be beneficial for the project" [LOD2]. Engaging with other projects running under the same funding scheme was also seen as potentially beneficial, "to exchange, see what is their research focus and if there may be some overlaps or similarities" [CC1].

\section{How to learn? Framings, boundary concepts, and third places}

The project partners promoted a variety of events or opportunities to foster learning within ENABLE. Across case studies, this included workshops with local stakeholders, participation in expert groups, thematic meetings with individual stakeholders, or training events. Additionally, consortium workshops in each case study city brought together the project partners, allowing them to internally discuss different aspects of the project (including self-reflections on the transdisciplinary process itself), as well as getting to know each case study better through field trips and direct interactions with local stakeholders.

Common across case study cities was an effort to meet project needs through the events and learning opportunities promoted, while aligning them with ongoing "real" local GBI planning and management processes and challenges for the planning and management of GBI ( $\rightarrow$ When, $\rightarrow$ Why). This has guided the framing of each event and the choice of appropriate boundary concepts, around which to focus discussions. For example, in Barcelona the concept of nature-based solutions (linked to GBI) served as an overarching boundary concept. Then, each event was framed around specific topics related to it, such as the evaluation of effective green roof strategies (Langemeyer et al. 2020) or the resilient flow of ES (De Luca et al. 2021). In Stockholm, a resilience assessment process provided an overarching framing, with each event serving as a stepping stone in the process (Borgström et al. 2021). Researchers there made an effort to "find a language and commonalities, common boundary objects to talk about. We've had to work very hard to find something that they could start their dialogue about" [STO2]. They also conducted "constant framing exercises that we had to do to explain what we were doing and also for us to learn about the system. The framing was everything from writing invitations, writing documentation, having the first presentation at all the workshops that we had ... all these meetings have a very careful thinking about how we start them, how we talked about the system that we wanted to discuss with the actors. So using words that we know that they know about but also then linking them to the conceptual framework within the project, that was a very tricky part" [STO2]. The Oslo case offered an example of another kind of approach. There, the leading ENABLE researcher engaged with ongoing processes as a member of expert groups.

These sorts of collaborative approaches can promote a genuine bridging of research and practice, hence addressing a critical challenge for knowledge exchange, that of providing access to research knowledge in ways that meet stakeholders' needs and constraints (Hurley et al. 2016), and enhancing knowledge utilization (Hoffmann et al. 2019). This is aligned with the notion of problem solving organized around a particular application, an attribute of transdisciplinary knowledge production (Gibbons et al. 1994). Framing issues persuasively is an integral part of responding to policy windows, increasing the chances that the research is taken up by policy (Rose et al. 2020). Boundary concepts such as the ones described here can help finding shared interests and bridge understanding across multiple knowledge domains (Opdam et al. 2015, Roux et al. 2017).

Across different framings, goals, and formats, several interviewees stressed the fact that the events described here promoted learning both for researchers and other stakeholders ("It's also learning for us, because we always use these forums for giving key stakeholders the opportunity to present and discuss their work ... There's also a learning process in two directions" [BAR1]; "we had a nice exchange [with a local stakeholder], which I would count as a learning event for both sides. For us as researchers as well as the local stakeholders" [HAL2] ( $\rightarrow$ Who). This illustrates the efforts from ENABLE partners in promoting third places (Roux et al. 2017), and is aligned with the notion that collaboration between individuals is needed to gain a fuller understanding of dynamic social-ecological systems (Olsson et al. 2004, Fazey et al. 2005). In an urban planning context like the one in ENABLE, planning practice benefits from new perspectives and improved understanding of problems and solutions from research, while research benefits from being informed by practice problems and practical knowledge (Hurley et al. 2016). This also helps building informal and formal linkages between the project team and other stakeholders, which can play a key role in enhancing the use of knowledge coming from the project (Hoffmann et al. 2019).

\section{When to learn? Key stages, temporal alignment}

The most relevant topic emerging from the interviews, related with this dimension, was the temporal alignment of the research project with ongoing processes in each case study city, in order to maximize the relevance of the former to the latter $(\rightarrow$ How $)$. This shows recognition that timing influences both the extent to which research findings are likely to be perceived as relevant by decision makers, and the way that knowledge from research is used in the decision-making process (Reed et al. 2014), aligned with the notion of "policy windows" (Rose et al. 2020). It played a relevant role to guide the "research design and selection of methods" (one 
of the key stages introduced in the analytical framework), and it seemed to play a bigger role in the cases where stakeholder engagement was more extensive. For example, in Barcelona, with stakeholder workshops taking place around three times a year, the topics of the meetings varied "depending on the needs of the project at some point, at the same time we try also to talk about topics that are relevant for the stakeholders" [BAR2]. However, aligning project and others' timelines involved some trade-offs: "At times the two timelines did not align too smoothly, so we tried to bring in ENABLE inputs at specific times that we thought were relevant. So trying to address different stakeholders' needs and desires in terms of outcomes, which has sometimes maybe detracted from the more pedagogical design of the process" [STO1].

The time preceding the project's beginning often played an important role for aligning the project with the needs and interests of local stakeholders, thereby increasing its relevance. In most cases, ENABLE was part of broader, pre-existing processes involving the researchers and local stakeholders. There were also consultations with stakeholders in the project's preparation phase, "about their needs, what are the priority questions, what are the key topics they want to work on through this process and also thinking about key areas in the city for interventions" [BAR1]. This kind of setting the scene and determining what was relevant for the city was seen as a "critical phase" and "a very useful approach in making the entire stakeholder engagement process worth the effort for the stakeholders" [BAR1] ( $\rightarrow$ Why, $\rightarrow$ How $)$. This illustrates the key stage of "problem identification and structuring" (Pohl and Hadorn 2007, Enengel et al. 2012), being analogous to the "problem transformation" process, the first phase in Jahn et al.'s model of an ideal transdisciplinary research process, whereby societal and scientific problems are linked to form a common research object (Jahn et al. 2012).

The time following stakeholder engagement events was also stressed, particularly in the Barcelona and Stockholm cases, as important to contact stakeholders, requesting feedback from them, and for focused internal reflection: "We test our ideas and approaches with the stakeholders in the individual meetings. And then we have the reporting back phase, where we presented results to the stakeholders and asked for additional feedback. Depending on the study this is more or less intensive" [BAR1] $(\rightarrow$ What, $\rightarrow$ How). This is more related with the stages of "data analysis and triangulation," "reflection/interpretation and synthesis" or assessing new knowledge, and also "dissemination of results/new knowledge" (Pohl and Hadorn 2007, Enengel et al. 2012, Hoffmann et al. 2019). The two latter stages were also the main focus of stakeholder workshops organized across cities, toward the end of the project.

\section{Cross-cutting topic: barriers to learning}

Several barriers to learning within the project have been pointed out. Concerning interactions between the project team and other stakeholders, barriers included the following: different "cultures of participation" and different starting points across cities (in some cities, there were previous collaborations between the ENABLE researchers and local stakeholders, in others not, or the general willingness to participate was low); reaching stakeholders "who do not see themselves as stakeholders" [STO1]; conflicts in scheduling, particularly relevant for stakeholders like grassroots groups, neighborhood associations, or NGOs $(\rightarrow$ Who); ENABLE's level of abstraction, making it hard for stakeholders to grasp its conceptual framework and demanding extra effort to make it more concrete through illustrative examples. Some stakeholders who could have been beneficial to the learning process were not engaged $(\rightarrow$ Who). Reasons included changes in personnel within local organizations, which demand renewing contacts and rebuilding trust with researchers, bad or unwanted relationships between researchers and stakeholders, issues of trust among stakeholders ("If you involve people with very strong and very different opinions ... it could take a long time just to find common ground and start to build trust" [STO1]), lack of time from stakeholders like politicians or businesses, and different schedules (e.g., between stakeholders participating on a professional vs. voluntary basis). In this respect, one interviewee noted that "[w]e do have a gap in cooperating with stakeholders from the private sector, that would be in theory and in practice I am not really sure if that would have been helpful for this stakeholder process to learn more. Obviously we could have learned different things, but probably we would have missed out others" [BAR1]. This reflects the need to consider the best form, level, and scale of participation, tailored to the research topic and the preferences and capacities of different stakeholders, instead of assuming that more participation is always better (Enengel et al. 2012, Lang et al. 2012).

Within the consortium, the parallel evolution of a common theoretical framework during the project was thought to have negative implications for the design and integration of empirical methods. A similar issue has been experienced by other authors, for example, in the context of transdisciplinary synthesis projects (Hoffmann et al. 2017). The level of consistency between case studies was often mentioned as not satisfactory. There was the feeling that different teams were working using different approaches "and because of this the opportunities for mutual learning are not as big as they could have been had everyone worked on much more similar things" [LOD1], or if there had been "a more joint comparative analysis" [LOD2]. For one interviewee there was a tension between trying to understand the system and then also adding the aspects of change. There was a focus on the former, which left the researchers with little capacity to address the latter. Finally, time and resource constraints (both from researchers and other stakeholders) were also seen as a barrier. We hypothesize that the barriers described here can be associated with the explorative nature of the project, and the different research teams iteratively working toward a joint understanding of it, making the end goal less clear.

Difficulties related to the use of terms or jargon, including different interpretations thereof, also posed a barrier to learning, mainly within the consortium, but also in engaging with stakeholders. "Sometimes we managed to reach some sort of consensus, in other cases we just had to step back and leave the differences where they were" [STO1]. The triad of GBI availability, accessibility, and attractiveness was mentioned most often. Some partners struggled with the exact definition of each one of those concepts and to some extent different teams used the concepts differently, posing a challenge when it came to crosscase integration. Similar issues of coherence in interpretation were noted for the concepts of perceptions, institutions, governance, or justice. These are known communicative integration challenges 
in transdisciplinary research (Lang et al. 2012). Regarding possible reasons underlying such difficulties, not putting enough effort into discussing terminology and differences in how different people express their ideas was mentioned. One partner who works in applied research felt there was an overload of complex theoretical terms. In relation to stakeholder engagement, the language also needed adjustments according to stakeholders' backgrounds. For example, in Barcelona, stakeholders were concerned about the concept of nature-based solutions, because they were more familiar with the concepts of ecosystem services or environmental services and green infrastructure. Although the difficulties described above posed barriers to learning, discussions on finding common ground for definitions were "particularly insightful for all" [LOD1] and they have resulted in "a deeper understanding of what the terms could mean" [STO1]. This is a positive learning outcome and is aligned with the idea that a "learning zone" can emerge out of a situation of discomfort (beyond the comfort zone), as conceptualized by Freeth and Caniglia (2020). Establishing some kind of a common language that advances mutual understanding and agreement also supports integration in transdisciplinary research (Jahn et al. 2012).

It is also useful to identify unmet expectations and the reasons behind them. In ENABLE's learning process these were mainly related to four issues:

(i) Several interviewees were expecting more comparative work (using joint approaches like common scenario development) to be conducted during the project than it did. Reasons for this included the constellation of disciplines and expertise in the project, different interests across research partners, or the need to be pragmatic in face of the existing amount of work. This provides an alternative expression of the concern that "transdisciplinary settings allow for mutual learning but not for joint research", (Maasen and Lieven 2006:406);

(ii) The balance between a more theoretical or empirical approach. Whereas one researcher thought that ENABLE ran too much as a scientific project, thereby missing more contact with stakeholders from other cities to learn "from those who deal with realities" [LOD2], another researcher would have wanted "more in-depth discussion on how do we best connect methods, theories, frameworks" [STO1]. This mirrors the two contrasting approaches to transdisciplinarity found in the literature: a lifeworld approach vs. an inner-scientific approach (Jahn et al. 2012), which are linked with a tension between local or context-specific knowledge vs. generalized knowledge (Raymond et al. 2010, Enengel et al. 2012). Hoffmann et al. (2019) regard these as two processes of knowledge production, which transdisciplinary research processes strive to combine: a societal one, where stakeholders address a particular sustainability problem, and a scientific one, where researchers develop research on that particular problem;

(iii) Not being able to conduct some analyses, or at least reaching as far as desired. This was noted, for example, for system and agent-based modeling, as "data gathering was so hard" [HAL1], or learning about justice and resilience together, which was not entirely possible, because "it has been so much work just to link green-blue infrastructure just to these two dimensions" [STO2]. Related with this, one interviewee noted that possibly researchers have tried to address too many topics and that "we might have gotten further if we focused on fewer issues" [OSL1];

(iv) There were difficulties in implementing a planned mobility scheme for young researchers across the cities. This was seen by some as a missed opportunity because it "is a very fruitful way of learning and understanding and exchange" [STO2]. It is a very concrete example of an effort to foster conditions for collaborative learning, in line with suggestions by Freeth and Caniglia (2020). One interviewee noted that expectations have changed several times over the course of the project, which is not necessarily negative, as illustrated by the Barcelona case, where most of the studies conducted were carried out as they emerged as relevant during the project's lifetime.

\section{Cross-cutting topic: role of context}

The role of context, in a project like ENABLE analyzing real complex urban social-ecological systems, became apparent in several responses. Different cities are in different stages in terms of capacities, existing data, and knowledge. The starting point in each city determines to a smaller or greater extent how far one can go in terms of testing new ideas or approaches. "Maybe ecosystem services and green infrastructure are two examples for that: Barcelona has incorporated that already, other cities have not, so if you now come up with new concepts and you elaborate further on this, but the baseline is not given to work with these concepts, then obviously that is much more difficult" [BAR1]. As another interviewee put it, "I would love to be advanced but first I need to have a basic database" [LOD2]. There are also different cultures of participation shaped by the levels of trust and interest in such participatory processes. This became apparent when comparing the stakeholder engagement that took place for example in the Nordic cities (Oslo, Stockholm) represented in the project and in post-socialist cities (Halle, Łódź). Other contextual factors inherent to stakeholders, like cultural differences, e.g., different languages, or different interests, had to be dealt with when engaging with them. Political changes or changes in personnel within stakeholder organizations, like local authorities, can imply contextual changes in perspectives or attitudes and demand building new relationships between project researchers and other stakeholders. Even among project researchers, "your personal background and legacies play a role how you see things and how you understand progress, conflicts, dependence, weakness, success," so that it becomes relevant "to see how previous learning shapes recent learning"[HAL1]. These insights corroborate the notion that "[t]ransdisciplinarity is a contextspecific negotiation" (Klein 2004:521)

\section{Study's limitations and strengths}

A relevant limitation of our application was the inclusion of only the consortium partners, or core scientists (Enengel et al. 2012). Including the views of other stakeholders involved in the project would allow us to assess the learning process more comprehensively. It would also contribute to our approach's ability to, at least partly, assess social learning, a change in understanding in the individuals involved, and how did the process occur through social interactions and processes between actors within a social network (Reed et al. 2010). However, this was not possible for practical reasons. In Appendix 1 we provide the interview protocol developed specifically for that purpose, for future applications. 
The double role of the co-authors also as researchers in the ENABLE project demands some clarification and reflection. The first author was part of the research team leading the case study for the city of Halle (Saale) in Germany. This allowed him to be more actively involved in, and consequently gain deeper insights about, the project activities taking place in that city, than for the remaining case studies. However, he took more of a secondary role in his involvement on most of the activities specific to the Halle case study, allowing for a rather more distanced perspective. Nevertheless, it is impossible to equate this to a situation where the first author would be external to a specific case study or even to the whole project consortium. In principle that would allow for a more distanced perspective, but it could also carry disadvantages with it, most notably a lower level of trust between interviewer and interviewees, with negative impact on the (quality of) information given by interviewees or on their willingness to be interviewed at all by someone external to the project. Aware of the limitations inherent to this study's context, we took some precautions. The first author strove to draw his analysis solely from the material resulting from the interviews. He also wrote the draft manuscript of the article, while the remaining co-authors contributed at a later stage and were not involved in processing interview data. This was important because they were also interviewed for the study. By appending the coded interview transcripts to the article (Appendix 3), we also give readers the opportunity to make their own judgments on our findings and claims, in face of the underlying data.

The analytical framework developed in this research proved useful to us for capturing the learning process. It enables a broader analysis than each one of the frameworks adapted for its development (Enengel et al. 2012, Hoffmann et al. 2017, Roux et al. 2017) because it covers more dimensions. For example, 'including the 'who' and 'when' may lead to a more sophisticated conceptualization of knowledge that goes beyond simply categorizing different types of knowledge and instead emphasises knowledge as more as a process that can be modelled" (Evely et al. 2012:7, unpublishedmanuscript). Also, the questions developed to guide the interviews have elicited from the interviewees the information needed to operationalize the framework. We argue that our approach can be useful for future transdisciplinary research projects with similar scope and in different geographic contexts, not only for ex post analysis as we did, but also ex ante, to consider the different aspects of the learning process explored here at a planning stage. As one interviewee put it: "One thing that could be very beneficial for us researchers who are aiming at these very complex research and knowledge processes is to find tools for ourselves to capture this, like having this interview got me thinking about things that I would not necessarily have time or room or acknowledged that I would need to reflect upon. Because if I have that self-reflexive routine that would make this transfer of experiences and insights between projects and processes more clear and visible for me and maybe for others as well" [STO2]. This statement is aligned with the notion that learning outcomes may lead to increased reflexivity, but they can also result from reflexivity changes (Beers and van Mierlo 2017). Applying our approach in other projects would allow gathering additional empirical data to build a more robust body of evidence regarding the findings of this exploratory research.
Whereas the analytical framework supporting our analysis can be used in different stages of a learning process, the interview protocol we developed to operationalize the framework is suitable for an ex post analysis. Nevertheless, we acknowledge the importance of continuous reflexivity throughout transdisciplinary research efforts (Polk and Knutsson 2008, Lang et al. 2012). In the ENABLE project, this was pursued in different ways, for example in meetings among case study teams, or through time slots in project workshops dedicated to joint reflection. However, reporting on the whole reflection process is beyond the scope of this article.

\section{Fostering a learning process within transdisciplinary research projects: take-home messages}

Interviewees have reflected on what were the main take-home messages from the project. Based on their answers and further reflection among the authors, we present a set of lessons learned, aiming to support future similar transdisciplinary research projects. Regarding their validity, we acknowledge the exploratory nature of this research. Nevertheless, one should note that transdisciplinarity is "problem solving capability on the move," so it is hard to predict "where this knowledge will be used next and how it will develop" (Gibbons et al. 1994:13). The following emerged as main lessons learned (clustered around six themes), which can be helpful for future similar initiatives. With these take-home messages we aim at supporting similar efforts:

1. Capitalizing on what already exists: (a) Assess what sort of systematic learning can be gained from already existing data and knowledge, e.g., feeding it into dynamic models, before collecting new data. There is often the tendency to add more data rather than learn from what already exists. (b) Take advantage of opportunities to engage with ongoing policyrelated processes, instead of designing stakeholder engagement processes from scratch that do not have a policydriven purpose or relevance.

2. Addressing trade-offs inherent to different types of knowledge: (a) Find a balance between addressing local stakeholders' concerns and conducting comparative research. Transdisciplinary urban research should be relevant for stakeholders, building on their needs if it is to be impactful. Nevertheless, comparing problems across cities helps put the magnitude of local problems in perspective and in context, and sorting out priorities. It also helps thinking about future scenarios, because one can see alternative states that a given city could be in. Approaching different case studies with a common approach is particularly useful for learning among scientists. These goals can be achieved for example by establishing cross-case working groups targeting specific sets of issues and promoting interactions between researchers and local stakeholders from other cities. Being part of a multi-city endeavor can also leverage stakeholder engagement (higher willingness to participate if people know the same effort is being conducted in other cities, especially "model"/ frontrunner cities. (b) Take into account the important role of context in real complex urban social-ecological systems. This relates to the previous point and is particularly relevant when trying to draw more general insights from different case studies. 
3. Fostering inter- and transdisciplinarity: (a) For integrated research running in multiple case studies, promote a continuous (as possible) dialogue between the different research teams. In ENABLE, conducting a deeply integrated transdisciplinary project over a dispersed network proved challenging in this regard. Having a mobility scheme in place, which allows extended stays from researchers in partner organizations, might be helpful. ENABLE had such a scheme but it was not fully realized, so reflecting on its potential was part of the learning process. (b) Embrace different views, expectations, the variety of knowledge people have, and the way they use this knowledge. Accept that there are multiple possible pathways toward a certain desirable state or goal. This might require stepping out of one's comfort zone, e.g., in terms of one's academic background, which can be useful to stimulate learning in interdisciplinary collaborative research (Freeth and Caniglia 2020). Paying attention to how one frames issues and looking for ways to find a common ground can prove useful to deal with such differences. This demands being aware of and assuming certain researcher roles, like that of a process facilitator (facilitating the learning process), knowledge broker (mediating between different perspectives), or selfreflexive scientist (being reflexive about one's positionality and normativity, as part of the system or process under study; Wittmayer and Schäpke 2014). (c) Assign different roles within the team promoting the learning process. This can enable different team members to have different perspectives on the same process. This requires the respective human resources, for example, one person will in most cases not be enough to cover all the different needs of the process, like facilitating and being an observer. Constant reflection on researchers' roles is also advisable; see previous point and Wittmayer and Schäpke (2014) for additional roles.

4. Engaging stakeholders: (a) Consider the pros and cons of different stakeholder engagement formats when designing the engagement process. For example, smaller focus groups bring less perspectives together than a larger stakeholder workshop, but they can create a safer space for discussion among stakeholders, while they can also free the researchers from other roles (like being more a facilitator), with benefits for the learning process in both cases. A mix of different formats in different stages of the project, targeting specific objectives, can be most useful for the learning process. Choosing the best mix should take into account the distinct interests, roles, and practices of communication brought by stakeholders. (b) Accept that virtually no one participatory process is perfect. Every project has its limitations, leading to trade-offs in terms of who is involved and what is learned. It might not always be needed and suitable to involve stakeholders in all phases of the project, because different stakeholders contribute differently to different stages of the research process. Participation is shaped by the research aims and should consider stakeholders' values, preferences, interests, power levels, or constraints. (c) Be explicit about what is on the agenda in terms of stakeholders or processes exerting pressure on GBI, underlying conflicts, or factors hindering research or initiatives to promote GBI.

5. Supporting a learning environment: (a) Promote exploration and researchers' own learning within the research team. This was seen as a very positive experience from ENABLE because of its flexibility, and as something that is not taken for granted, when compared to other projects with a more rigid approach. (b) Acknowledge that different kinds of learning opportunities can be important to foster learning, each contributing with its own benefits to the whole learning experience. ENABLE researchers identified various activities in this regard, for example, the writing of scientific articles as an interdisciplinary learning process, internal workshops providing a safe-to-fail environment, or workshops in other case study cities giving insight into other contexts. (c) Encourage learning also beyond the boundaries of the project. Strive for sharing the project's products and knowledge with stakeholders at different levels, enabling a sustained communication channel between the researchers and other stakeholders. (d) Acknowledge the importance of failure in both process and outcomes. Analyzing non-success can reveal the weak points of a system, which can put it onto an undesired pathway. Reflecting on failing efforts can be insightful not only for the internal learning process but also for others to avoid making the same mistakes. In ENABLE, having safe-to-fail opportunities was seen as beneficial for learning, in line with the notion that a "learning zone" can emerge by going beyond an understimulating comfort zone (Freeth and Caniglia 2020).

6. Fostering reflexivity: Develop tools and routines to capture the learning process taking place in the project. Having a self-reflexive routine can facilitate the transfer of experiences and insights between projects and processes. Several ENABLE researchers found the exercise reported in this article as useful, to trigger thinking about issues for which they would not necessarily have the time or acknowledged they would need to reflect upon.

\section{CONCLUSION}

Our analytical framework for capturing the learning process taking place in transdisciplinary research projects covers different dimensions of the learning process (Why, What, Who, How, When). It draws inspiration from and expands existing similar frameworks, and has been operationalized through an interview protocol across five European urban regions. The framework helped us distill a set of recommendations for future similar transdisciplinary research projects. These include capitalizing on what already exists, addressing trade-offs inherent to different types of knowledge, fostering inter- and transdisciplinarity, engaging stakeholders, supporting a learning environment, and fostering reflexivity. More generally, the case application also provided empirical insights for each of the framework's dimensions, and identified cross-cutting issues concerning barriers to learning and the role of context. Further research is needed to test and develop the framework's applicability for more diverse groups of stakeholders; the case only drew on the experiences of the researchers in the project consortium. Finally, while ours was an ex post application, the framework can also be used ex ante to plan transdisciplinary projects that enhance learning in its multiple dimensions, and throughout projects to identify and engage with barriers to learning and make best use of evolving insights. 
Responses to this article can be read online at: https://www.ecologyandsociety.org/issues/responses. $\mathrm{php} / 12631$

\begin{abstract}
Acknowledgments:
We would like to thank three anonymous reviewers for their constructive comments on an earlier version of this article. We also thank the colleagues who have given their time for the interviews supporting this research. This research was funded through the 2015-2016 BiodivERs A COFUND call for research proposals, with the national funders the Swedish Research Council for Environment, Agricultural Sciences, and Spatial Planning; Swedish Environmental Protection Agency; German Aerospace Center (DLR); National Science Centre (Poland); the Research Council of Norway; and the Spanish Ministry of Science, Innovation and Universities. We acknowledge support by the German Research Foundation (DFG) and the Open Access Publication Fund of Humboldt-Universität zu Berlin.
\end{abstract}

\section{Data Availability:}

The data supporting the findings of this study are available as appendix to the article.

\section{LITERATURE CITED}

Andersson, E., S. Borgström, D. Haase, J. Langemeyer, A. Mascarenhas, T. McPhearson, M. Wolff, E. Laszkiewicz, J. Kronenberg, D. N. Barton, and P. Herreros-Cantis. 2021. A context-sensitive systems approach for understanding and enabling ecosystem service realization in cities. Ecology and Society 26(2):35. https://doi.org/10.5751/ES-12411-260235

Andersson, E., S. Borgström, D. Haase, J. Langemeyer, M. Wolff and T. McPhearson. In press. Urban resilience thinking in practice: ensuring flows of benefit from green and blue infrastructure. Ecology and Society.

Andersson, E., J. Langemeyer, S. Borgström, T. McPhearson, D. Haase, J. Kronenberg, D. N. Barton, M. Davis, S. Naumann, L. Röschel, and F. Baró. 2019. Enabling green and blue infrastructure to improve contributions to human well-being and equity in urban systems. BioScience 69(7):566-574. https://doi. org/10.1093/biosci/biz058

Barton, D., D. Haase, A. Mascarenhas, J. Langemeyer, F. Baro, C. Kennedy, Z. Grabowski, T. McPhearson, N. Hjertager Krog, Z. Venter, and V. Gundersen. 2020. Enabling access to greenspace during the COVID-19 pandemic: perspectives from five cities. The Nature of Cities, 4 May. https://www.thenatureofcities. com/2020/05/04/enabling-access-to-greenspace-during-the-covid-19pandemic-perspectives-from-five-cities

Beers, P. J., and B. van Mierlo. 2017. Reflexivity and learning in system innovation processes. Sociologia Ruralis 57(3):415-436. https://doi.org/10.1111/soru.12179

Biernacka, M., and J. Kronenberg. 2019. Urban green space availability, accessibility and attractiveness, and the delivery of ecosystem services. Cities and the Environment (CATE) 12(1):5.
Borgström, S., E. Andersson, and T. Björklund. 2021. Retaining multi-functionality in a rapidly changing urban landscape: insights from a participatory, resilience thinking process in Stockholm, Sweden. Ecology and Society 26(4):17. https://doi. org/10.5751/ES-12432-260417

Brandt, P., A. Ernst, F. Gralla, C. Luederitz, D. J. Lang, J. Newig, F. Reinert, D. J. Abson, and H. von Wehrden. 2013. A review of transdisciplinary research in sustainability science. Ecological Economics 92:1-15. https://doi.org/10.1016/j.ecolecon.2013.04.008

Cash, D. W., W. C. Clark, F. Alcock, N. M. Dickson, N. Eckley, D. H. Guston, J. Jäger, and R. B. Mitchell. 2003. Knowledge systems for sustainable development. Proceedings of the National Academy of Sciences 100(14):8086-8091. https://doi.org/10.1073/ pnas. 1231332100

Clark, W. C., L. Van Kerkhoff, L. Lebel, and G. C. Gallopin. 2016. Crafting usable knowledge for sustainable development. Proceedings of the National Academy of Sciences of the United States of America 113(17):4570-4578. https://doi.org/10.1073/ pnas. 1601266113

Cvitanovic, C., J. McDonald, and A. J. Hobday. 2016. From science to action: principles for undertaking environmental research that enables knowledge exchange and evidence-based decision-making. Journal of Environmental Management 183:864-874. https://doi.org/10.1016/j.jenvman.2016.09.038

De Luca, C., J. Langemeyer, S. Vaňo, F. Baró, and E. Andersson. 2021. Adaptive resilience of and through urban ecosystem services: a transdisciplinary approach to sustainability in Barcelona. Ecology and Society Vol. 26 Iss. 4 in press.

Dunford, R., P. Harrison, A. Smith, J. Dick, D. N. Barton, B. Martin-Lopez, E. Kelemen, S. Jacobs, H. Saarikoski, F. Turkelboom, W. Verheyden, J. Hauck, P. Antunes, R. Aszalós, O. Badea, F. Baró, P. Berry, L. Carvalho, G. Conte, B. Czúcz, G. Garcia Blanco, D. Howard, R. Giuca, E. Gomez-Baggethun, B. Grizzetti, Z. Izakovicova, L. Kopperoinen, J. Langemeyer, S. Luque, D. M. Lapola, G. Martinez-Pastur, R. Mukhopadhyay, S. B. Roy, J. Niemelä, L. Norton, J. Ochieng, D. Odee, I. Palomo, P. Pinho, J. Priess, G. Rusch, S.-R. Saarela, R. Santos, J. T. van der Wal, A. Vadineanu, Á. Vári, H. Woods, and V. Yli-Pelkonen. 2018. Integrating methods for ecosystem service assessment: experiences from real world situations. Ecosystem Services 29:499-514. https://doi.org/10.1016/j.ecoser.2017.10.014

Enengel, B., A. Muhar, M. Penker, B. Freyer, S. Drlik, and F. Ritter. 2012. Co-production of knowledge in transdisciplinary doctoral theses on landscape development - an analysis of actor roles and knowledge types in different research phases. Landscape and Urban Planning 105(1-2):106-117. https://doi.org/10.1016/j. landurbplan.2011.12.004

Fazey, I., J. A. Fazey, and D. M. A. Fazey. 2005. Learning more effectively from experience. Ecology and Society 10(2):4. https:// doi.org/10.5751/ES-01384-100204

Freeth, R., and G. Caniglia. 2020. Learning to collaborate while collaborating: advancing interdisciplinary sustainability research. Sustainability Science 15(1):247-261. https://doi.org/10.1007/ s11625-019-00701-Z 
Gibbons, M., C. Limoges, H. Nowotny, S. Schwartzman, P. Scott, and M. Trow. 1994. The new production of knowledge: the dynamics of science and research in contemporary societies. SAGE, London, UK.

Hadorn, G. H., S. Biber-Klemm, W. Grossenbacher-Mansuy, H. Hoffmann-Riem, D. Joye, C. Pohl, U. Wiesmann, and E. Zemp. 2008. The emergence of transdisciplinarity as a form of research. Pages 19-39 in G. H. Hadorn, H. Hoffmann-Riem, S. BiberKlemm, W. Grossenbacher-Mansuy, D. Joye, C. Pohl, U. Wiesmann, and E. Zemp, editors. Handbook of transdisciplinary research. Springer, Dordrecht, Netherlands. https://doi. org/10.1007/978-1-4020-6699-3 2

Hoffmann, S., C. Pohl, and J. G. Hering. 2017. Exploring transdisciplinary integration within a large research program: empirical lessons from four thematic synthesis processes. Research Policy 46(3):678-692. https://doi.org/10.1016/j.respol.2017.01.004

Hoffmann, S., J. Thompson Klein, and C. Pohl. 2019. Linking transdisciplinary research projects with science and practice at large: introducing insights from knowledge utilization. Environmental Science and Policy 102:36-42. https://doi. org/10.1016/j.envsci.2019.08.011

Horvath, P., D. N. Barton, E. A. Hauglin, and H. W. Ellefsen. 2017. Blue-green factor (BGF) mapping in QGIS. User Guide and Documentation. NINA Report 1445. Norwegian Institute for Nature Research, Oslo, Norway.

Hurley, J., C. W. Lamker, E. J. Taylor, D. Stead, M. Hellmich, L. Lange, H. Rowe, S. Beeck, P. Phibbs, and A. Forsyth. 2016. Exchange between researchers and practitioners in urban planning: achievable objective or a bridge too far?/The use of academic research in planning practice: who, what, where, when and how?/Bridging research and practice through collaboration: lessons from a joint working group/Getting the relationship between researchers and practitioners working/Art and urban planning: stimulating researcher, practitioner and community engagement/Collaboration between researchers and practitioners: Political and bureaucratic issues/Investigating Research/ Conclusion: Breaking down barriers through international practice?. Planning Theory and Practice 17(3):447-473. https:// doi.org/10.1080/14649357.2016.1190491

Jahn, T., M. Bergmann, and F. Keil. 2012. Transdisciplinarity: between mainstreaming and marginalization. Ecological Economics 79:1-10. https://doi.org/10.1016/j.ecolecon.2012.04.017

Klein, J. T. 2004. Prospects for transdisciplinarity. Futures 36 (4):515-526. https://doi.org/10.1016/j.futures.2003.10.007

Kuckartz, U., and S. Rädiker. 2019. Analyzing qualitative data with MAXQDA. Springer, Cham, Switzerland. https://doi. org/10.1007/978-3-030-15671-8

Lang, D. J., A. Wiek, M. Bergmann, M. Stauffacher, P. Martens, P. Moll, M. Swilling, and C. J. Thomas. 2012. Transdisciplinary research in sustainability science: practice, principles, and challenges. Sustainability Science 7(1):25-43. https://doi. org/10.1007/s11625-011-0149-X

Langemeyer, J., and J. J. T. Connolly. 2020. Weaving notions of justice into urban ecosystem services research and practice.
Environmental Science \& Policy 109:1-14. https://doi. org/10.1016/j.envsci.2020.03.021

Langemeyer, J., D. Wedgwood, T. McPhearson, F. Baró, A. L. Madsen, and D. N. Barton. 2020. Creating urban green infrastructure where it is needed - a spatial ecosystem servicebased decision analysis of green roofs in Barcelona. Science of The Total Environment 707:135487. https://doi.org/10.1016/j. scitotenv.2019.135487

Łaszkiewicz, E., P. Czembrowski, and J. Kronenberg. 2020. Creating a map of the social functions of urban green spaces in a city with poor availability of spatial data: a sociotope for Lodz. Land 9:183. https://doi.org/10.3390/land9060183

Maasen, S., and O. Lieven. 2006. Transdisciplinarity: a new mode of governing science? Science and Public Policy 33(6):399-410. https://doi.org/10.3152/147154306781778803

Olsson, P., C. Folke, and F. Berkes. 2004. Adaptive comanagement for building resilience in social-ecological systems. Environmental Management 34(1):75-90. https://doi.org/10.1007/s00267-003-0101-7

Opdam, P., J. Westerink, C. Vos, and B. de Vries. 2015. The role and evolution of boundary concepts in transdisciplinary landscape planning. Planning Theory and Practice 16(1):63-78. https://doi.org/10.1080/14649357.2014.997786

Pohl, C., and G. H. Hadorn. 2007. Principles for designing transdisciplinary research. oekom, Munich, Germany. https:// doi.org/10.14512/9783962388638

Polk, M., and P. Knutsson. 2008. Participation, value rationality and mutual learning in transdisciplinary knowledge production for sustainable development. Environmental Education Research 14(6):643-653. https://doi.org/10.1080/13504620802464841

Posner, S. M., E. McKenzie, and T. H. Ricketts. 2016. Policy impacts of ecosystem services knowledge. Proceedings of the National Academy of Sciences of the United States of America 113(7):1760-1765. https://doi.org/10.1073/pnas.1502452113

Raymond, C. M., I. Fazey, M. S. Reed, L. C. Stringer, G. M. Robinson, and A. C. Evely. 2010. Integrating local and scientific knowledge for environmental management. Journal of Environmental Management 91(8):1766-1777. https://doi. org/10.1016/j.jenvman.2010.03.023

Reed, M. S. 2008. Stakeholder participation for environmental management: a literature review. Biological Conservation 141 (10):2417-2431. https://doi.org/10.1016/j.biocon.2008.07.014

Reed, M. S., A. C. Evely, G. Cundill, I. Fazey, J. Glass, A. Laing, J. Newig, B. Parrish, C. Prell, C. Raymond, and L. C. Stringer. 2010. What is social learning? Ecology and Society 15(4):r1. https://doi.org/10.5751/es-03564-1504r01

Reed, M. S., L. C. Stringer, I. Fazey, A. C. Evely, and J. H. J. Kruijsen. 2014. Five principles for the practice of knowledge exchange in environmental management. Journal of Environmental Management 146:337-345. https://doi.org/10.1016/j.jenvman.2014.07.021

Restrepo, M. J., M. A. Lelea, and B. A. Kaufmann. 2018. Evaluating knowledge integration and co-production in a 2-year collaborative learning process with smallholder dairy farmer 
groups. Sustainability Science 13(5):1265-1286. https://doi. org/10.1007/s11625-018-0553-6

Ritter, F., A. Muhar, and M. Fiebig. 2010. Transdisziplinärer Dialog: Fachwissen und Erfahrungswissen im Austausch über Sommer-Bergtourismus und Klimawandel [Transdisciplinary dialogue: expert and experiential knowledge in a discourse on summer mountain tourism and climate Change]. GAIA Ecological Perspectives for Science and Society 19(3):194-203. https://doi.org/10.14512/gaia.19.3.9

Rose, D. C., N. Mukherjee, B. I. Simmons, E. R. Tew, R. J. Robertson, A. B. M. Vadrot, R. Doubleday, and W. J. Sutherland. 2020. Policy windows for the environment: tips for improving the uptake of scientific knowledge. Environmental Science and Policy 113:47-54. https://doi.org/10.1016/j.envsci.2017.07.013

Roux, D. J., J. L. Nel, G. Cundill, P. O'Farrell, and C. Fabricius. 2017. Transdisciplinary research for systemic change: who to learn with, what to learn about and how to learn. Sustainability Science 12(5):711-726. https://doi.org/10.1007/s11625-017-0446-0

Scholz, R. W. 2001. The Mutual learning sessions. Pages 117-129 in J. T. Klein, R. Häberli, R. W. Scholz, W. GrossenbacherMansuy, A. Bill, and M. Welti, editors. Transdisciplinarity: joint problem solving among science, technology, and society: an effective way for managing complexity. Birkhäuser Verlag, Basel, Switzerland. https://doi.org/10.1007/978-3-0348-8419-8_11

Serrat, O. 2017. Knowledge solutions: tools, methods, and approaches to drive organizational performance. Springer, Singapore.

Tuinstra, W., E. Turnhout, and W. Halffman. 2019. Usable knowledge. Pages 126-140 in E. Turnhout, W. Tuinstra, and W. Halffman, editors. Environmental expertise: connecting science, policy and society. Cambridge University Press, Cambridge, UK. https://doi.org/10.1017/9781316162514.011

van Mierlo, B., J. Halbe, P. J. Beers, G. Scholz, and J. Vinke-de Kruijf. 2020. Learning about learning in sustainability transitions. Environmental Innovation and Societal Transitions 34:251-254. https://doi.org/10.1016/j.eist.2019.11.001

VERBI Software. 2019. MAXQDA 2020. VERBI Software, Berlin, Germany.

Vilsmaier, U., M. Engbers, P. Luthardt, R. M. MaasDeipenbrock, S. Wunderlich, and R. W. Scholz. 2015. Case-based mutual learning sessions: knowledge integration and transfer in transdisciplinary processes. Sustainability Science 10(4):563-580. https://doi.org/10.1007/s11625-015-0335-3

Walter, A. I., S. Helgenberger, A. Wiek, and R. W. Scholz. 2007. Measuring societal effects of transdisciplinary research projects: design and application of an evaluation method. Evaluation and Program Planning 30(4):325-338. https://doi.org/10.1016/j. evalprogplan.2007.08.002

Wittmayer, J. M., and N. Schäpke. 2014. Action, research and participation: roles of researchers in sustainability transitions. Sustainability Science 9(4):483-496. https://doi.org/10.1007/ $\underline{\text { s11625-014-0258-4 }}$ 


\section{Appendix 1}

Interview protocol for researchers

\section{Introduction}

\subsection{Aim of this questionnaire}

This questionnaire aims at capturing the learning process that accompanied the project implementation, from the point of view of different actors involved in the process.

\subsection{What do we mean with "learning process"?}

The learning process refers to the production of knowledge as a joint process among stakeholders and scientists (Vilsmaier et al., 2015; Walter et al., 2007), building on the notion of mutual learning, defined as "the basic process of exchange, generation, and integration of existing or newly developing knowledge in different parts of science and society" (Scholz, 2001). You can also think about "insights" or "perspectives" gained through the process.

\subsection{Disclaimer on data handling}

Results of this questionnaire will be used exclusively for research purposes under the scope of the ENABLE project. Presentation of results will not identify any respondent's name. No personal information such as phone number or bank details will be collected. E-mail address will only be collected if voluntarily given by the respondent (for purposes of receiving further information on the project), but will not be included in the presentation of results. By proceeding you consent to take the survey (you can revoke this at any time).

\section{Questions on the learning process}

2.1. In which ENABLE city did you conduct your research?

2.2. What events or other opportunities to foster learning did you promote in your ENABLE case study city? In which stages of the project did they take place? 
2.3. What knowledge or ideas/insights/perspectives did you gain through your participation in the project (even if you don't consider them as something you have "learned")?

2.4. Through which project-related activities (e.g. workshops in other ENABLE cities, stakeholder workshops in own city) do you think you have learned the most? And the least?

2.5. Did you learn any terms (like technical terms) that were new to you? If yes, how useful do you find them for your activities? Did you experience some difficulty communicating with/understanding others due to the terms/jargon used?

2.6. Do you feel you learned something from the research team? And from other actors in the city? Can you identify what you have learned from each of them? (main items)

2.7. Do you think there were other actors, who could have been beneficial to the learning process, but who were not engaged in the project? Were there any particular reasons to not engage them?

2.8. For which purposes do you see the knowledge created in the project useful (e.g. supporting GBI planning/managing processes)?

2.9. In which ways is the knowledge produced in the project useful for you (as support to your activities)?

2.10. What new knowledge or new insights resulting from the project do you consider the most relevant for the planning and management of green and blue infrastructure in your case study city?

2.11. Did the project meet your expectations regarding what you wanted to learn about? If not, what would you have liked to learn about, which was not possible through the project? 


\section{Questions related with the Most Significant Change}

3.1. What did you find most interesting and useful from the project? What were the main "take-home messages"?

The questions below are relevant during the MSC interviews and should be introduced, but only if they are not spontaneously mentioned by participants.

3.2. Could you actually apply some of the new knowledge/insights/ideas resulting from the project in your own activities (e.g. in other research projects)?

3.3. Could you identify any barriers that prevented knowledge exchange between the research team and local actors?

3.4. Based on your experience with ENABLE, how should knowledge exchange strategies and processes be designed in the future to enhance the learning process?

3.7. Is there anything you want to add regarding your experience with the project, which has not been mentioned so far?

\section{Interview protocol for stakeholders}

\section{Introduction}

\subsection{General ENABLE introduction}

ENABLE is a EU-funded research project that aims to develop and test new methods and tools to leverage the potential of GBI interventions in neighbourhoods and across metropolitan regions while adopting a social and environmental justice perspective and taking into account the perceptions of local stakeholders. It tests possible GBI solutions to urban challenges in the metropolitan regions of Halle, Barcelona, Łódź, Stockholm and Oslo, while also exchanging with the city of New York.

\subsection{Aim of this questionnaire}


This questionnaire aims at capturing the learning process that accompanied the project implementation, from the point of view of different actors involved in the process.

\subsection{What do we mean with "learning process"?}

The learning process refers to the production of knowledge as a joint process among stakeholders and scientists (Vilsmaier et al., 2015; Walter et al., 2007), building on the notion of mutual learning, defined as "the basic process of exchange, generation, and integration of existing or newly developing knowledge in different parts of science and society" (Scholz, 2001). You can also think about "insights" or "perspectives" gained through the process.

\subsection{Disclaimer on data handling}

Results of this questionnaire will be used exclusively for research purposes under the scope of the ENABLE project. Presentation of results will not identify any respondent's name. No personal information such as phone number or bank details will be collected. E-mail address will only be collected if voluntarily given by the respondent (for purposes of receiving further information on the project), but will not be included in the presentation of results. By proceeding you consent to take the survey (you can revoke this at any time).

\section{Questions on the learning process}

2.1. In which role(s) did you get involved with ENABLE (e.g. practitioner in organization X; researcher at university Y; citizen with no particular affiliation)?

2.2. How is your work related to Green and Blue Infrastructure in the city?

2.3. When did you participate in project's activities (e.g. workshops, field trips)?

2.4. Would you have liked to participate in other stages of the project but you think the project did not give you the opportunity to do it? If yes, in which stages?

2.5. What knowledge or ideas/insights/perspectives did you gain through your participation in the project (even if you don't consider them as something you have "learned")? 
2.6. Through which project-related activities (e.g. hands-on exercises; dialogues with others) or outputs (e.g. maps, models, indicators) do you think you have learned the most? And the least?

2.7. Did you learn any terms (like technical terms) that were new to you? If yes, how useful do you find them for your activities? Did you experience some difficulty communicating with/understanding others due to the terms/jargon used?

2.8. Do you feel you learned something from the research team? And from other actors in the city? Can you identify what you have learned from each of them?

2.9. Do you think there were other actors, who could have been beneficial to the learning process, but who were not engaged in the project?

2.10. For which purposes do you see the knowledge created in the project useful (e.g. supporting GBI planning/managing processes)?

2.11. In which ways is the knowledge produced in the project useful for you (as support to your activities)?

2.12. What new knowledge or new insights resulting from the project do you consider the most relevant for the planning and management of green and blue infrastructure in the city?

2.13. Did the project meet your expectations regarding what you wanted to learn about? If not, what would you have liked to learn about, which was not possible through the project?

\section{Questions related with the Most Significant Change}

3.1. What did you find most interesting and useful from the project? What were the main "take-home messages"? 
The questions below are relevant during the MSC interviews and should be introduced, but only if they are not spontaneously mentioned by participants.

3.2. Could you actually apply some of the new knowledge/insights/ideas resulting from the project in your own activities?

3.3. Did you feel that you could influence some aspects of the project (e.g. directing research questions; identifying issues to focus research efforts)?

3.4. Do you think that the project promoted interactions with other actors in the city?

3.5. Could you identify any barriers that prevented knowledge exchange between the research team and local actors?

3.6. Based on your experience with ENABLE, how should knowledge exchange strategies and processes be designed in the future to enhance the learning process?

3.7. Is there anything you want to add regarding your experience with the project, which has not been mentioned so far?

\section{References}

Scholz, R.W., 2001. The Mutual Learning Sessions, in: Klein, J.T., Häberli, R., Scholz, R.W., Grossenbacher-Mansuy, W., Bill, A., Welti, M. (Eds.), Transdisciplinarity: Joint Problem Solving among Science, Technology, and Society: An Effective Way for Managing Complexity. Birkhäuser Basel, Basel, pp. 117-129. doi:10.1007/978-3-0348-8419-8_11

Vilsmaier, U., Engbers, M., Luthardt, P., Maas-Deipenbrock, R.M., Wunderlich, S., Scholz, R.W., 2015. Case-based Mutual Learning Sessions: knowledge integration and transfer in transdisciplinary processes. Sustainability Science 10, 563-580. doi:10.1007/s11625-015-0335-3

Walter, A.I., Helgenberger, S., Wiek, A., Scholz, R.W., 2007. Measuring societal effects of transdisciplinary research projects: Design and application of an evaluation method. Evaluation and Program Planning 30, 325-338. doi:10.1016/J.EVALPROGPLAN.2007.08.002 


\author{
Appendix 2 \\ Informed consent form
}

Research project title: ENABLE

Research investigator: André Mascarenhas

Research Participant's name:

Within the ENABLE project, we are conducting a study on the learning process taking place during the project. For that study, we are conducting interviews with members of the research team, to gather their insights on that topic, based on their experience during the project. No personal data will be collected through this interview. The results of the study are to be published in the form of an open-access scientific article.

This consent form is to ensure that you understand the purpose of your involvement and that you agree to the conditions of your participation. Please read the information contained in this form and then sign it to certify that you approve the following:

- the interview will be recorded and a transcript will be produced;

- you will have access to the transcript and be given the opportunity to correct any factual errors;

- the results of the study are to be published in the form of an open-access scientific article;

- the transcript of the interview will be analysed by André Mascarenhas as research investigator;

- access to the interview transcript will be limited, during the writing of the scientific article, to the co-authors (André Mascarenhas, Johannes Langemeyer, Erik Andersson, Sara Borgström, Dagmar Haase), and afterwards will be made available as supplementary material to the scientific article;

- any summary interview content, or direct quotations from the interview, that are made available through academic publication or other academic outlets will be anonymized so that you cannot be identified, and care will be taken to ensure that other information in the interview that could identify yourself is not revealed;

- the actual recording will be deleted after the scientific article has been published;

- you have the right to stop the interview or withdraw from the research at any time;

- any variation of the conditions above will only occur with your further explicit approval. 
Should you have any further questions or concerns about your participation, please contact:

André Mascarenhas

Humboldt-Universität zu Berlin

Unter den Linden 6,

10117 Berlin

Germany

+49 (030) 2093-9415

Participant signature

Date

Researcher signature

Date 
Appendix 3

Coded interview transcriptions 


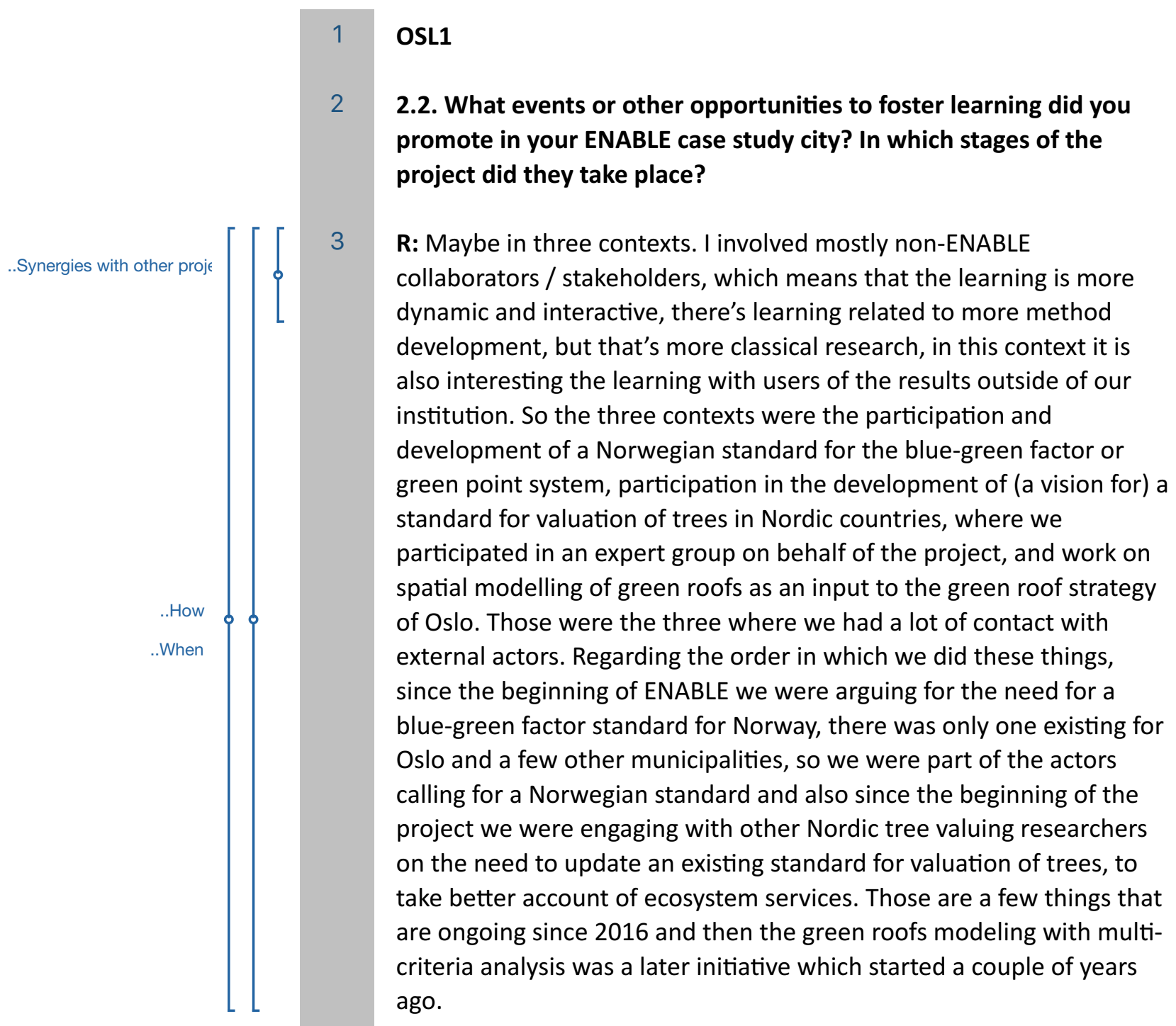

2.3. What knowledge or ideas/insights/perspectives did you gain through your participation in the project (even if you don't consider them as something you have "learned")?

R: The fact that conclusions or hypothesis you might already have had working in your city, they are either rejected or reinforced by the possibility to compare with other cities. So I found it very useful the work that was done on comparing green space access and availability, the comparative mapping work across the cities I found that very useful to sort out what was important and what wasn't important to focus on in Oslo. Sounds a little bit contradictory in the sense that we should as a researcher be working on city specific needs but it's easy to get the needs of the city and the research interests mixed up, and it was kind of easier to sort things out sitting together with other cities and hearing about their priorities and also comparing if access to green space was really a big issue in Oslo or if it's just a big issue locally. Those kind of things become clear when it has this comparison possibility that the project gives you. 


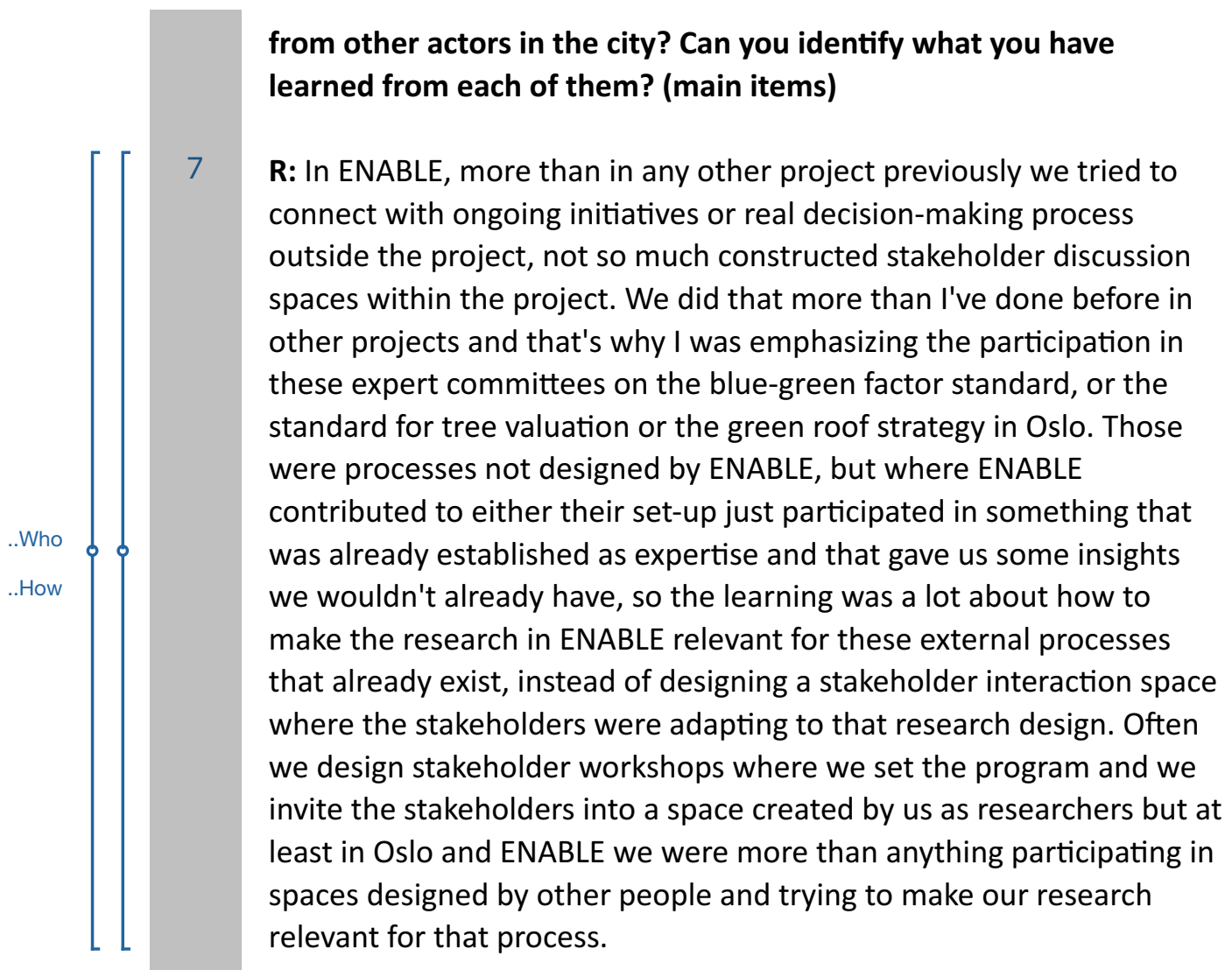

2.4. Through which project-related activities (e.g. workshops in other ENABLE cities, stakeholder workshops in own city) do you think you have learned the most? And the least?

R: See processes mentioned in 2.2. The learning was a lot about how to make ENABLE results relevant to these other processes.

2.5. Did you learn any terms (like technical terms) that were new to you? If yes, how useful do you find them for your activities? Did you experience some difficulty communicating with/understanding others due to the terms/jargon used?

R: I guess we spent quite a long time but that was a complementary one on deciding about these filters. I don't think I ever used the concept of filters before.(unclear) We were kind of participating in its definition from the start but possibly [STO1] had used this concept before, but it was a new concept to me or a new framework.

Difficulties: I can't remember any situation where we were obviously talking past each other, but the discussion on the filters took a long time so that's maybe evidence that we weren't putting the same things into those concepts to begin with, but of course we set up a process to understand each other from the start, so that was normal.

2.7. Do you think there were other actors, who could have been beneficial to the learning process, but who were not engaged in the 


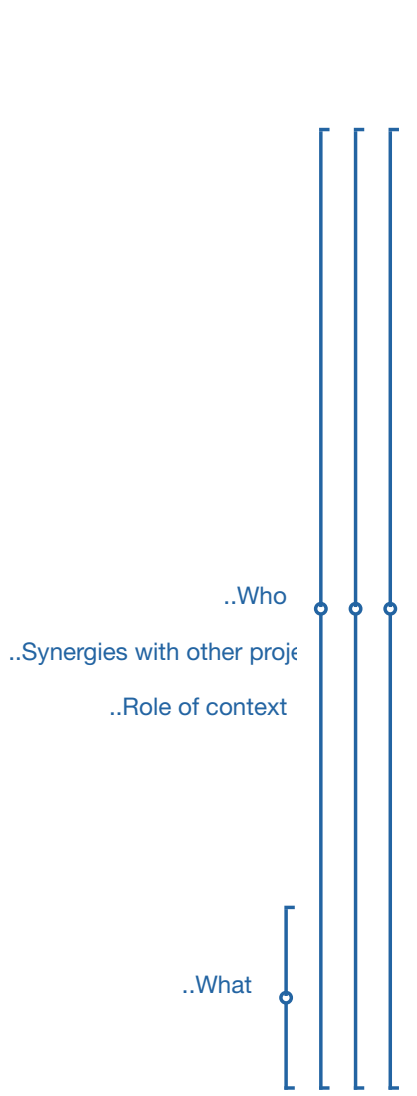

15

16
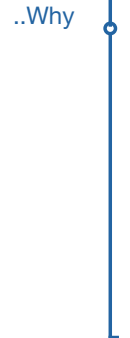

17

18

R: In every project on urban ecosystem services we continue we have to work with engagement with the municipalities, it's not like you just do it in one project and then everything stops. You have to keep coming back to it, Often several times within the same project, because the municipality has - even the Oslo municipality, the best equipped municipality in Norway - has very tight budgets and personnel time to engage with research projects. And there's a lot of experts with whom we make a relationship, who quit and move on, then there's new personnel and you have to start the whole trustbuilding exercise from the beginning again. That has happened several times with different agencies (like the planning and building agency, the environment agency, the water and sewage agency and so on), so it's a constant effort to renew contacts. In variable ways I could have hoped for more engagement from the environment agency, but the reasons for that are due to personnel changes. It's not a structural thing about ENABLE or even a structural weakness of the environment agency or the municipality, it's just the reality that - if you want another learning experience - that's probably the kind of metaexperience in the background that engaging with the stakeholders is a continuous and time-demanding process.

\subsection{For which purposes do you see the knowledge created in the project useful (e.g. supporting GBI planning/managing processes)?}

R: Those three processes - the green-blue factor, the tree valuation exercise and the spatial modeling of green roofs. One way of structuring the purposes of the research that I've used previously is informative purposes, decisive purposes and technical support purposes. For those three processes the green roofs modeling was for the purpose of spatial prioritization of where green roofs fill demand gaps and provide most effect for the use of space and that's a decisive purpose targeted at planning and zoning and then for the valuation of trees working on the Nordic standard that would be used by Oslo municipality that's a technical support purpose because it's equipping the city with a tree damage compensation assessment that's up-todate including ecosystem services and the same would go for that the blue green factor standard, it's technical support purpose.

\subsection{In which ways is the knowledge produced in the project useful for you (as support to your activities)?}

R: I could come back to the three tools I was talking about before which all will lead to future work because they're being integrated into standards or plans in the municipality or at national level, so I think I will come back to them in the future most definitely, but one thing recently was... there would be no way I couldn't even thought of reacting to the current shutdown and the relevance for green space research without having interacted with the cities in ENABLE and the 


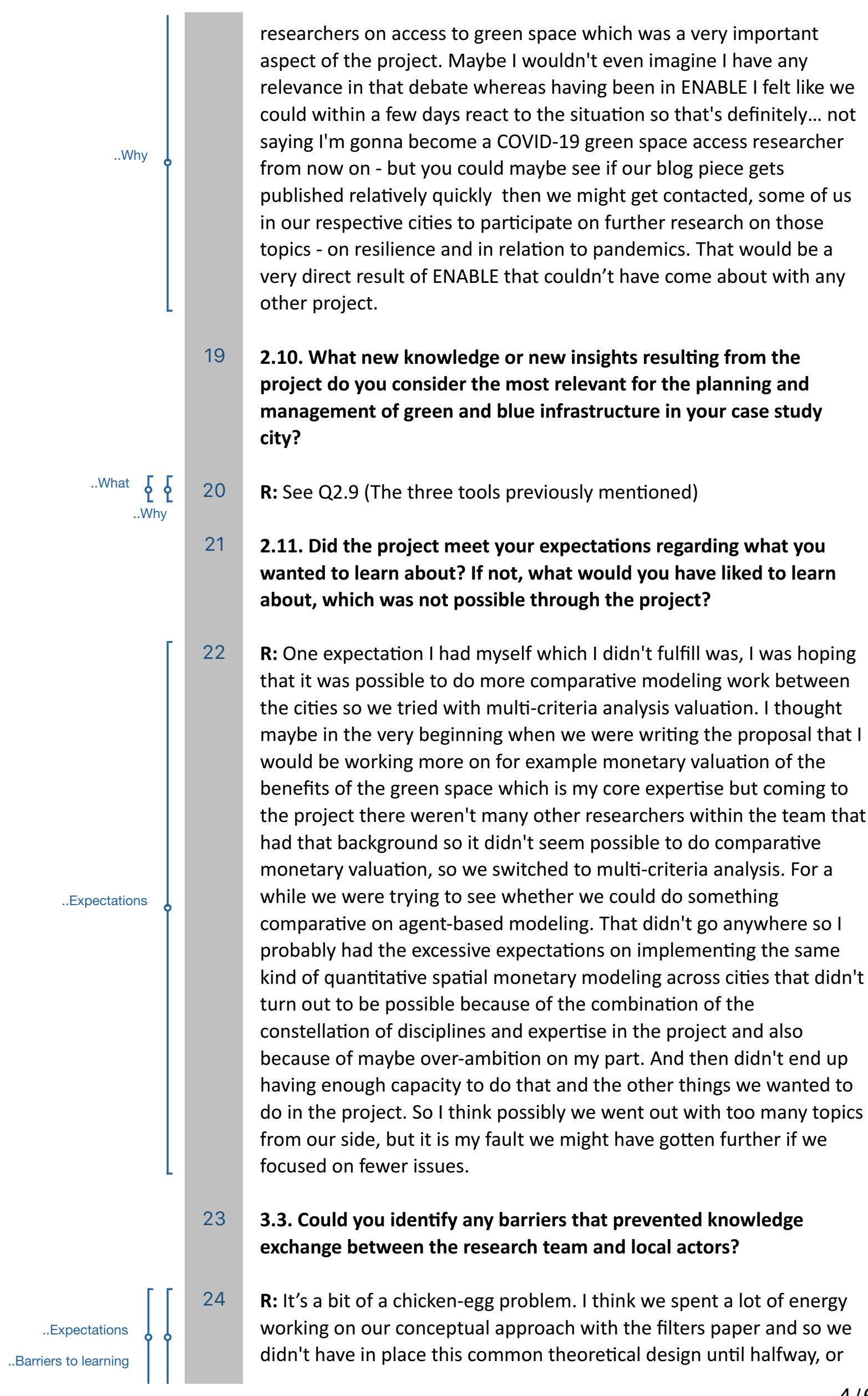




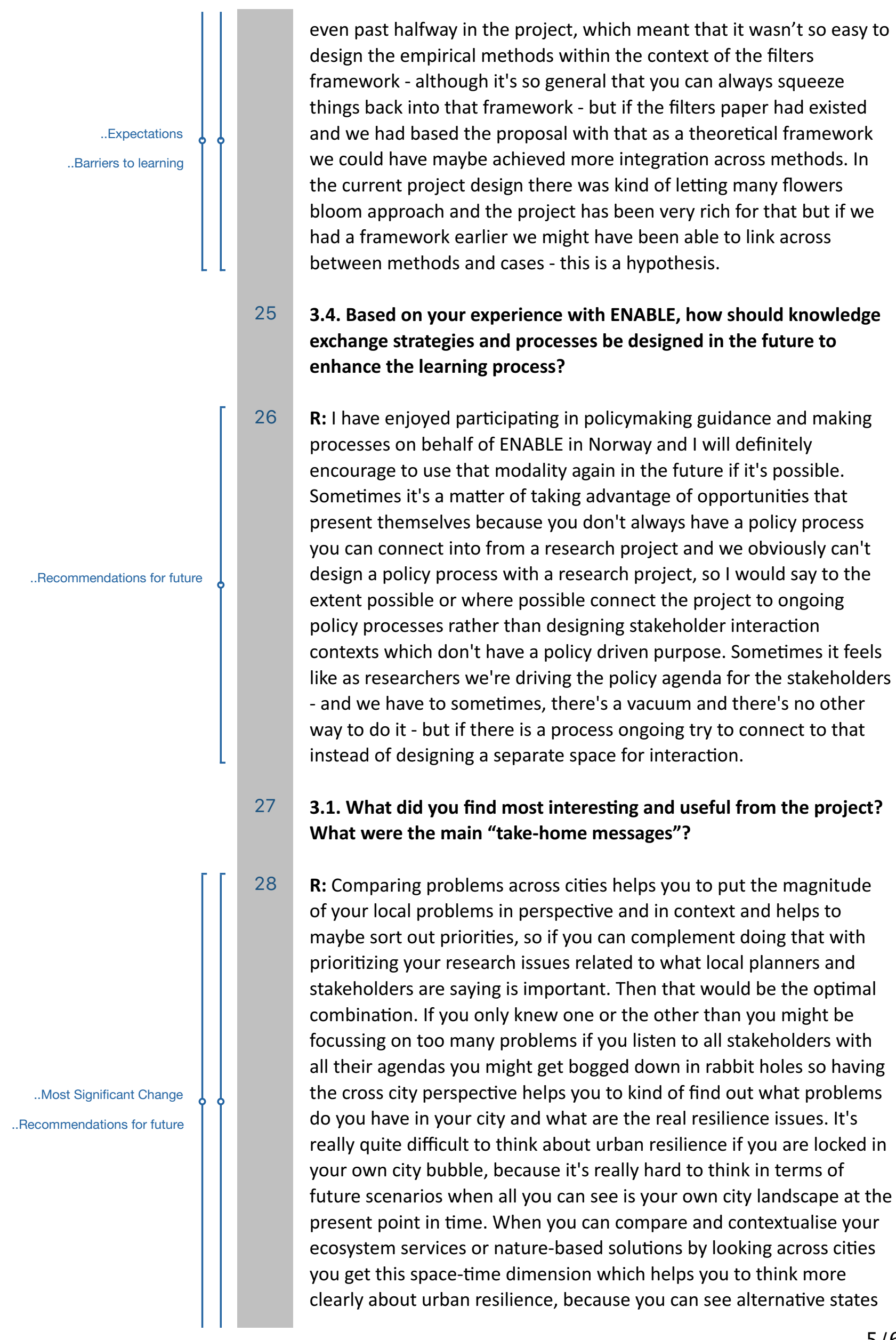


..Most Significant Change

Recommendations for future that your city could be in and that's not possible or at least much more difficult when you only work in your own city bubble. If I think in a very conceptual way that might be a take-home message from ENABLE. You can't really do urban resilience studies well unless you have a cross-city comparison approach.

29 End 
2.2. What events or other opportunities to foster learning did you promote in your ENABLE case study city? In which stages of the project did they take place?

R: Two workshops in Halle with stakeholders, one more at the beginning of the process, the other one more towards the end.

2.3. What knowledge or ideas/insights/perspectives did you gain through your participation in the project (even if you don't consider them as something you have "learned")?

R: There was one big insight: The scales in the city operate independently. Existing problems at the local scale are not reflected by urban planners. For example the bad image of Halle Newtown where people don't use offers of municipality. Urban planners don't understand, that giving money to and engage active people (like [local stakeholder name]) does not solve the issue. The Issue is in the pattern of the population in the city, which is reinforced by the city government by putting all neglected groups there. The point here is that sometimes one scale doesn't see the other and vice versa. This told me also that our core principles in landscape ecology or urban ecology of scale transparency or scale transmission might be correct at natural science side but might be misleading in some spheres of the social- and planning economic side. Arjen Buijs with his mosaic approach might be closer to how this works.

2.6. Do you feel you learned something from the research team? And from other actors in the city? Can you identify what you have learned from each of them? (main items)

R: Yes, there were two issues that were not very positive and that unexpectedly did not work. The first issue is that the Q-method doesn't work. I was so optimistic that this method could yield additional knowledge and could be complemented with the mental mapping and I am not sure what exactly went wrong. The second issue was the resilience assessment. It is so much shaped to the conditions of the researchers who are developing this concept that it is hard to adapt it to any other content that might run under a slightly different regime.

2.4. Through which project-related activities (e.g. workshops in other ENABLE cities, stakeholder workshops in own city) do you think you have learned the most?

R: The local workshops / the Halle workshop, because I started to learn this gap (mentioned before). The Halle workshop started a new thinking about green planning in cities and related to different social / income groups. Also the last final workshop in Brussels showed that 


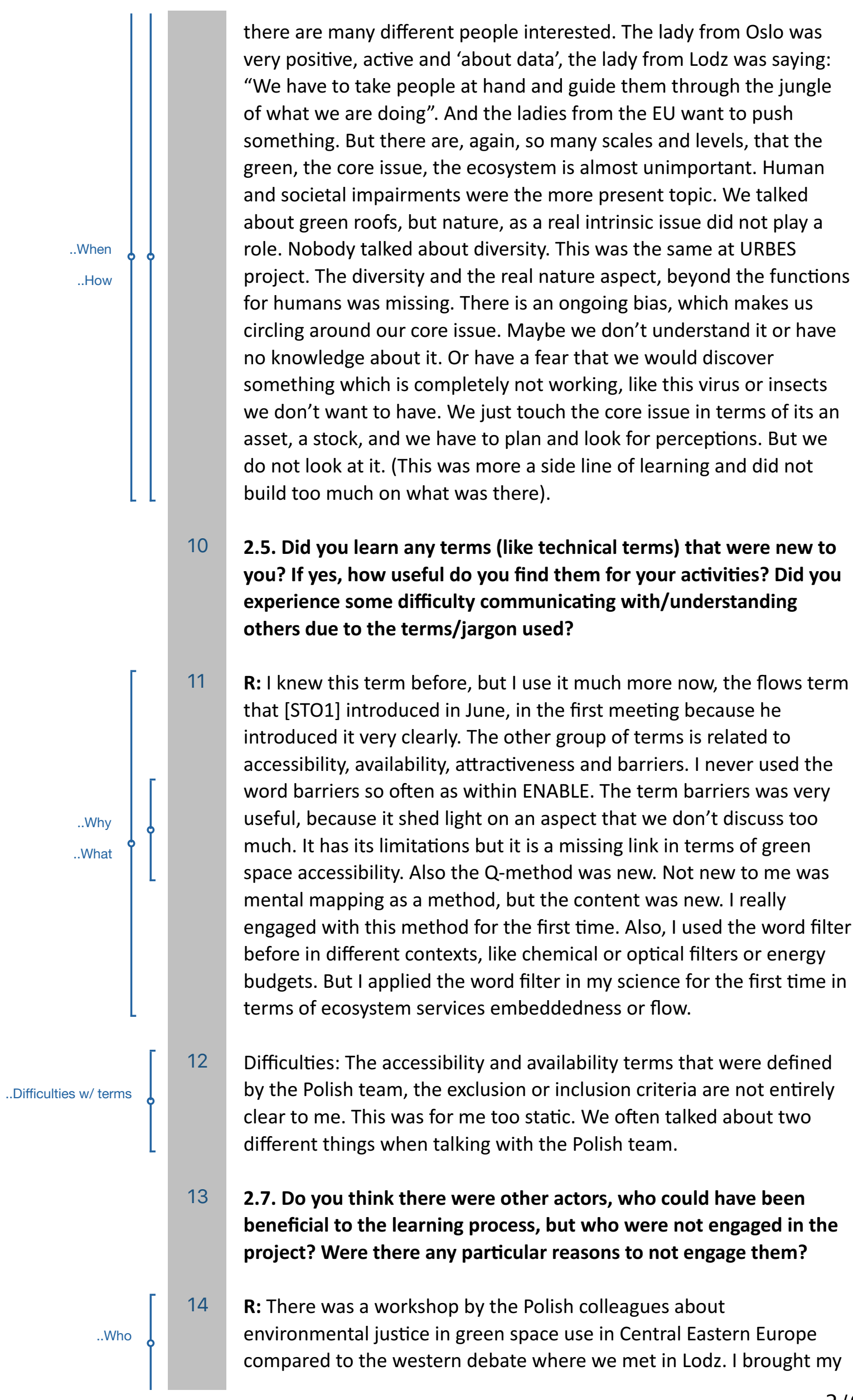




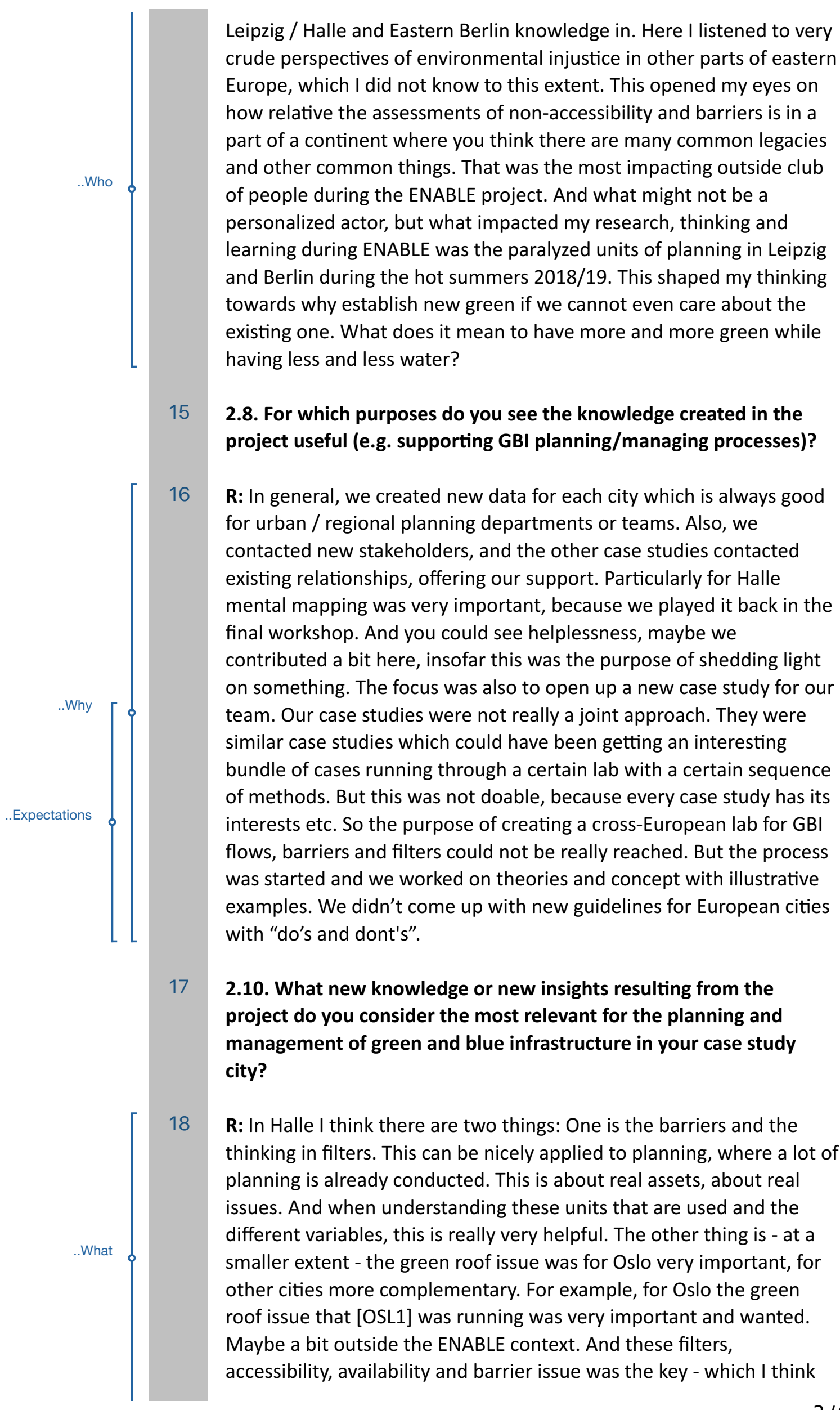


you should remember when thinking about ENABLE. Not so much the resilience assessment they did in Stockholm, because it was hard to see how other case studies who were doing this and could really benefit from this. It was a really hard exercise without a clear big benefit.

\subsection{In which ways is the knowledge produced in the project useful for you (as support to your activities)?}

20 R: In terms of pure methods, the application of mental mapping in Stockholm and Halle, which really went well and we got interesting results. It is a kind of complement to the survey types I use so far in green spaces like PPGIS (public participation geographic information systems) or similar participatory observations or surveys and so on. This was really a gain. The second was to be aware of impairments, that we have so many issues that seem very loosely and that it's not really about intrinsic functioning of nature. This is a very sad finding. It was not really about acknowledging the dangers for nature that we run in under climate change. The basic requirements for nature were simply ignored. We don't get into the systems and living organism next to humans in this nature. We talk about "co-" but we try to push our impressions through everything and we see green as a servant, and this makes me sad.

\subsection{Did the project meet your expectations regarding what you} wanted to learn about? If not, what would you have liked to learn about, which was not possible through the project?

22 R: Firstly, we wanted to continue what we started in URBES. And secondly, related to the case study, I wanted to get away from Berlin and Leipzig and open up a new case study, which is still more fragile than these growing poles. So, this was a very regional related issue. My expectations were that we get deeper into where we had to stop in URBES. And we did this with the accessibility and barriers, which is a nice continuation of the ecosystem service results from URBES. Also, the resilience assessment, where our plan in URBES didn't work out. This didn't work out in ENABLE as good as the accessibility and barriers issue. I wanted to get the system modelling and agent-based modelling in, because the case studies were interesting and we have new case studies, but I saw that the data gathering was so hard. I was disappointed that we didn't manage to get the system- and agentbased models running in the lifetime of the project. We have a good pre-requisite now, but my expectations were higher than what we could achieve. They need more time and cannot be done with so many case studies. Maybe with one case study you could get a deeper understanding and establish a system as well as an agent-based model. But with so many case studies and so many spread workloads it seems impossible. If I could rewrite ENABLE, I would say we should collect the knowledge, compile it, structure it, and try to develop a desk-study on the knowledge we have acquired and get into a 


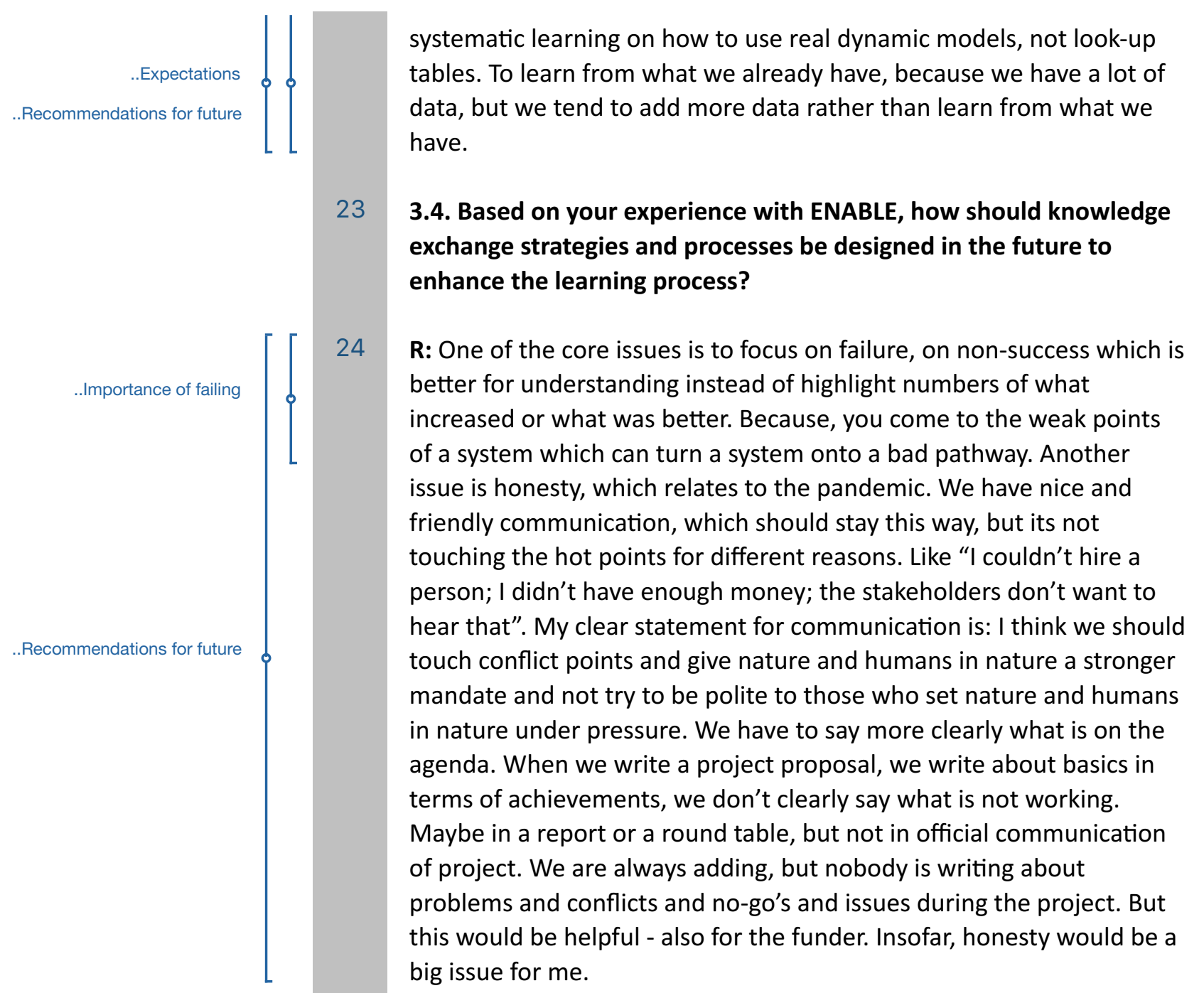

25

26

\subsection{Could you identify any barriers that prevented knowledge exchange between the research team and local actors?}

R: There is a certain mutual dependence that shapes the interaction, and it is characterized by limited resources and limited power. And it is one part of a neo-liberally shaped system where a lot of deficits need to be fought. For example, in science we have half positions or $25 \%$ positions that create very fragile conditions, also for planners.

Environmental and social budgets are the first to be cut, which makes us a very vulnerable group of people that try to make the best out of these situations. We are mutually dependent - they have to include science and we have to apply our knowledge to disseminate case studies, so we are relevant. The celebrating of the mutual relevance shapes our relationships in the same way as real interest. But I'm not sure if mutual dependence is more important than the interest in nature and in people. All in all, this vulnerability in the system shapes us all, since we are not the powerful actors like e.g. actors from the housing market, they won't listen. And we know this and we know that our suggestions are non-valid if we don't include powerful actors. This general dependence became very clear in ENABLE. 
27 3.1. What did you find most interesting and useful from the project? What were the main "take-home messages"?

28 R: Firstly, that scales matter but they don't always communicate. Second, we are circling around the real co-habitation of humans and nature in cities. We look at nature as a stock or asset but forget about its real importance. And third, we need more empirical data measurements and knowledge from the nature side. We were strong at the social side and weak at the nature side and like this, co-working and co-learning cannot work.

29 3.7. Is there anything you want to add regarding your experience with the project, which has not been mentioned so far?

30 R: At the workshop with the Eastern Europeans from Romania, Hungary, Slovakia and Ukraine in Lodz it became clear to me that where you come from, your personal background and legacies play a role how you see things and how you understand progress, conflicts, dependence, weakness, success. We saw this in ENABLE, comparing the restrictive opinions by [colleague name] compared to the "we know how this works"-attitude from [colleague name]. Your local context plays a role how you learn even if you see the same things. In another round of interview after ENABLE you could ask people about what sources of remembering, of personal knowledge, of tacit knowledge they use to reflect and mirror projects like ENABLE. It would be interesting to see how previous learning shapes recent learning. But this needs more preparation to formulate the right questions. The negative shape of change and overall loss shapes peoples' minds as well as experience of no real change or other changes. I saw this in ENABLE, but we need a concept to really articulate this in a structured and systematic way. 


\section{HAL2}

2.2. What events or other opportunities to foster learning did you promote in your ENABLE case study city? In which stages of the project did they take place?

R: At the beginning we had a big event (Halle workshop with ENABLE partners and local stakeholders) and a smaller flexible event centric to the topic of barriers at the end. But we also had a small and temporary visit to the ladies of the Quartiersmanagement, where we had a nice exchange, which I would count as a learning event for both sides. For us as researchers as well as the local stakeholders. When we went to Halle Neustadt, we had the brainstorming and the exchanging using a map. We also went to Neutopia, but this was more for informing each other, not necessarily capacity building in terms of learning. When the students were in the field for mental mapping, it was a little bit in between. Part of the method, when engaging with people, asking for support could be counted as learning. But the assessment itself I would purely count as an investigation method in the field.

\subsection{What knowledge or ideas/insights/perspectives did you gain through your participation in the project (even if you don't consider them as something you have "learned")?}

R: There were various levels where I could gain some insights and ideas. First I was reminded of the challenges of working with stakeholders, in terms of problem understanding, the time budget and capacity in total. There is a vicious circle in the co-design process: The less capacity the municipality has, the less it is able or interested in contributing to the co-design process. This was a challenge for us working in Halle, working with the limited time availability and the limited problem understanding of the stakeholders. From my perspective, what I learned for the next project I would focus on a certain set of problems and don't try to address the whole bunch of project-goals to the stakeholders. This became clear to me at the barrier workshop, which was a little bit too small for us but in general it was quite concentred talk and debate and exchange about a certain set of barriers and how to benefit from GBIs in its different facets from physical, institutional and perceptional perspectives. This was also something new for stakeholders to start thinking about the interlinkages. In summary: the capacity building as learning. And secondly, although you are focussing one specific question it is quite diverse when you start talking about different perspectives on the one hand and different overlaps on the other hand. And this is very interesting for stakeholders, decisionmakers as well as from a scholarly perspective. ENABLE cities, stakeholder workshops in own city) do you think you 


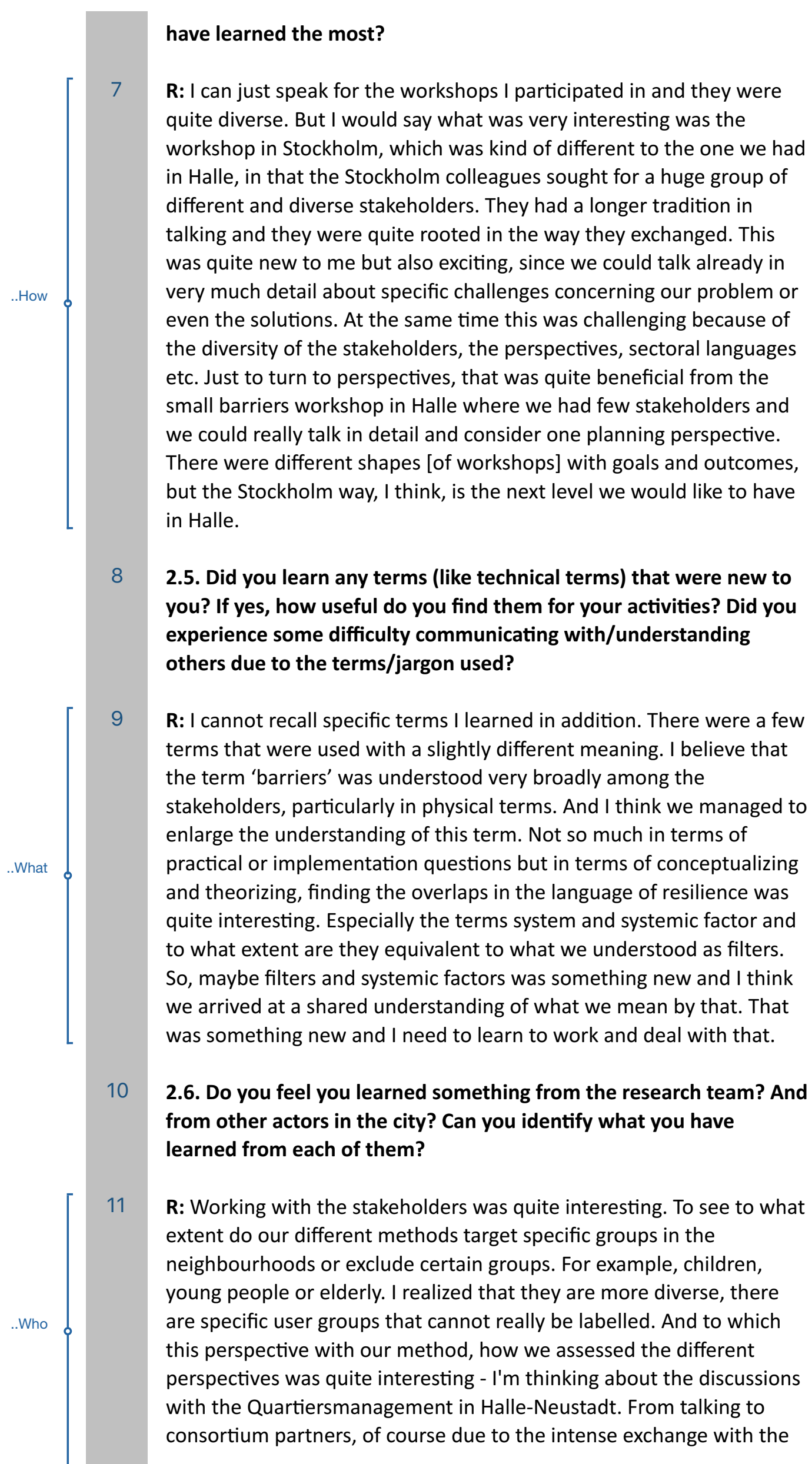


colleagues in Lodz we are able to further conceptualize the barrier perspective. This was something that we jointly further developed with a more socio-ecological touch and not so much in institutional setting, but of course with plenty of overlaps and synergies.

\subsection{Do you think there were other actors, who could have been beneficial to the learning process, but who were not engaged in the project? Were there any particular reasons to not engage them?}

R: I remember how we started conceptualizing the system of our case studies, sitting in Berlin and drawing the system dynamics model and mapping different components in the model. And comparing to who was actually on the table - when you engage with stakeholders you realize that you hardly can cover all those components. Of course that depends on how you set the boundaries of your system. From our perspective, talking about socio-ecological settings and the access to GBI benefits as one aspect in that, for instance we did not have any stakeholders from private housing companies or other more profitoriented stakeholders who actually have quite decisive impact on GBI benefits. Smaller enterprises for instance who are really important for community sense within the neighbourhood. We had the Quartiersmanagement, the city administration and planning officials and local grassroots initiatives, but no private actors.

\subsection{For which purposes do you see the knowledge created in the} project useful (e.g. supporting GBI planning/managing processes)?

R: Everything we did is useful but the question is for whom. A lot of what we did could be used for further scholarly work and case studies, but in terms of implementation, we created an extended understanding of barriers and the overlaps, embedded in a broader system - thinking about who are the other actors in play. This was interesting to think about for the stakeholders and if they use it further, that might also lead to a certain implementation, which we haven't achieved with ENABLE. For example, one stakeholder from the city administration was very interested in the way we looked at barriers from different perspectives but also on the way we incorporated housing market mechanisms, which are important for the way how people distribute in space, which is quite decisive to the actual accessibility to the benefits of green and blue infrastructure. This is what I meant with broader context. In ENABLE we just started to work together with Halle stakeholders. We did what we could but in terms of available capacities on both sides, it would be nice to have gone one step further towards implementation. We have not really contributed to a specific goal in the city but rather contributed to a more diverse problem understanding or awareness. Shifting the perspective away from implementation, I would say, the conceptualization of barriers and thinking about systemic filters, and then bridge it to empirical observation could be useful to be further developed, to be fed with more details. If you enrich this with more 


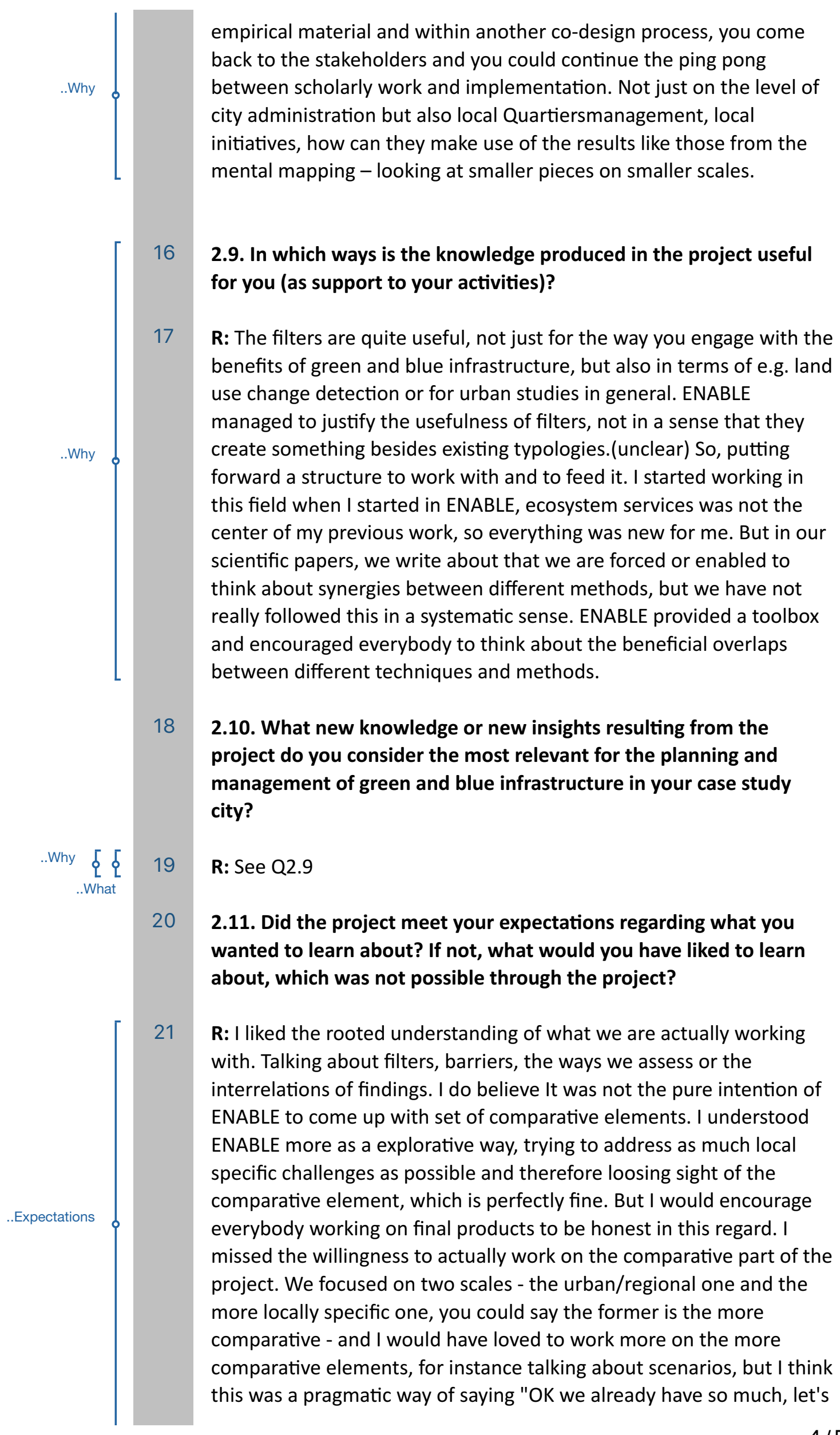




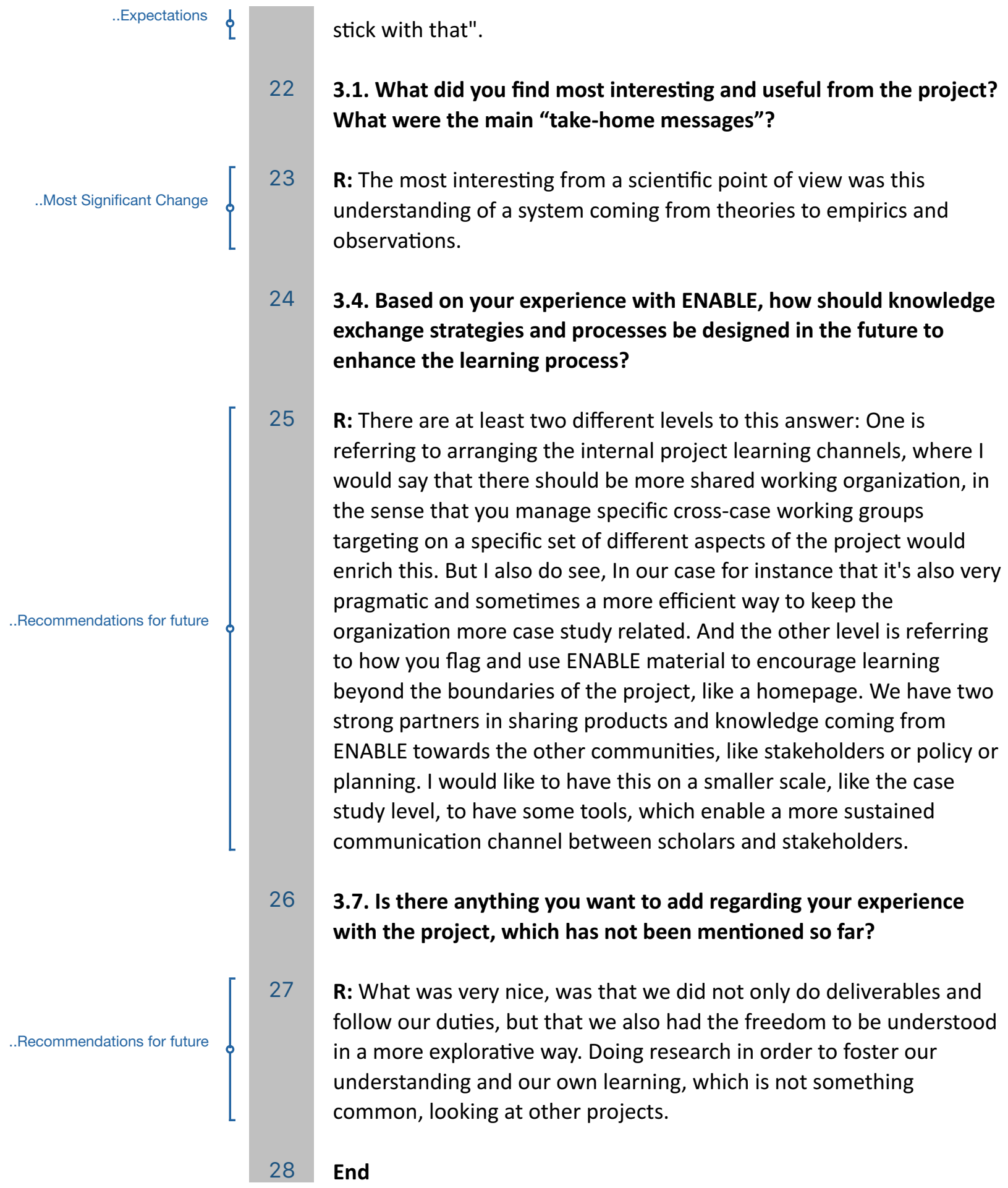




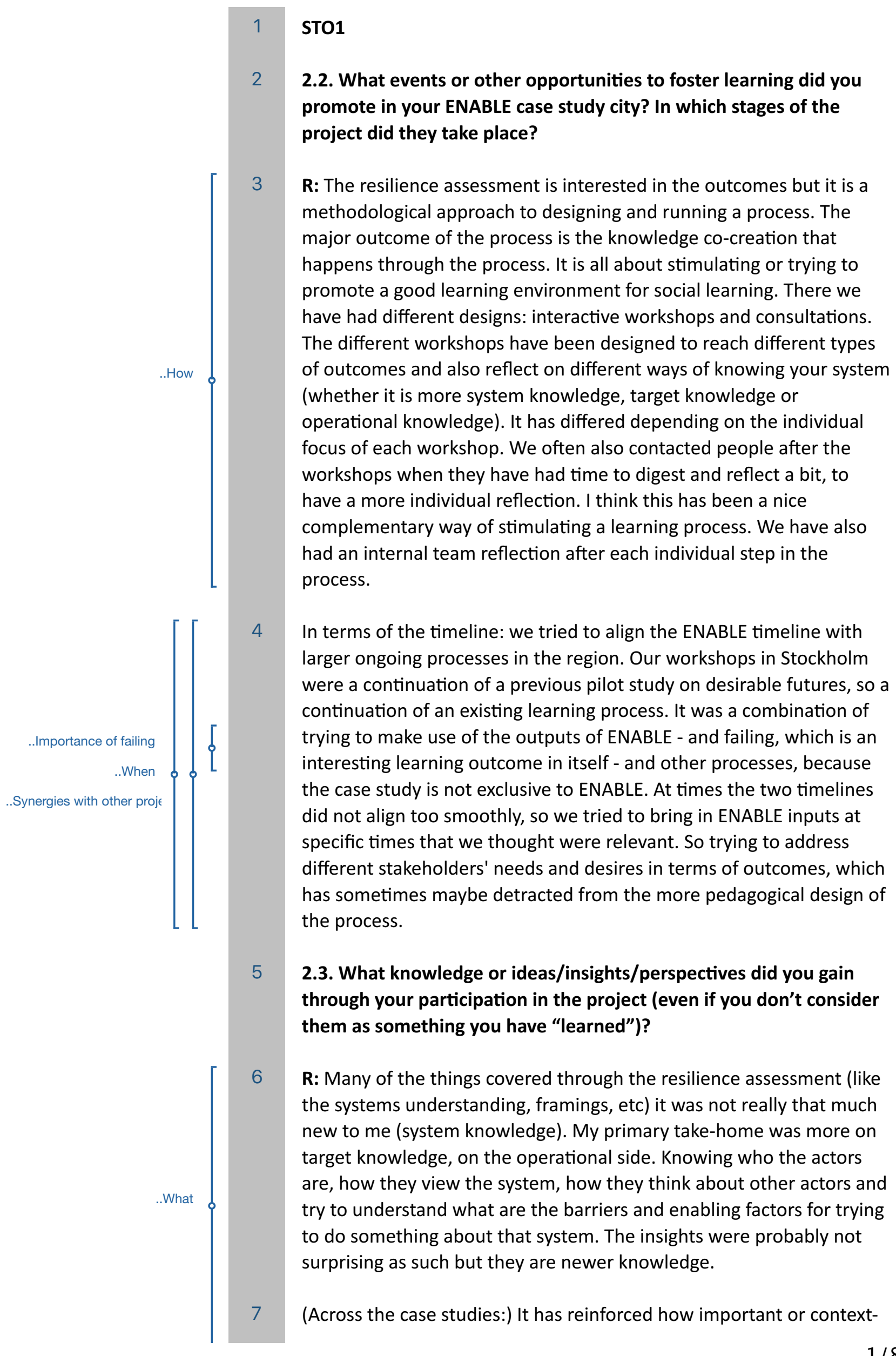




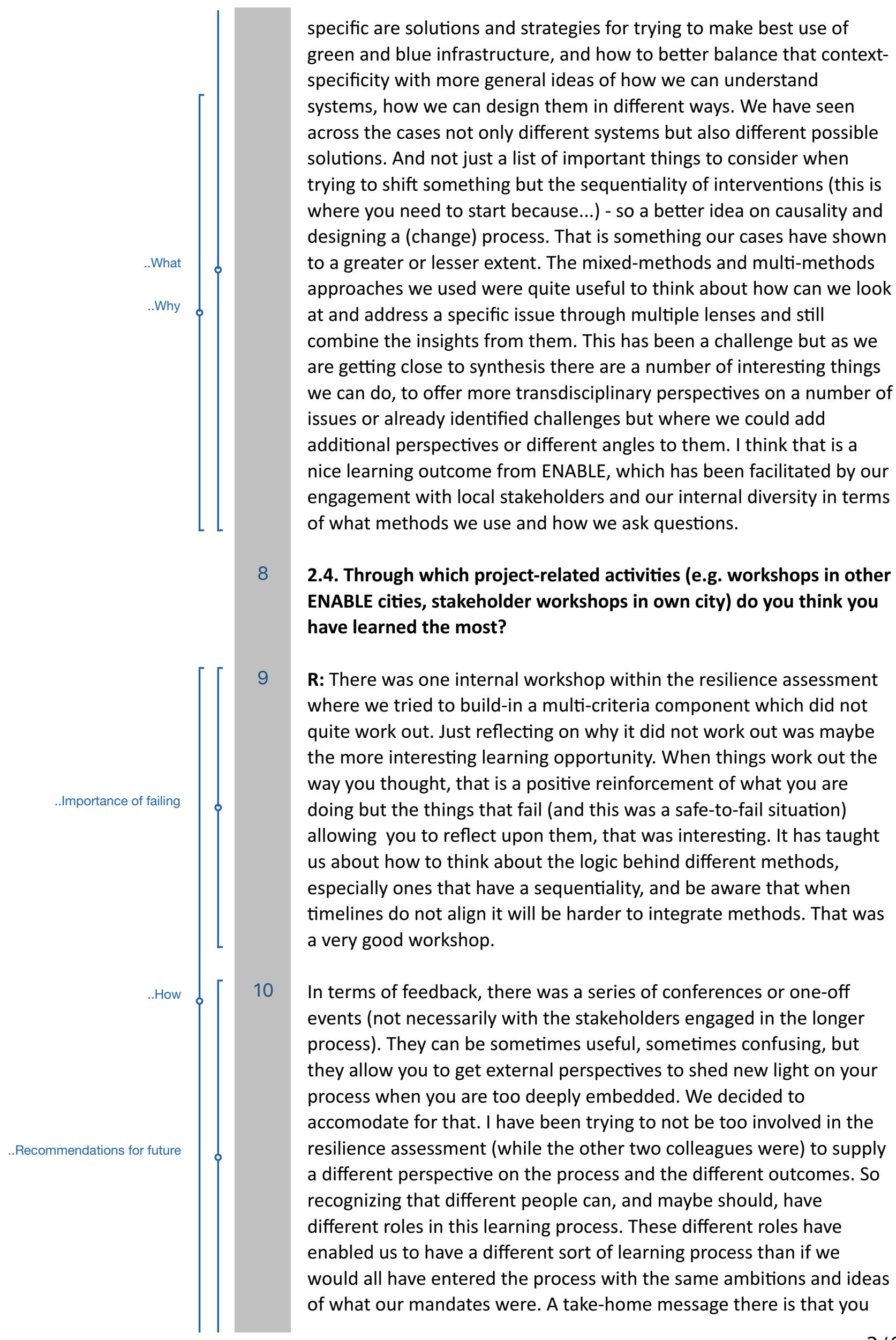




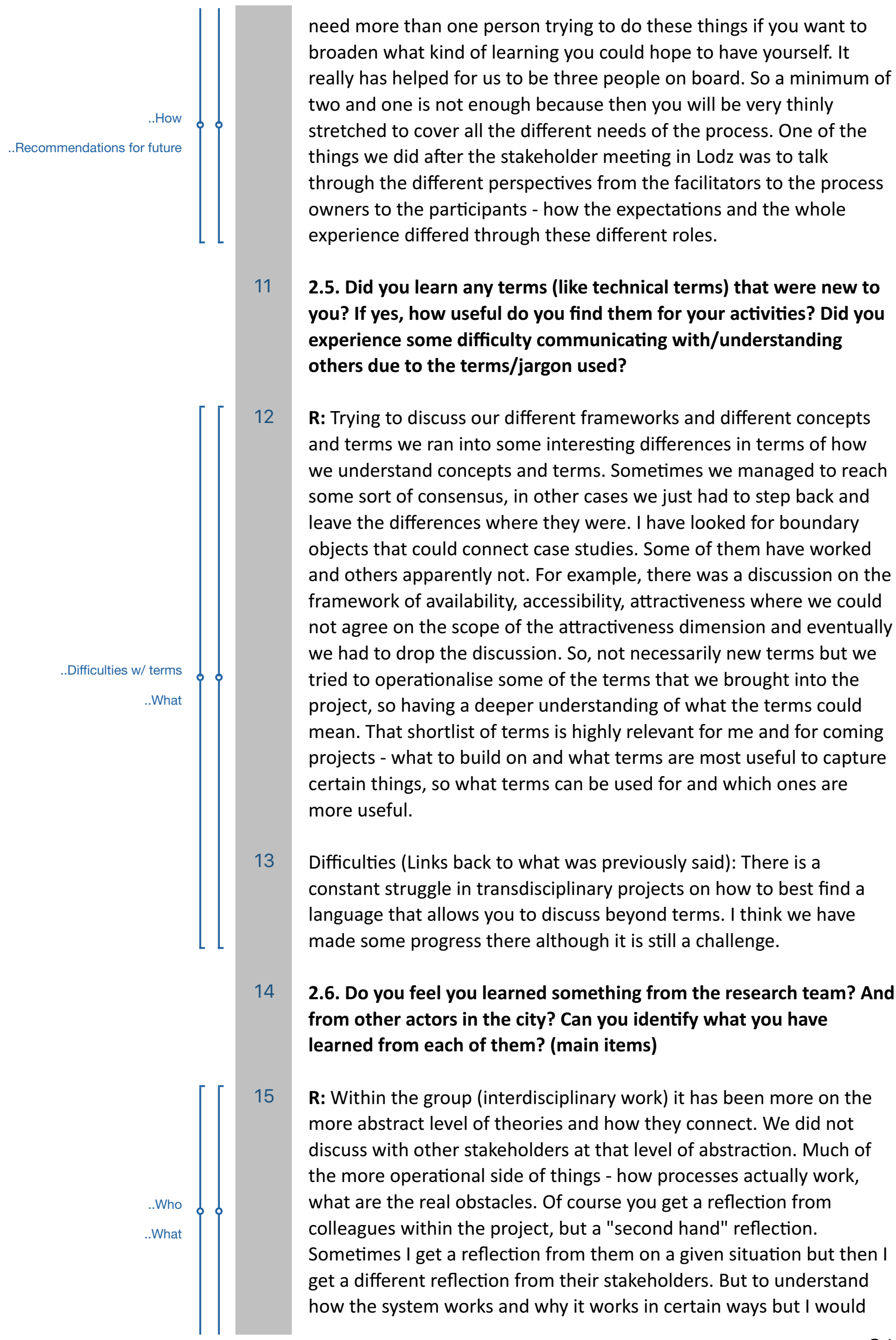




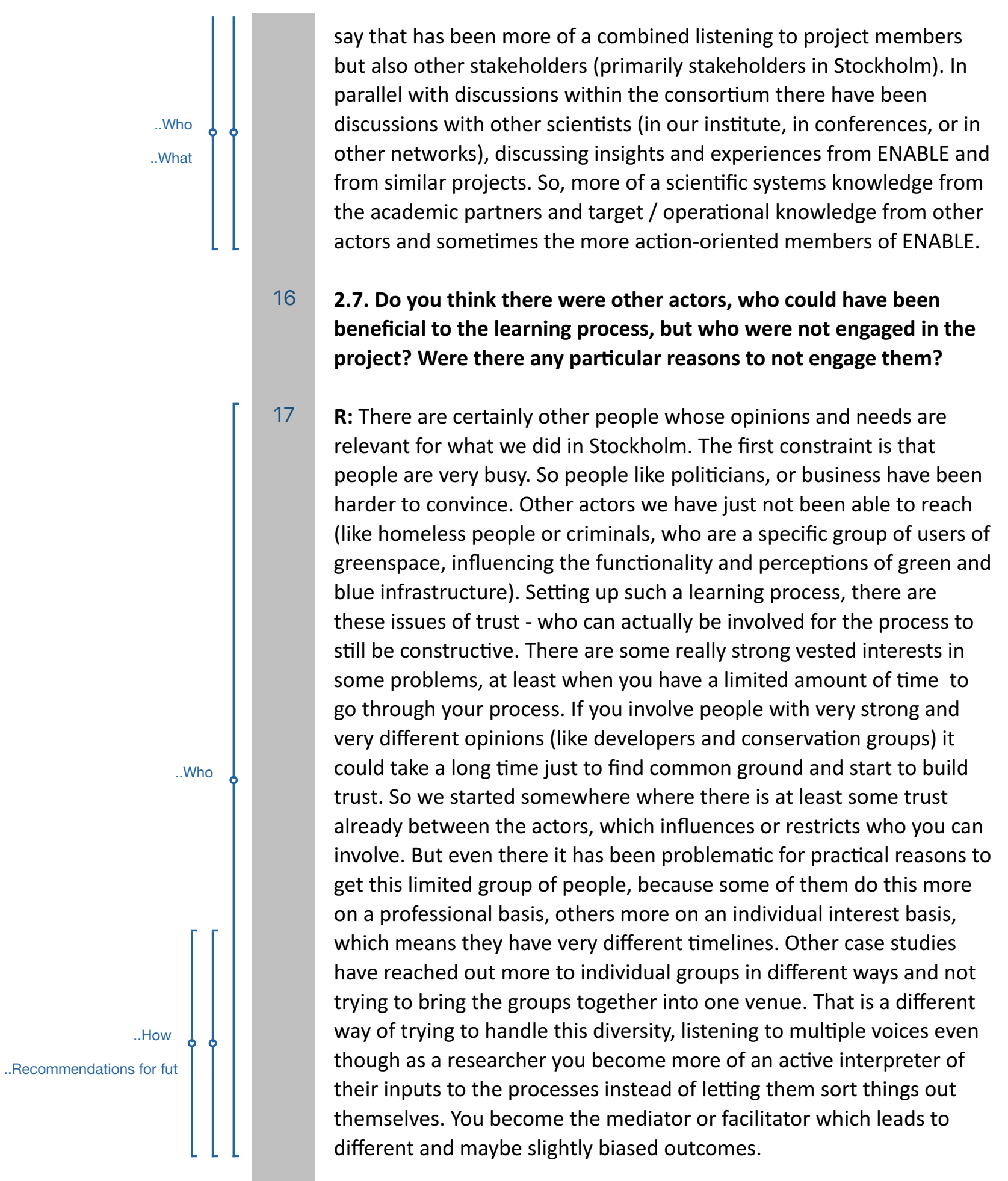

18 2.8. For which purposes do you see the knowledge created in the project useful (e.g. supporting GBI planning/managing processes)?

19 R: It has elements of all of them (planning and management), but overall the most relevant contribution is how we design these joint learning processes or how we think about science and research in different ways can inform practice (can be planning practice or something else). This is something we are trying to get out with these policy options, where we try to think about what types of knowledge have we generated. Everything from the more factual that could 


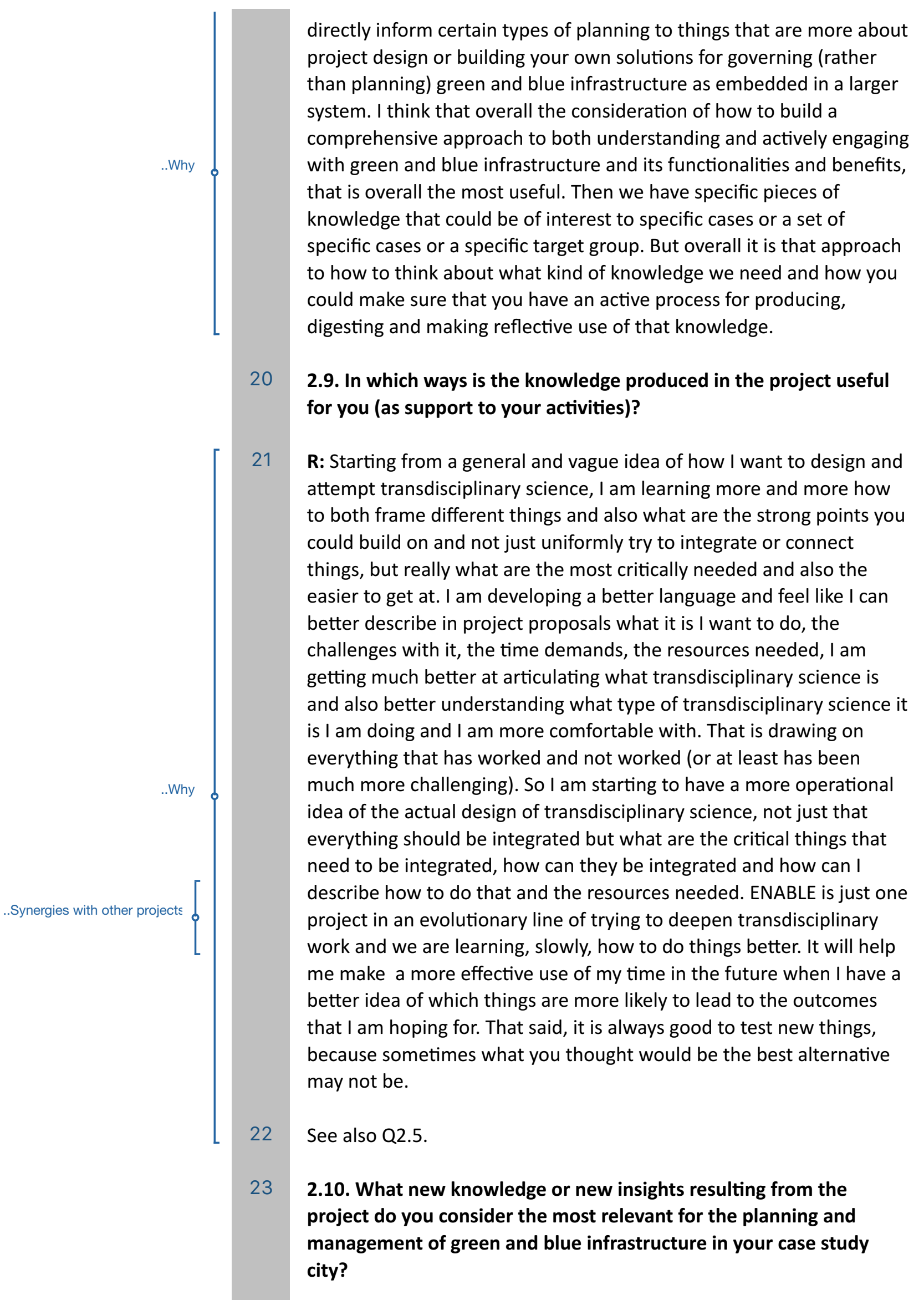

24 R: What we tried to do was break some of the silos / sectoral divisions of who does what in terms of planning and management. What we 


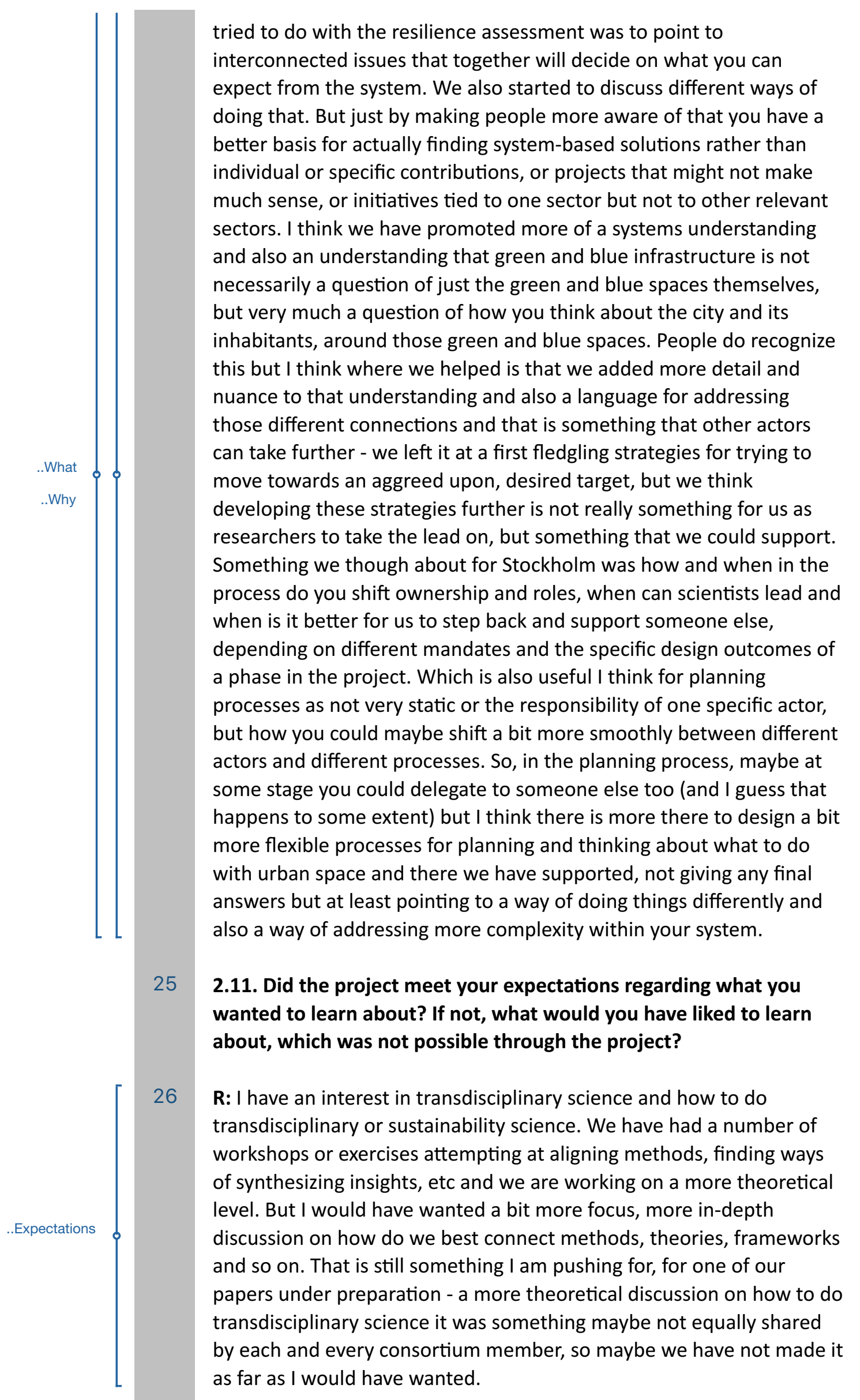


28 R: In terms of challenges I really realized (or reinforced) how difficult it is to run a deeply integrated transdisciplinary project when you only meet infrequently or every six months or so. It is much easier when you can have a continuous dialogue or discussion with people. Trying to do integrated studies over a dispersed network has been a challenge and that is certainly something to take with me for future collaborations - how big can the consortium be, how tightly connected is the group and based on that what is a relevant ambition for integration.

We are a nice multidisciplinary team but there are some perspectives I would have loved to have within ENABLE, a couple of viewpoints that maybe we are missing, people with a different understanding of things that could have been beneficial to have in the discussions. Maybe in retrospect it could have been interesting (although tere is an issue of time) to have not only our internal workshops but also workshops with other people to join us on a broader discussion of the ENABLE framework and how we do things. We have had it at some of our joint conferences but they have not really been dedicated to this issue and maybe sometimes a bit too big. It could have been interesting to have a clearer design of working within the core team and then connecting both to a larger academic world and to other stakeholders.

\subsection{Could you actually apply some of the new knowledge/insights/ ideas resulting from the project in your own activities (e.g. in other research projects)?}

R: Yes for further proposal writing. ENABLE is just one of other things we do in Stockholm and I bring insights from ENABLE to all these other processes, but also in my interactions with other stakeholders. If I am not the organiser of workshops I could be the expert member of someone else's process and there I bring insights from ENABLE, both more factual about green and blue infrastructure, but also on how to think about co-creation and knowledge processes to those processes. That is very useful. ENABLE came from similar insights from multiple processes and it will feed into a second generation of similar processes.

\subsection{Could you identify any barriers that prevented knowledge exchange between the research team and local actors?}

R: There are the classics of time and resource constraints. These things do take a lot of time and we had different starting points across case studies, for example in Stockholm we have a long tradition ourselves of working together with others but there is also a long tradition of trying to have some sort of joint processes and exchange in the Swedish system. In Lodz, for example it is very different. 


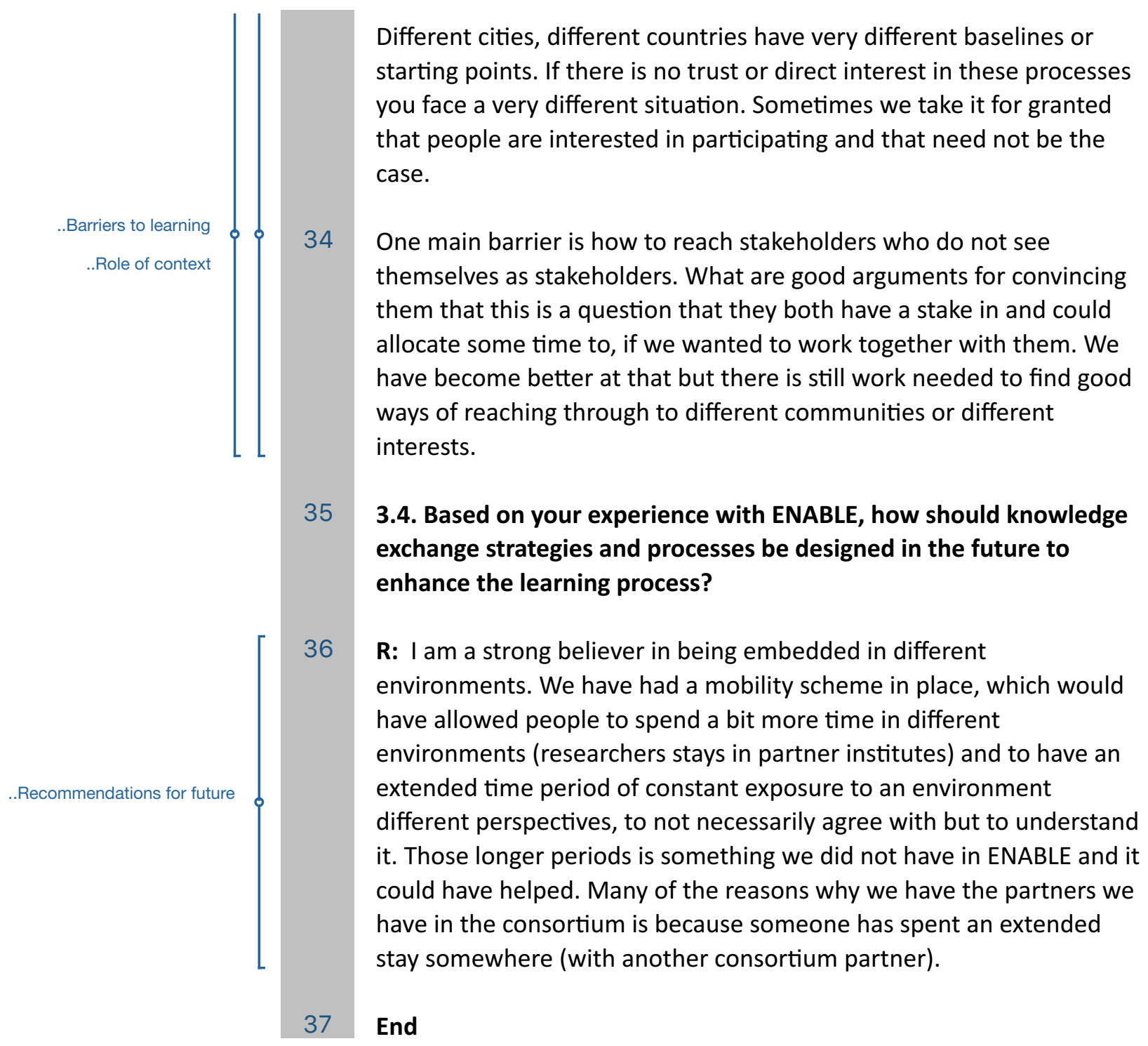


2.2. What events or other opportunities to foster learning did you promote in your ENABLE case study city? In which stages of the project did they take place?

R: One thing that we have put a lot of effort into was to find a language and commonalities, because we've had a very diverse group of stakeholders, ranging from people being there on their free time just because they cared about the area or had a specific interest in the area, to people who had a strategic responsibility, not necessarily being locally anchored or having visited the area, but had a formal responsibility. That said, we've had to work very hard to find something that they could start their dialogue about. For us that turned out to be activities taking place in the green-blue infrastructure in the landscape. Just to come to that it was a learning for us. That started for them also to feel that what is the activity as a joint tool for them to learn about each other, others' perspectives and the project. Another thing was the constant framing exercises that we had to do to explain what we were doing and also for us to learn about the system at the same time we also tried to be a bit ahead of the process. So I would say the framing and finding common boundary objects to talk about, and not use the ones that are favouring in different groupings, so say, is it red list of species - no that is not a go, is it ecosystem services - no, not necessarily, so finding something that is neutral and very generic, that was one thing we did in order to find a dialogue and then indirectly that dialogue is supposedly leading to learning, or at least exchange. The framing was everything from writing invitations, writing documentation, having the first presentation at all the workshops that we had, I'm talking about the resilience thinking process that became five or six workshops and all these meetings have a very careful thinking about how we start them, how we talked about the system that we wanted to discuss with the actors. So using words that we know that they know about but also then linking them to the conceptual framework within the project, that was a very tricky part.

\subsection{What knowledge or ideas/insights/perspectives did you gain through your participation in the project (even if you don't consider them as something you have "learned")?}

R: One of the main insights, a bit surprising but also confirming that the institutional barriers in terms of formal administrative boundaries has a huge, surprisingly large impact in how people talk about values. We had this landscape where we have this formally protected area in the middle - that was the setup, and all along until the end they had very hard difficulties in discussing the whole landscape. It was inside or outside that boundary, it was so strict, and I mean the whole outset of the project is to discuss the flows. I think both [STO1] and I were surprised about how difficult that was. The other thing that I learned was also that, when it comes in the Swedish context to nature 


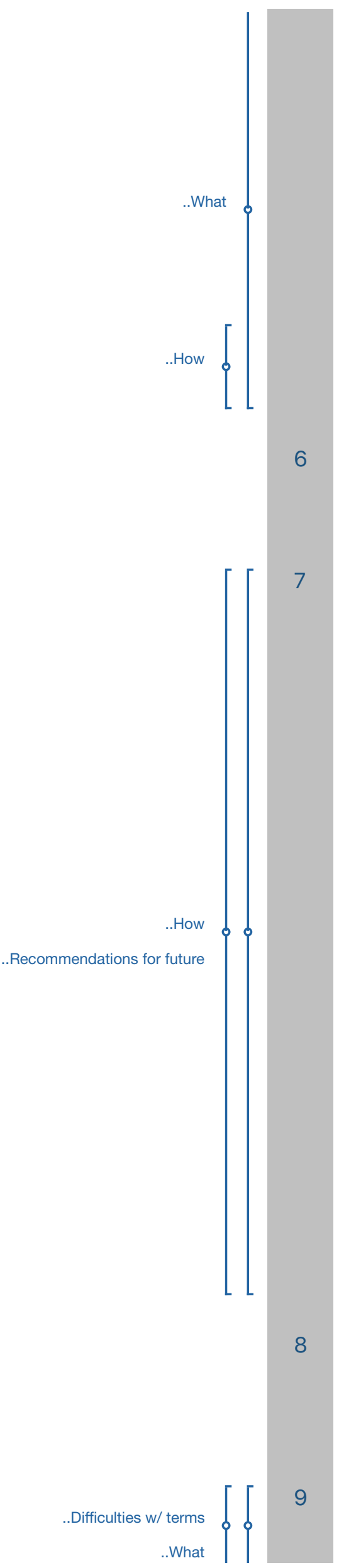

conservation and green-blue infrastucture, it is a framing about things that are not built in our city, it is still very much on the conservation side. So, the notion of change - because that is something we really wanted and hoped that the stakeholders would start thinking of and help us to formulate what is changing in the system and how can we then build capactity to handle that change - that was something that became very external and abstract, like climate change. Then we had to put a lot of effort into translating that climate change, big thing, into something like "what will happen in this particular landscape". And also to think about demographic changes. So change was very difficult and the institutional barriers was very difficult and I would add learn by doing, learning by mistakes in trying to develop tools for discussing these things along the way.

\subsection{Through which project-related activities (e.g. workshops in other ENABLE cities, stakeholder workshops in own city) do you think you have learned the most?}

R: If we stick to our case study, then I think the smaller settings with more homegeneous groups discussing things, where they could frame a story and there is not so much on negotiating, so for example talking with environmental strategists from the municipality or with interest organisations, these smaller focus groups actually helped me better to understand the system. If I would re-design the process I would actually be more careful in having these focus groups and then great diversity and then focus groups again, instead of trying to mix the perspectives at all stages. That is something that I bring with me from a methods point of view. And maybe also: one of our goals was to build capacity and there is something where you discuss things in more closed settings where you have more of a safe environment, and of course it is very tricky for the municipal officials to sit with their stakeholders and then be held responsible for things, this kind of tensions in terms of mandate and responsibility, to handle that in the meetings, while they were going on, I think that impacted how freely people talked about things. So we were too naive and ambitious when it came to participation, I learned the most about the system and about the different perspectives when we actually had these focus groups rather than when we had these huge diverse groups, because then as a researcher I became more of a facilitator, a negotiator, pedagogue, communicator person than actually someone learning more about the issue or the system. We had so much focus about being overly inclusive at all stages and I would not do that again.

2.5. Did you learn any terms (like technical terms) that were new to you? If yes, how useful do you find them for your activities? Did you experience some difficulty communicating with/understanding others due to the terms/jargon used?

R: Starting from the latter: the concept of institutions has been super tricky for me throughout the project and that comes from the 
consortium discussions, so the different ideas about institutions, that is one thing. The other thing has been the tensions between trying to understand the system and then also adding the aspects of change, so it is kind of similar to the struggles we have had in the Stockholm case, I also see them in the consortium, where we have had a lot of these "we need to describe, we need to understand, we need to map out" and then have had not so much capacity to add the change that is actually part of the core of the project. So that has been one thing. Then about the concepts that I have learned, one thing that sticked to my mind was when the municipality described - so we are dealing with a very complex organised municipality, it is huge and it has lots of capacity in terms of money comparatively, but they explained that a lot of the challenges have to do with the internal dynamics of the municipality, and then you have not added other actors at all, just that very strong actor - and they described us the tools that they have just to make sure that they know what each and everyone is doing, and one is called "ledstång" in Swedish, which is actually the handle in a staircase, so every time they encounter some kind of confusion, they go to that document which clarifies who (which division within the municipality) has the right to do what, and then they have what they call the interface (unclear), which is a bit similar because it also says "OK at this stage the other department takes over this issue", so they have tried to map out who is responsible for what, which is a way to artificially try to handle wicked problems like sustainability or landscape governance or flow of people or whatever, but it is a quick fix compared to changing the organisational setup. So, maybe not concepts as such as words but they are intruments, tools for the adaptation but not necessarily for the needed changes.

\subsection{Do you feel you learned something from the research team? And from other actors in the city? Can you identify what you have learned from each of them? (main items)}

R: The whole thing of working with participation, this how to design a co-creation, participatory, different degrees of inclusiveness, where research is part of the process, how to do that, I learned quite a lot in terms of do's and dont's, and also you can look at the stakeholders in terms of their capacity to think about strategies, about really concrete local things and how you need to recognize that and see how you can work with it but still keeping inclusive, so lots of insights and learning about how to work on participatory processes. I had started preENABLE but for sure this process that we have been running in Stockholm has added a lot. And critical reflections too, what is this collaborative approaches, what does it require, how much competence and even more specified different competence that is needed in that. So that has added to my knowledge. And I would say the similar goes for the consortium: how to work with different epistemologies, ontologies, where people come from different backgrounds, traditions, both in terms of geography, history of research in different countries or different university contexts and 


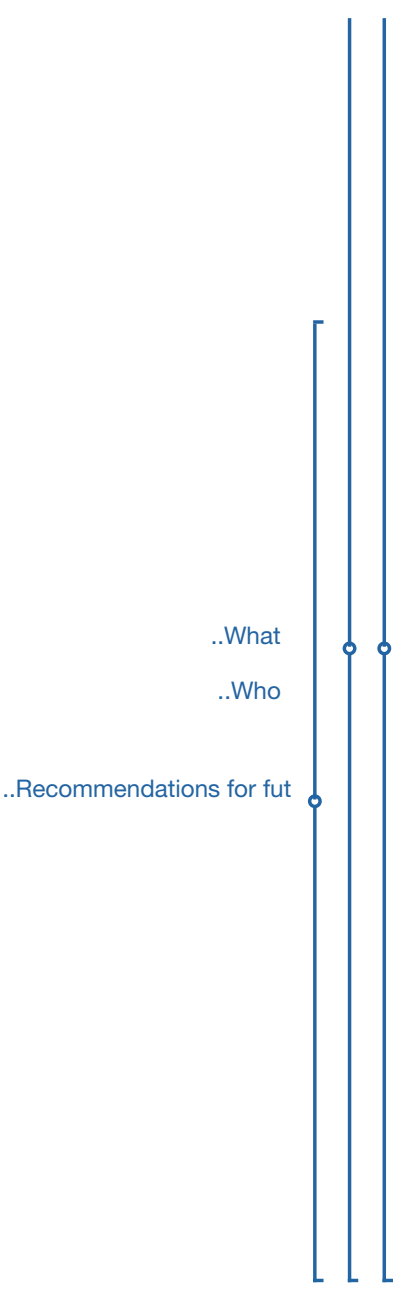

12

13 what is then the capacity that different researchers have, not to say that it is more or less but it is different capacities, and how you work with that, especially with the different researchers having different degrees of in-depth knowledge about the cases that you also want to involve. So a much more specific and a bit critical thinking and insights regarding the capacity and competence and how you need to be aware of that. The other thing is the power of small, maybe trivial activities, so just a meeting we had I proposed, could we create a figure for all the papers that we are writing and that is a way to not have that as a product but as a tool. So all the tools you need in interdisciplinary work; I remember when we tried to decide on a logo very interesting process, when we tried to create a joint project folder and the text with it, also very interesting, these small things that seem like: can we not just leave this to some communication expert to do that? I would rather say the opposite: this could be at the core of starting to find a common narrative or at least explore the diversity of narratives within the consortium. And also this not viewing paper writing processes as the focus on the product - of course that is the merit system we are in - but also see the writing process as an interdisciplinary learning. [STO1] and I have had quite substantial time sitting together and I have tried to support him in terms of "maybe we should ask this question", "maybe we should clarify like this", "maybe we should ask people for one slide with bullet points about questions they have", these small, pedagogical things that you can do in order for people to not just stick to their ordinary way of doing but actually trying to reach out and connect, finding common terms.

\subsection{Do you think there were other actors, who could have been beneficial to the learning process, but who were not engaged in the project? Were there any particular reasons to not engage them?}

R: At all meetings I am in, in the Stockholm region, and I have been working here for fifteen years or so, there is always the politicians, and I would not say that in the next project I would add them to it, because their relations to the civil servants is also a very intricate one that you need to be very careful about and make sure that you know what you are doing as a researcher if you set up that kind of discussions or dialogues, or interactions, but that is a group that we seldom invite - the decision-makers - and they are of course crucial if you are also aiming for change and capacity-building, but in a way we trust the officials to then grasp what they capture, what they feel is relevant and then build that into their organisation or in the communication with the decision-makers in a way we trust them to be that indirect link to the decision-makers. That is one group. The other aspect is that we have a challenge to engaging the public, where we go for the easy, or doable, feasible way, which is to engage with the interest organisations, and there is lot of engagement in society that doesn't necessarily take the form of a very traditional Swedish association (like Facebook groups and so on), and we have not yet found ways to engage with them and that is a big gap I would say. We 
clearly have an age bias towards elderly people in the interest organisations, those that actually have time and room in their life, or are used to come to this kind of settings. Not necessarily that we want to capture that diversity, but in a way we captured that through other methods, we have had these public data collections - the Q-method and the mental mapping - so in a way we have captured that information. What would have been fantastic is if the Q-method and mental mapping had occurred before our resilience process, which was not the case. In the coming projects what would be great is if - we have learned a bit more about how to set up a series of different methods to play out, what should be done first and what should then build on that - it would have been fantastic to have that material to build the resilience assessment process on, but that was not the case.

\subsection{For which purposes do you see the knowledge created in the project useful (e.g. supporting GBI planning/managing processes)?}

R: On the larger picture I would say the approach that we have in ENABLE is based on systems thinking and over and over again I encountered how great knowledge is produced, communicated, used and then confusion why it is not working out and I see this contextualization, so even if it is difficult, even if it is fuzzy, the system thinking is an important contribution and not as a product but as a process to constantly be part of and reminding different discussions, dialogues, meetings, being it in Brussels or in Flatten landscape about the system thinking, that I think is a very important contribution from this consortium and other similar consortia. Then, what we contributed to very much, and the actors say that in their evaluations and feedback, [STO1] and I in our projects in Stockholm we provide a platform for these stakeholders to meet and discuss things that they normally do not have room for discussing in their daily worklife context. That is interesting because it is not necessarily something you think that research or research projects should do, or is that really our task, but it is just the way it is. We allow these actors to actually get some space for thinking outside their immediate here and now problem-solving, handling fires here and there. Just the conference I attended the past days there was lot of appreciation: you created this space for us to lift a little bit and look at things in another way. For an allotment gardener in Flatten to meet with a green infrastructure planner, there are very few other platforms for that to happen and create that listening and link. Then it is up to them to see what they want to do, but at least it is happening because we are running these different kinds of workshops. And then I think we have a very important task here as researchers to continuously develop our thinking, our different epistemologies but at the same time be open to at least try to understand others and that I think we need to have better tools for. I mean in the ENABLE project we would have really needed some process facilitating capacities, someone responsible for our meetings, our interactions, who knows what research is about, so it is not like a manager but more like a researcher's facilitator 


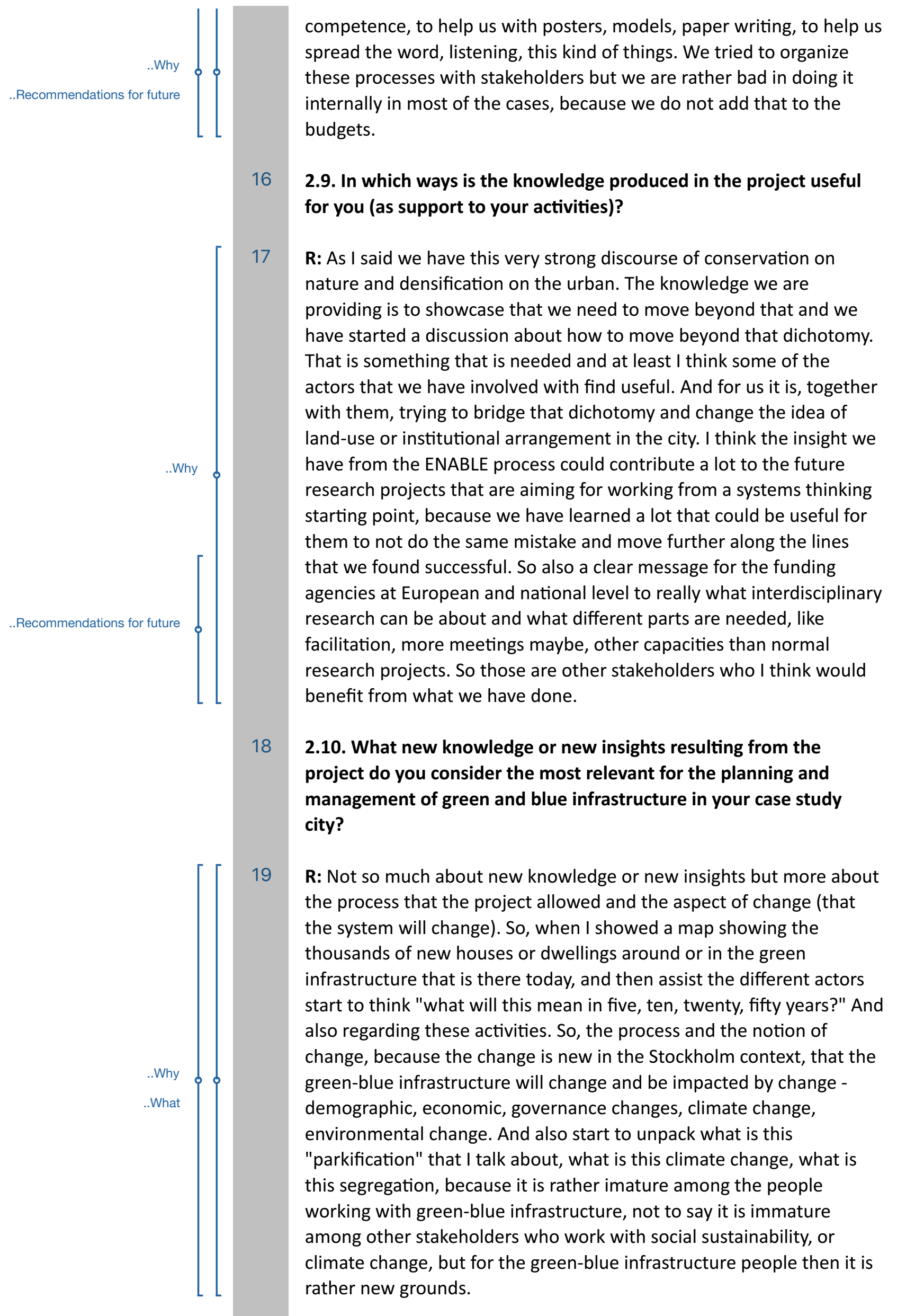


2.11. Did the project meet your expectations regarding what you wanted to learn about? If not, what would you have liked to learn about, which was not possible through the project?

21 R: If I think about the different work packages and think about different themes, I clearly see that we have work around justice, around resilience, but a dream would have been to learn about justice and resilience together and we did not really reach that. It has been so much work just to link green-blue infrastructure just to these two dimensions. You also clearly see now that we have a special issue on justice and we have another one with the ENABLE conceptual framework, which will include resilience and methods and method integration. That says a lot, that we have not come that far. My core research is about governance and that has not been - that was from the start so I cannot say I expected it - but I would have been able to contribute more if we have had that broader idea with the governance and not just the institutions. I have outlets for that in other projects, but still I think it is a bit cutting one of my arms off. And it pops up in the policy options, policy mapping, but it has not been so much part of the research but more of the background landscaping description and then it is there and we try to feed into it, but it has not been research as such, as part of how we understand the system and that has been frustrating. I can imagine that others feel the same because their arms have also been cut off in different ways that I do not know about, because I do not know that theme (like econometrics or modelling, or whatever). I think those are the trade-offs that we do when we do interdisciplinary research. It is tough, but it is also how it needs to be, because you cannot really add the in-depth of all the different aspects. Another thing, on a more practical note, which has to do with learning: we had lots of hopes and added to the proposal that we wanted people to sit in different contexts, visiting each other, like inresident Ph.D. students or post-docs and we had this mobility money and it has been really hard to set that money into action. It's a bit surprising and a bit disappointing that we have not had this opportunity of young scholars visiting different areas, because I think that is a very fruitful way of learning and understanding and exchange. That has been much harder than I thought.

\subsection{What did you find most interesting and useful from the project?} What were the main "take-home messages"?

R: That stakeholder interaction is very context-dependent. It is not rocket science to understand that, but to really see, visiting Lodz, sitting in the city hall and really see how are colleagues navigate that context, compared to how we do it in Stockholm, or when we sat at the meeting in Halle, that is a very important take-home message for me, to really understand what it means for interactive, transdisciplinary research with multiple case studies in dramatically different contexts. And it is very vulnerable since it is dependant on 


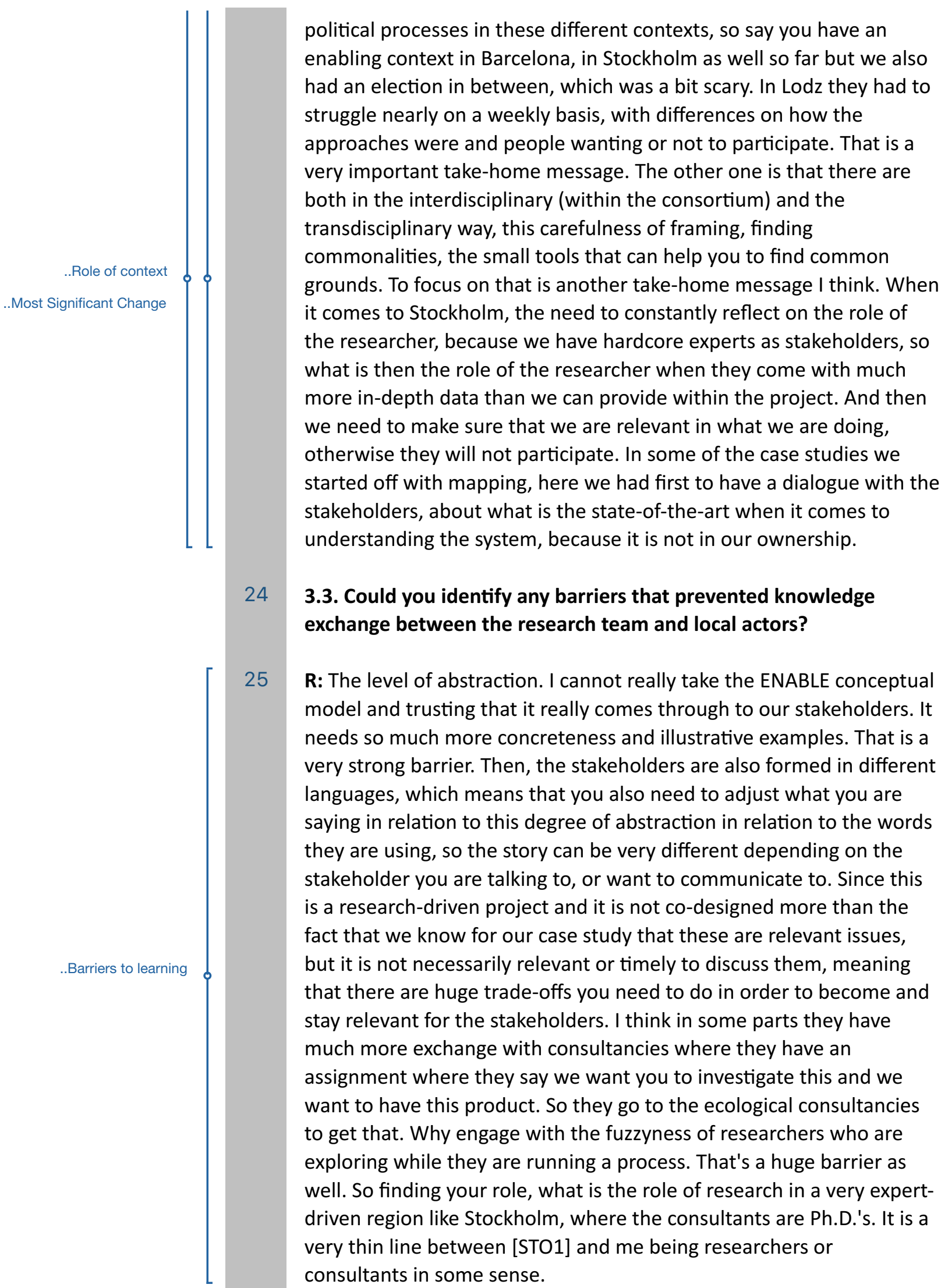

26

3.4. Based on your experience with ENABLE, how should knowledge exchange strategies and processes be designed in the future to enhance the learning process? 


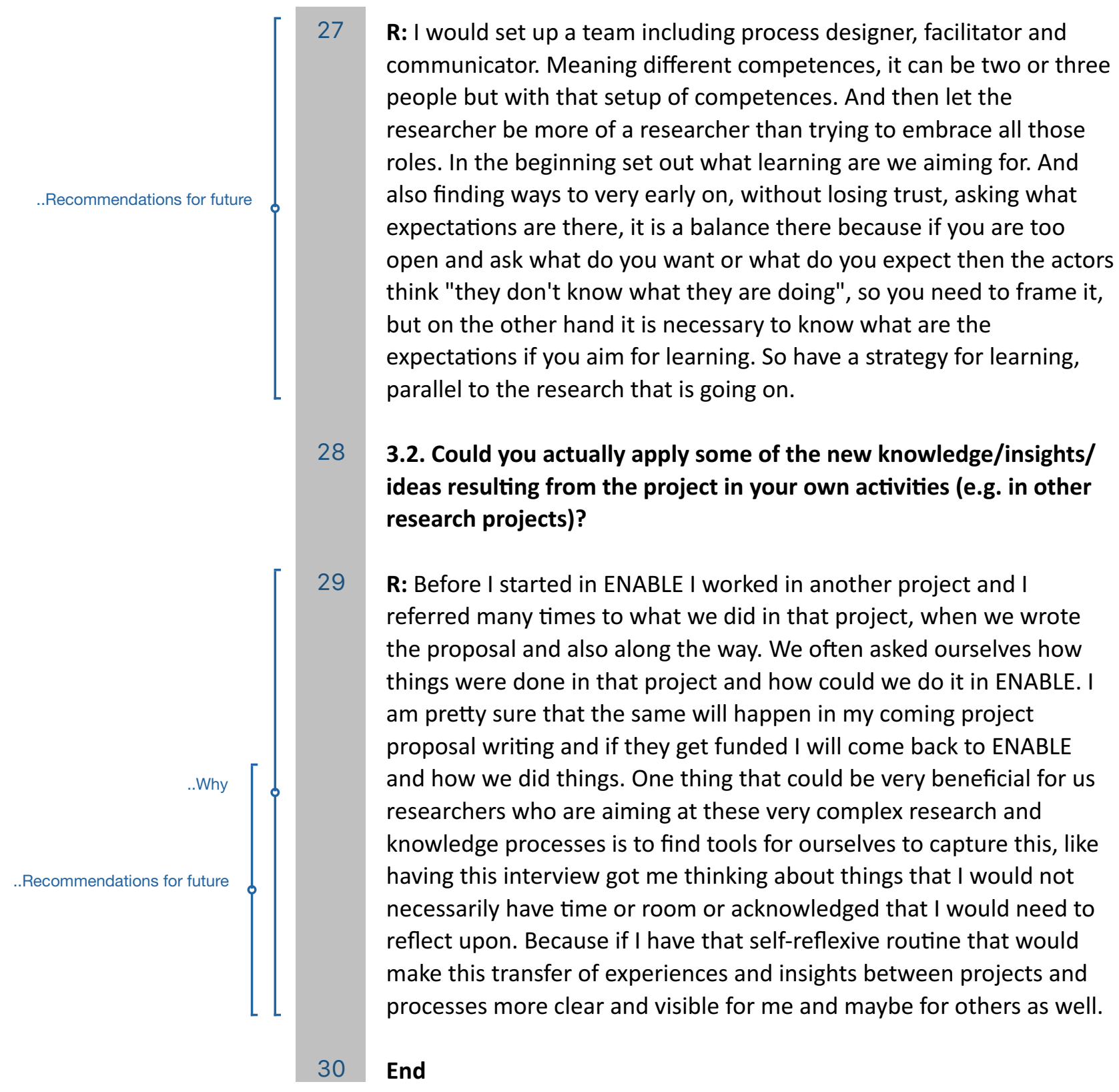




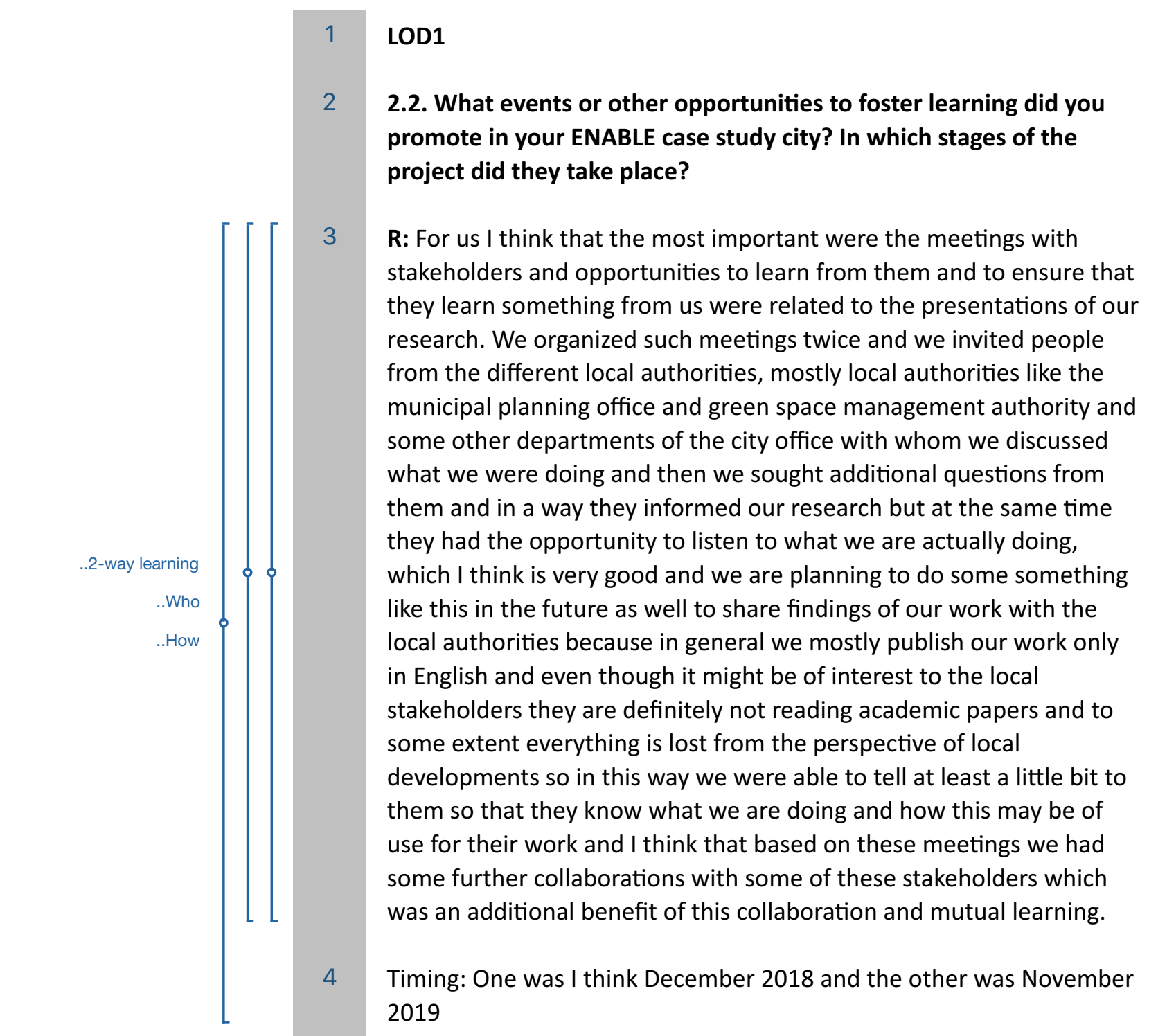

5 2.3. What knowledge or ideas/insights/perspectives did you gain through your participation in the project (even if you don't consider them as something you have "learned")?

6 R: Of course we learn all the time and the project offered us the opportunity to learn but it's not very clear what particularly was the result of this project and not of some other work that we had at the same time but in terms of learning I would say that for the first time we were doing this exercise with stakeholders that we invited them to meetings where we presented our research and I think this is something that we learned is very useful and that we would like to do in the future as well.

$7 \quad$ 2.4. Through which project-related activities (e.g. workshops in other ENABLE cities, stakeholder workshops in own city) do you think you have learned the most?

R: I think we could learn different things from different kinds of meetings depending on the audiences and depending on the format 


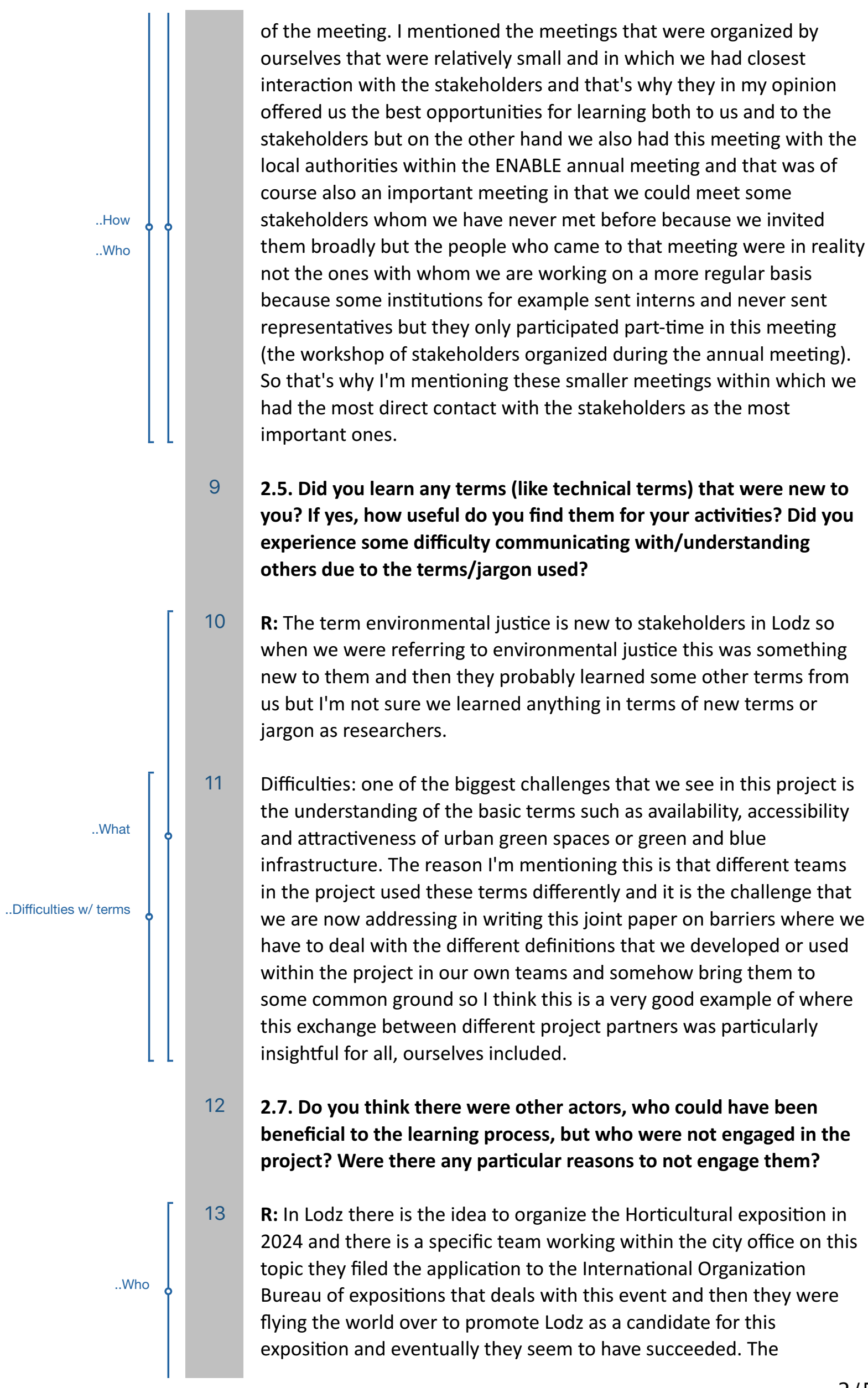


organization has agreed that the exhibition in 2024 is held in Lodz. They still are not sure whether there will be enough funding for this from the government and from the local authorities but there is already green light to organize things and there is quite a lot of investment in this direction. But this team is composed of people who are from a completely different world and they are really reluctant to work with us and they are quite impolite to be frank in the way they treat us as well and I think that this is a team with which we should probably work but we somehow don't want to work, we refrain from working with them, which is a challenge because they seem to be overtaking green space and issues in Lodz now given that this event is seen as such priority for the authorities. It's just that there is an institution that is responsible for a big forthcoming event with whom we don't have good contacts because they are not interested in local knowledge and research they are used to working in a completely different way when they want to have something done they invite big consulting companies to work on these issues and the way the big consulting companies typically work is to consult us as local stakeholders to develop the solutions so we typically refuse to work with these big consulting companies and this leads to a situation in which they consult other stakeholders who are not from Lodz who define design solutions for our city which is a mess really but this is how these people work they are used to work in this way.

\subsection{For which purposes do you see the knowledge created in the} project useful (e.g. supporting GBI planning/managing processes)?

R: There are a couple of things like this one is that we have another project called sociotope map for Lodz (a sociotope map is a map of different social functions of public green spaces in our city) and we developed this ourselves but in collaboration with the local authorities and we saw some interest on their part in this project and we hope that at some point they will be using this map and it is something that could support communication with inhabitants and this could also support public institutions' management practices, because it's all digitized, it's something that they have never had in digital format they always only use this in paper files and every office had a separate paper file for different things related to different green spaces. Now they have everything in one folder, in one electronic map. Another thing is that we somehow started to inform the local authorities on different green space availability and accessibility standards and they seem to have been very interested in what we've done. This is what we know from those meetings and they really want to develop some tools to be able to plan green spaces better in response to the needs of the society in terms of where green spaces are to satisfy the needs of the population. And then the third thing is related to the work of [colleague name] primarily and [colleague name] to some extent as well and it's about children and their way to school. They were working on whether children on their way to school are exposed to green spaces or to green space views, especially when they have to 


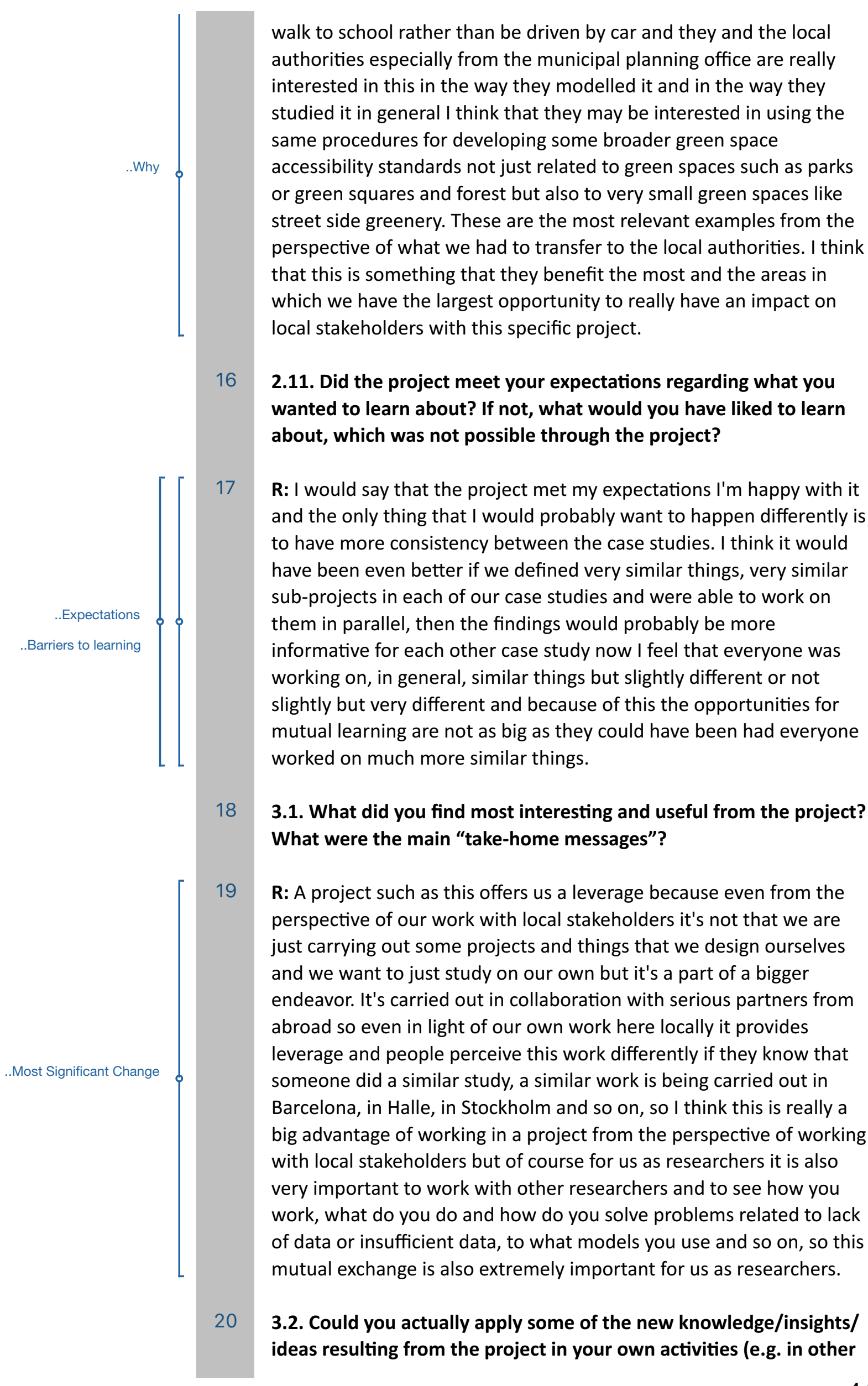




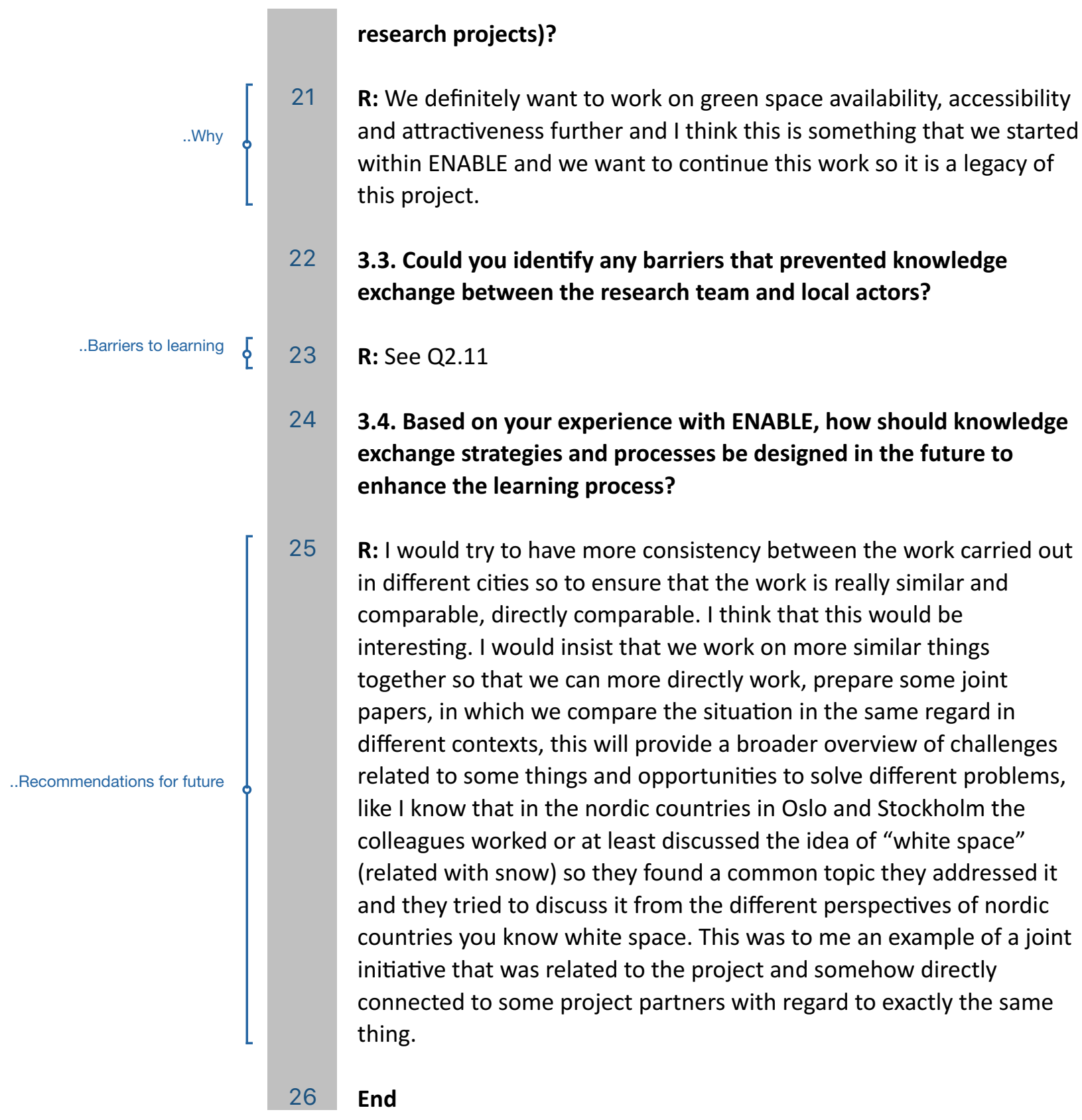




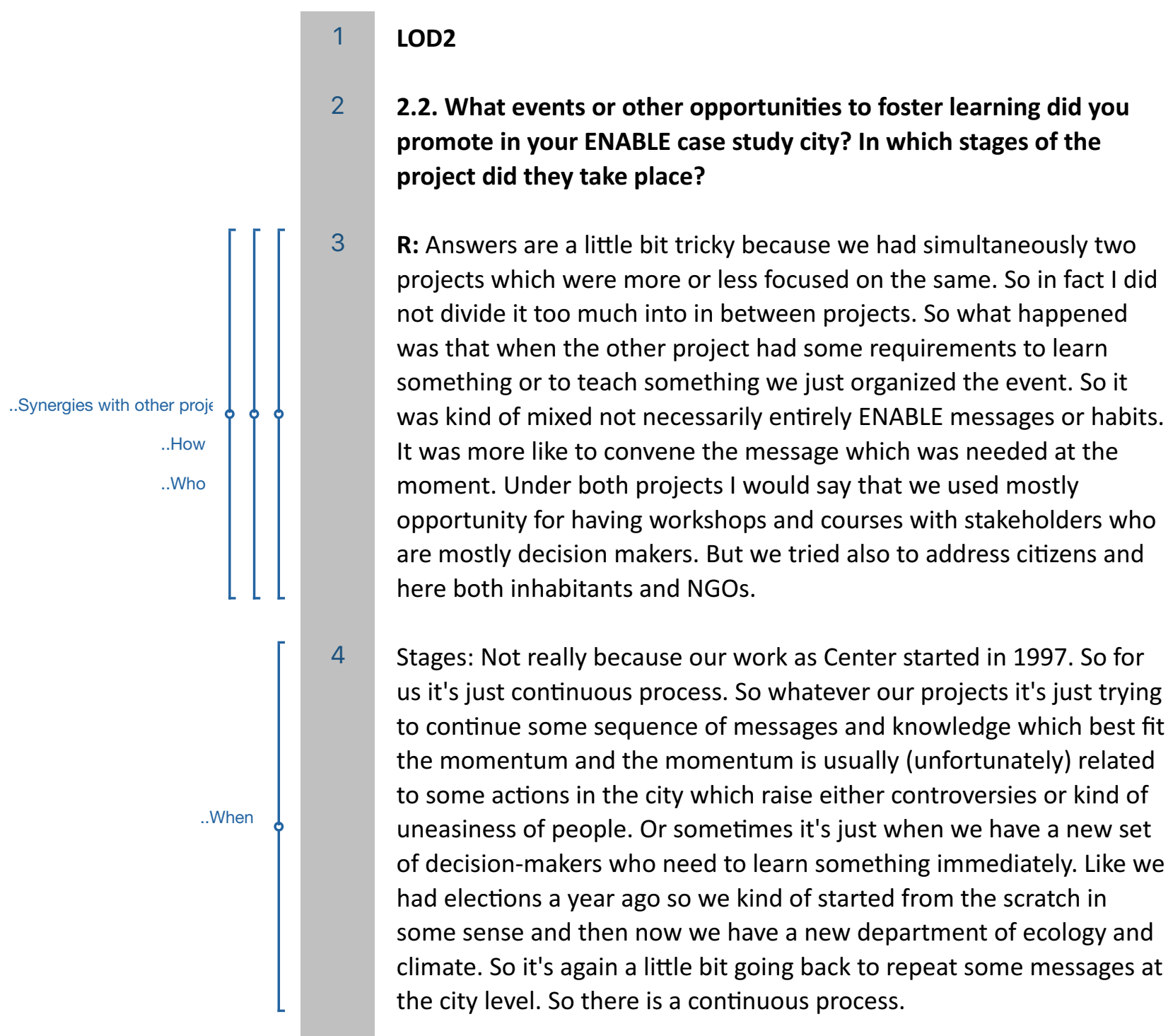

\subsection{What knowledge or ideas/insights/perspectives did you gain} through your participation in the project (even if you don't consider them as something you have "learned")?

R: We spent some time on needs of our citizens regarding Blue-Green Infrastructure. But definitely we never worked too much on justice issues. So this is something which was kind of new and this was also the first time when we looked closer at accessibility of spaces. So these were two things. And the third one I would say is: Even if we are somehow still in the process of resilience assessment we got a little bit more knowledge of what is it about.

2.6. Do you feel you learned something from the research team? And from other actors in the city? Can you identify what you have learned from each of them?

R: Definitely from consortium yes. Regarding other issues rather not. I would say that we mostly act as provider of information and knowledge than we gain something reading from outside. 


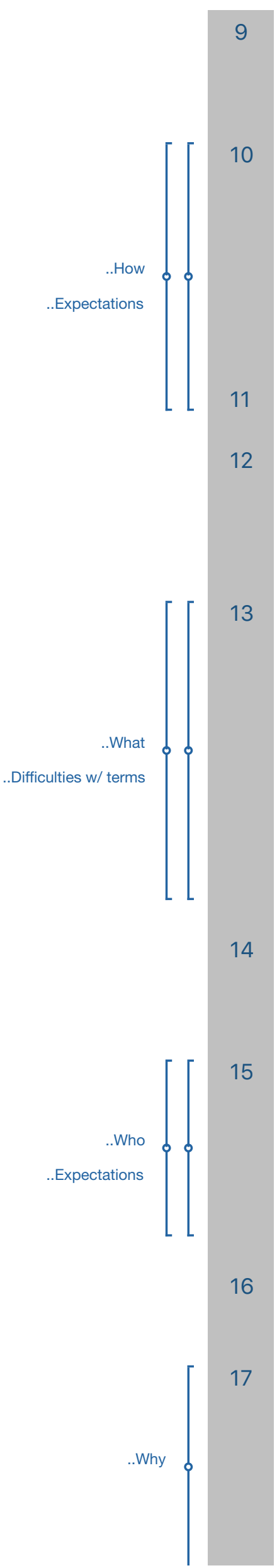

2.4. Through which project-related activities (e.g. workshops in other ENABLE cities, stakeholder workshops in own city) do you think you have learned the most?

R: As [LOD1] represents mostly the side of the project and work package, I represent more the side of the city and demos idea. So I don't think as a city we had too much contact with other cities. I would say almost none. So it was a little bit isolated as case. So we provided information to work packages but I don't feel having much exchange between the cities. So, it was more through the activities taking place in Lodz.

See also Q3.1

2.5. Did you learn any terms (like technical terms) that were new to you? If yes, how useful do you find them for your activities? Did you experience some difficulty communicating with/understanding others due to the terms/jargon used?

R: I don't think I faced something like that because we work more or less in the same environment - also, many of the people for a longer time. So there were not much mismatches in between. I would only say that regarding resilience assessment it was a little bit eye opening because I think that usually we kind of mess between sustainability and resilience which may not necessarily mean the same. I mean sustainability is always positive and resilience may sometimes reflect a reality so we don't accept as ecologist or you know other specialists. But I did not really experience this kind of different understanding of issues.

2.7. Do you think there were other actors, who could have been beneficial to the learning process, but who were not engaged in the project? Were there any particular reasons to not engage them?

R: Well, I think that ENABLE ran too much as scientific project - even if we have cities in. So for me we maybe missed this input from at least decision-makers. So we could get more from cities and learn as scientists more from those who deal with realities, not only the scientific approach. And I think that also maybe direct interaction between cities could be beneficial for the project.

\subsection{For which purposes do you see the knowledge created in the} project useful (e.g. supporting GBI planning/managing processes)?

R: I will not discover anything special because basically for spatial planning... which is not bad because for years we are trying to just build up arguments for a certain type of planning against other types of planning. So with each project we try to make one step further just to provide more evidence. And from this point of view ENABLE was very important because we managed to pull at least some data, some 


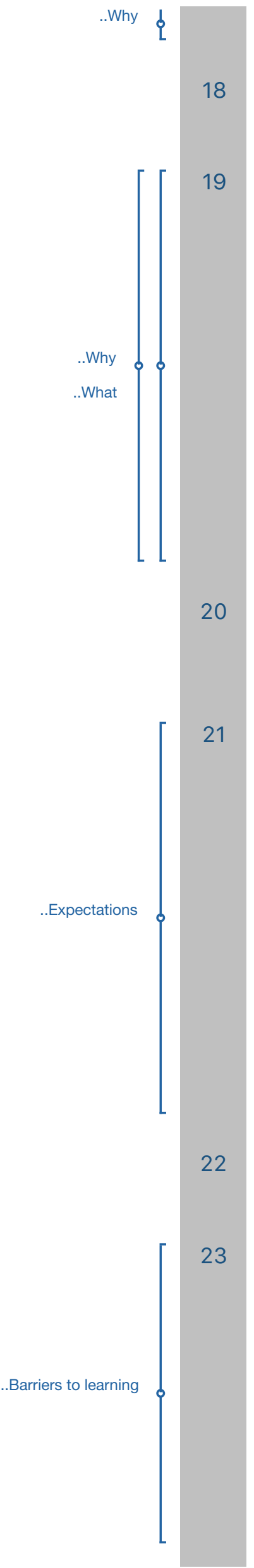

information about Blue-Green Network.

\subsection{In which ways is the knowledge produced in the project useful for you (as support to your activities)?}

R: We are still in the process of analysing information and hopefully we will deliver some more outputs soon. First of all, we learned some new methodologies like Blue Green Factor could be one of those which we can promote throughout the city or for different reasons and purposes. Another thing which is city-specific where data were never really pulled together to get kind of more holistic pictures. So it's always important to build this picture just to have a look at the city as such and then dig into particular issues. So ENABLE was important also for that reason. So hopefully we manage to analyze a little bit more about ecological properties of blue-green network and climate regulation and also these planning options. And as we are all the time in the process of writing new proposals so of course it's a piece for other projects.

\subsection{Did the project meet your expectations regarding what you wanted to learn about? If not, what would you have liked to learn about, which was not possible through the project?}

R: I think that in general the project met my expectations regarding a kind of overview of methodologies and things which are done in different places and how they are done. So from this point of view yes. What was not really met was my expectation to collaborate more with other cities and to have more joint comparative analysis and to have more things which are real outcome of the project. Because many things which we did, we did ourselves in the city. But let's say I could do this having another project with a bit of money. But in the project you also expect to build something together. And I missed a little bit this "together". So something which would tackle all the cities and analyse all commonalities or differences or so. This joint work happened in a limited way between two or three cities only, while it could be a more broad scale.

\subsection{Could you identify any barriers that prevented knowledge exchange between the research team and local actors?}

R: What was mentioned in Q2.11 and I would say if we agreed on common methodologies and then applied them in all the cities to gather a certain type of the information and to make comparison, all teams and all the cities would get to a certain level of knowledge and expertise. While if we shared methodology only to tackle certain aspects it means that some cities did not fit, I don't know, green roofs or something else because cities are different. And therefore we had no possibility to use common methodology to get the kind of common results. So it was still interesting but it was not, I would say, like the training for us and for cities. 
3.4. Based on your experience with ENABLE, how should knowledge exchange strategies and processes be designed in the future to enhance the learning process?

25 R: See Q3.3. It's always nice to have part of work which is built on specificity of the city. So this can be done just separately looking at good examples. But then there should be part which is common and something which is applied everywhere across scales and we can get a similar result to position ourselves in these other cities and processes and so on. So I would say that this push for more joint work would be very profitable. In another project, for example, learning about Bayesian belief network and how to use it was much easier. It was not so much common learning and capacity building within ENABLE. In fact this was something which was delegated to another project together with our workers. It was more about team building and building the capacity to tackle same problems across all the cities.

\subsection{What did you find most interesting and useful from the project? What were the main "take-home messages"?}

27 R: It's difficult to say one message. What was good and interesting and

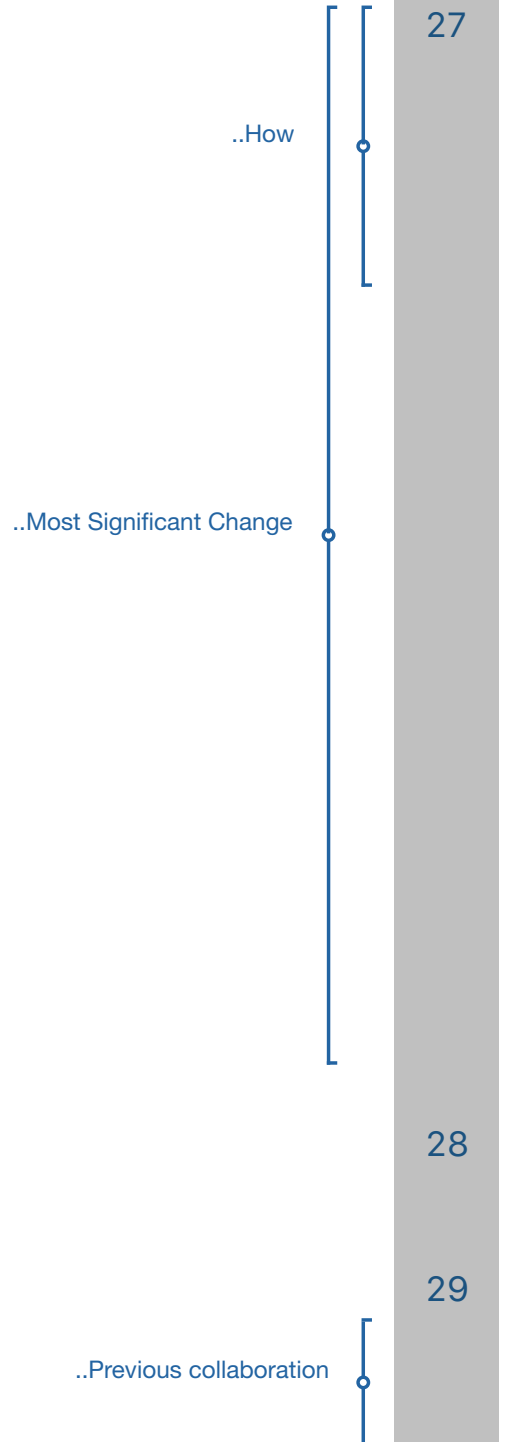
maybe I missed it for other cities: I learned a lot from the visit in Halle when we all saw the processes which go on there and how they are tackled in a life-world like how the common space is built and so on. So I learned a lot from experience and I missed the same examples, for example from Barcelona. So it would be nice to have the same overview. And another thing which is kind of take-home message is this kind of... I'm ecologist by education. And the situation put me and our team in the role of defenders of nature. So even if we try to keep the discussion about nature in the city and ecosystem services open we are expected even by citizens and by the city to be defenders. And I would say that talking to the team from Stockholm and Oslo and Halle made us more resilient, accepting different views and trying to find out a good way out of seeing the variety of expectations and also variety of knowledge people have and the way they use this knowledge. So there is no one trajectory towards a certain aim. Maybe we need to find out different ways to get to the same point which we would like to get while we try to be more rigid normally. This is what I would like to say. We give up a little bit from our rigidity although as I said, this is also the role which was prescribed to us not necessarily by ourselves but also from expectations of other players and other stakeholders.

\subsection{Is there anything you want to add regarding your experience} with the project, which has not been mentioned so far?

29 R: I would love to know what others learned. What was the variety of perspectives of team members. Because very early I got the impression that also the cities and teams within ENABLE have different 


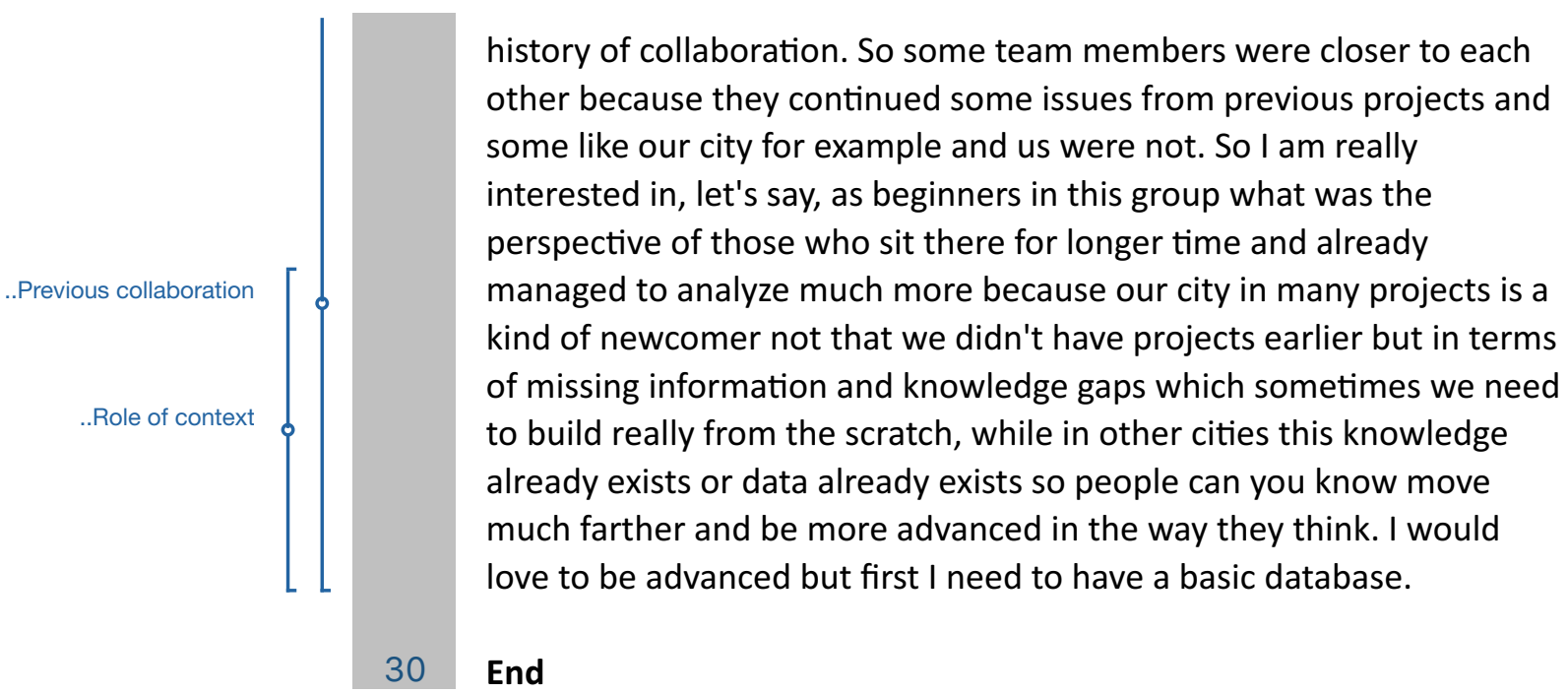




\subsection{What events or other opportunities to foster learning did you promote in your ENABLE case study city? In which stages of the project did they take place?}

The main events were our stakeholder workshops taking place three times a year, they were important at all stages of the project. Stakeholder engagement took place not only within the ENABLE project, but we were well aware of the ENABLE project in this process. As a preparation for the ENABLE project we were talking to the stakeholders in those workshops about their needs, what are the priority questions, what are the key topics that they want to work on through this process and also thinking about key areas in the city for interventions. This was a kind of setting the scene and we had two separate workshops, one working on the spatial one on the content to determine what is relevant in the city and I think this was a very useful approach in making the entire stakeholder engagement process worth the effort for the stakeholders. That was the formal instrument that we used, for presenting results, where we stand, testing new ideas, new conceptual approaches. It's also learning for us, because we always use these forums for giving key stakeholders the opportunity to present and discuss their work, so it's not a one-way direction, not only us providing input but also stakeholders interested in making their approaches more public, from different public entities (mainly), sometimes also private entities or NGOs. There's also a learning process in two directions. (I: Could you identify some key stages in the process?). The pre-phase (determining the needs and interests) was definitely one critical phase, before the project started and then the first six months, for the others we did a bit of back and forth there, we tested some of the ideas, approaches, concepts in the early phase but since we had different approaches this was going on in parallel. For particular studies we also had individual meetings with experts, city planners in the green space planning department or a public planning entity (Agencia de Ecologia Urba). We test our ideas and approaches with the stakeholders in the individual meetings. And then we have the reporting back phase, where we presented results to the stakeholders and asked additional feedback. Depending on the study this is more or less intensive. Then we have other studies where we are using stakeholder knowledge explicitly (the participatory resilience assessment for example) to gather information, so stakeholder knowledge becomes part of the empirical work. We have done that for several studies, for example prioritizing the importance of ecosystem services provided by green roofs to then come up with a city-wide green roof prioritization model. For the participatory resilience assessment we discussed what is the change of supply and demand of ecosystem services with regard to different extreme scenarios that the city could face and what would be appropriate policy measures to deal with that. 

through your participation in the project (even if you don't consider them as something you have "learned")?

R: A very general lesson is this: how to make your research really relevant to the people who are supposed to work with that. Getting the research from the lab to the end-users and practitioners, that is definitely what we have learned a lot about. In the future, and already now writing new projects it is pretty much determining the way start designing new studies, I am much more focusing on incorporating the needs of the end users at the very beginning of the process. There are many more lessons, it is hard to pick the key ones. Maybe I have changed my way of thinking about participatory approaches in general. I see much more the limitations linked to that and the bias that the selection of stakeholders brings with it. I was more optimistic about these approaches in the past, I still believe they are super essential, but I'm understanding much better the bias that is involved. There is no perfect participatory process, we can have some standards or ideas of how to conduct participatory research but we will never reach those ideals we will always stay at an unsatisfying level. Maybe it is comparable to what modelers do, they always try to represent the reality, but they will never be able to do it fully, in a participatory process that's very similar, you always have the constraint that networks already exist, that some people are key to engage with your work and others are not, and if you use the participatory processes not only for dissemination of your results but also for producing some new knowledge these will always be critical limitations.

\subsection{Through which project-related activities (e.g. workshops in other ENABLE cities, stakeholder workshops in own city) do you think you have learned the most?}

R: It is important to gain some additional insights from other cities to put into perspective what is going on in your own city. What helped me most was probably the participation in the resilient cities conference in Bonn last month, where there was not a single city presenting their approach, but the reality of multiple city planners and practitioners in the same room, so a dominance of that group and not of scientists. There you could really notice that cities are at very different stages in incorporating ideas that we have in ENABLE, we ran a workshop on more justice-related issues and the inclusion of people and I only realised in that moment how far advanced Barcelona is in these topics, even compared to northern European cities where, at least that was my stereotype, that are more advanced when it comes to incorporating people in decision-making. Talking to the planners there made very clear that they have very little experience and they are much more stuck into their departmental silos than what we see here in Barcelona. That was interesting to reflect on what we are doing here, here it goes more hand in hand: the knowledge we produce and what the city is thinking about and where they stand and 


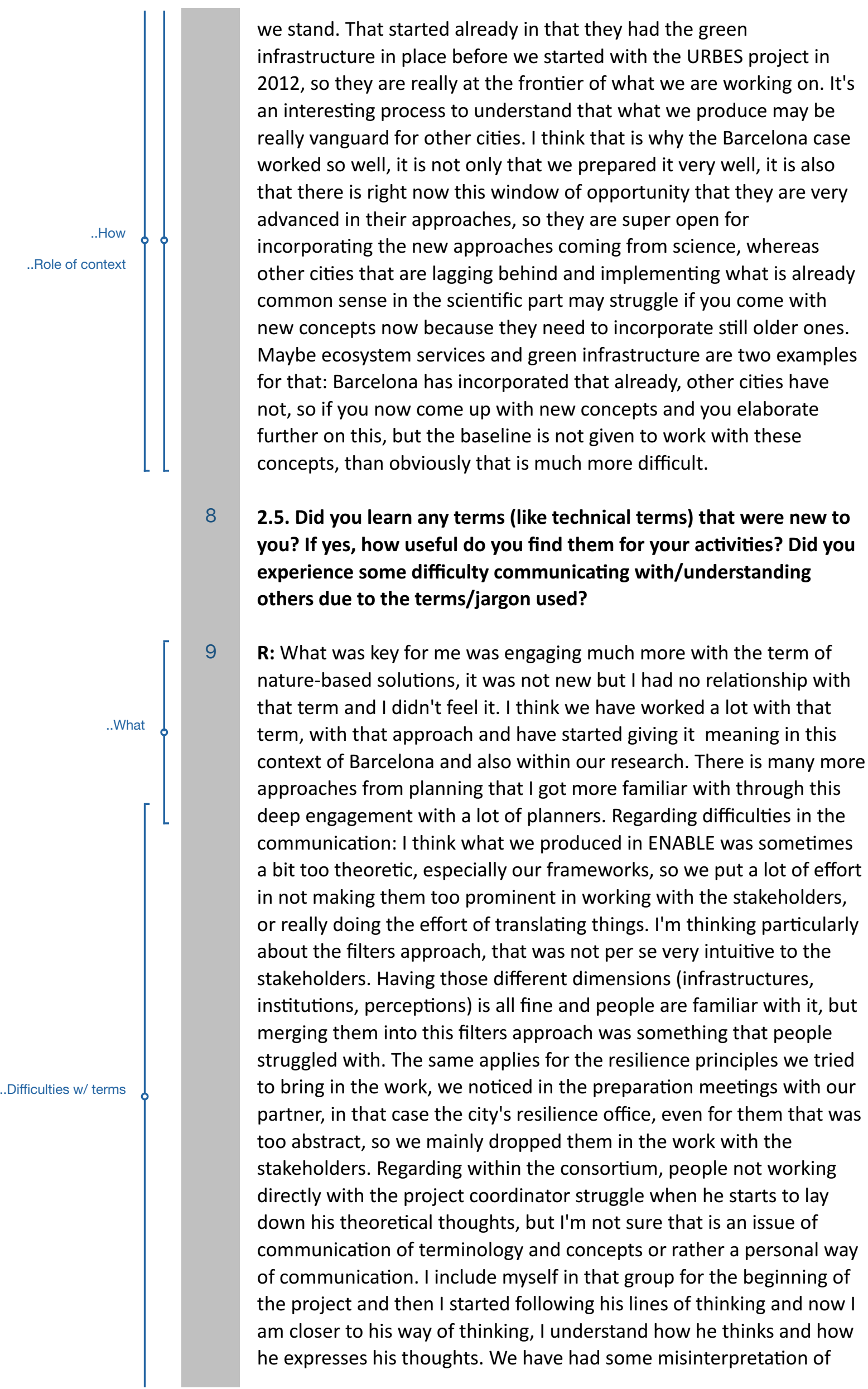


terms, that's for sure, and to some extent we still have them. We have still not reached a coherent justice framework; we are still struggling with the availability, accessibility, attractiveness framework from the Polish colleagues. I think the working together on the concepts was something we always wanted to do and we never really did. Maybe we did in the context of the main ENABLE framework, but on side questions we struggled much more; the definition of institutions for example, we still don't have a common understanding of institutions in the context of this project and the same applies for attractiveness or perceptions. This is not specific to ENABLE, but what is ENABLEspecific is that we tried and we failed, so I think our internal methodologies to get these definitions done was not very efficient. I thought about that I am not fully clear what would be a different approach there but we definitely were lacking some of the main review tasks in the very beginning.

2.6. Do you feel you learned something from the research team? And from other actors in the city? Can you identify what you have learned from each of them? (main items)

R: I think the realities and challenges of planners is something I have learned through this deep engagement with the planners in the city and beyond the city and that is shaping my way of doing interdisciplinary research in the future. Within the consortium, thinking about things in a more theoretical way, especially from the resilience-informed ideas was good and that was mainly due to learning from the project coordinator, even though the others were key for that, so it was not only the discussions with him but also the questions and discussion created with others. So it was not that I learned from the project coordinator, but he helped me to trigger my own thoughts. I reflected a lot on the way of doing integrated research, integrating different methods and that was mainly due to reflections with colleagues on why is it working in Barcelona, thinking in a more rational way about the things we do in a more intuitive way it worked well, so why did it work well. That is a question I reflected on a lot with partners (like [LOD1], [OSL1]), thinking about their own processes and reflecting on the process we have going on here, so combining different methods and making them most useful that's definitely a lesson I have learned and reflected upon more thoroughly.

\subsection{Do you think there were other actors, who could have been} beneficial to the learning process, but who were not engaged in the project? Were there any particular reasons to not engage them?

R: It goes in the direction of what I have said in the beginning, that I have learned that there is no perfect participatory process and that you will never reach that ideal. We do have a gap in cooperating with stakeholders from the private sector - that would be in theory and in practice I am not really sure if that would have been helpful for this stakeholder process to learn more. Obviously we could have learned 


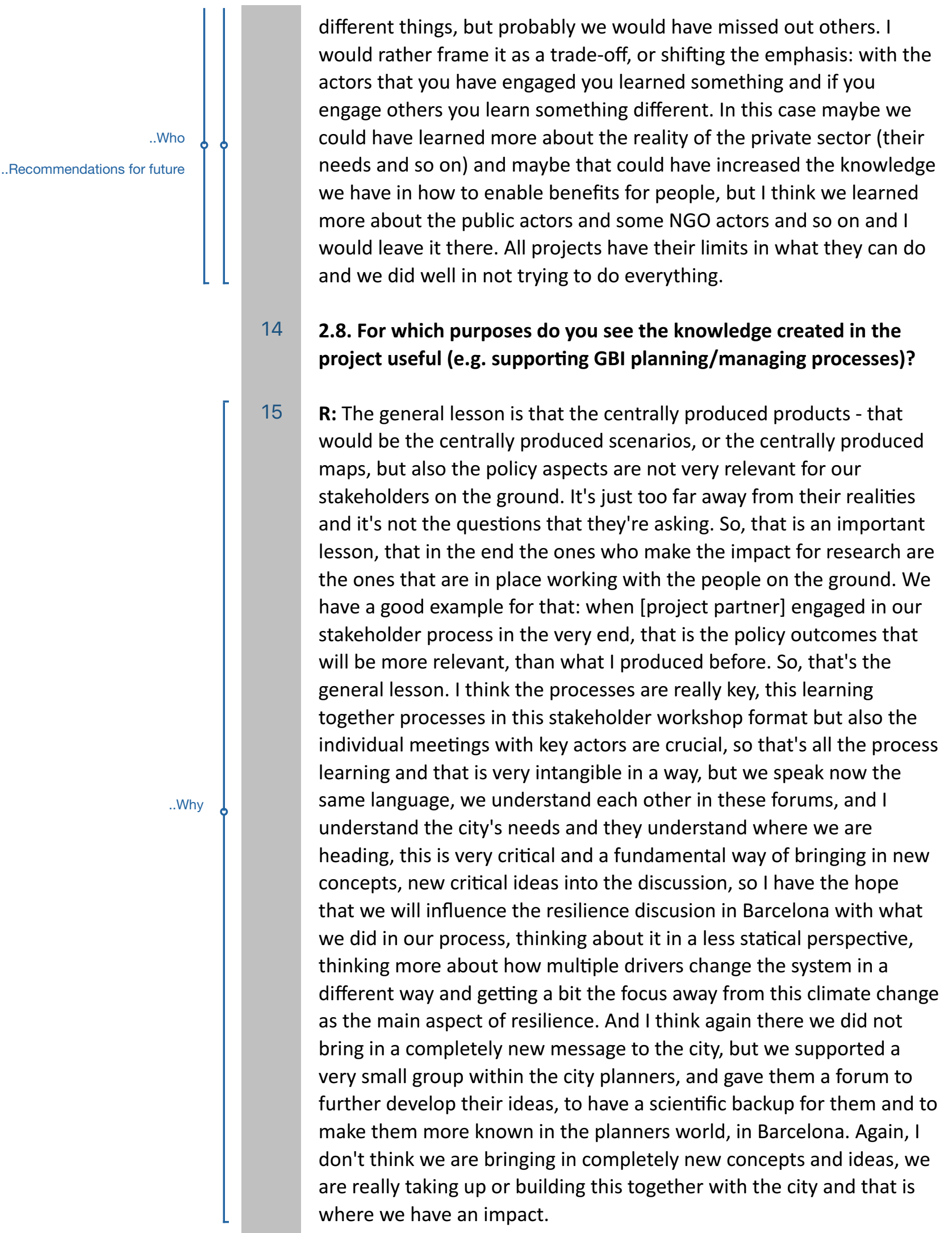

2.10. What new knowledge or new insights resulting from the project do you consider the most relevant for the planning and management of green and blue infrastructure in your case study city? 
R: That is maybe the strongest impact long term that we have now on the newly developed resilience strategy that is right now underway and one of the core meetings to establish this was one of our stakeholder meetings. So that is the hope I have that it is reflected there, but there are other things that are more concrete: we have done a valuation of ecosystem services from street trees and looking at justice aspects in their distribution and that is definitely information that the city will take up because they were very keen on having this, making the value of street trees more visible in a city where we have lower green but many street trees. Another thing that I am expecting to have impact, and again it falls on fruitful ground in the city, is our work on gender differences in the use of parks. The city has just this year brought up a document for incorporating gender perspectives in urban planning and this is the first empirical evidence that they have for the gender inequalities in the use and the flow of benefits from urban parks, so this will definitely have some impact and there are other things like the green roofs study will give some guidance and so on. One thing is the process and then there are other more concrete studies that tackle one specific need or specific knowledge the city was lacking.

\subsection{In which ways is the knowledge produced in the project useful for you (as support to your activities)?}

(I: you already mentioned that for you the knowledge or the learnings you got from the project were useful, for example, in how you design new studies or new proposals and that you are more focused in incorporating the end needs of the users in the process, so that was a way in which the ENABLE experience was useful for you, are there any others that you can think of?)

20 R: As said before, there were some conceptual things that I have taken up, that have advanced my own perspective, and maybe there are also some methodological issues, even though that was relatively small in what I would assume I have learned here, a little bit on the Bayesian Belief Network modelling and maybe the modelling the Berlin group is doing as well, understanding a bit more how that works; understanding how to create integrations with my own work.

2.11. Did the project meet your expectations regarding what you wanted to learn about? If not, what would you have liked to learn about, which was not possible through the project?

R: It was quite a messy process, it was difficult to navigate through this process and I think the expectations have changed over the course of the project several times, so I cannot really remember what were the initial expectations. I think I don't have that very clear. I think the trajectory was quite surprising. As co-lead of work package 2 I thought I would work more on policies, which in the end I did not do, and we had those very strong focuses on the Barcelona case, and none of the 


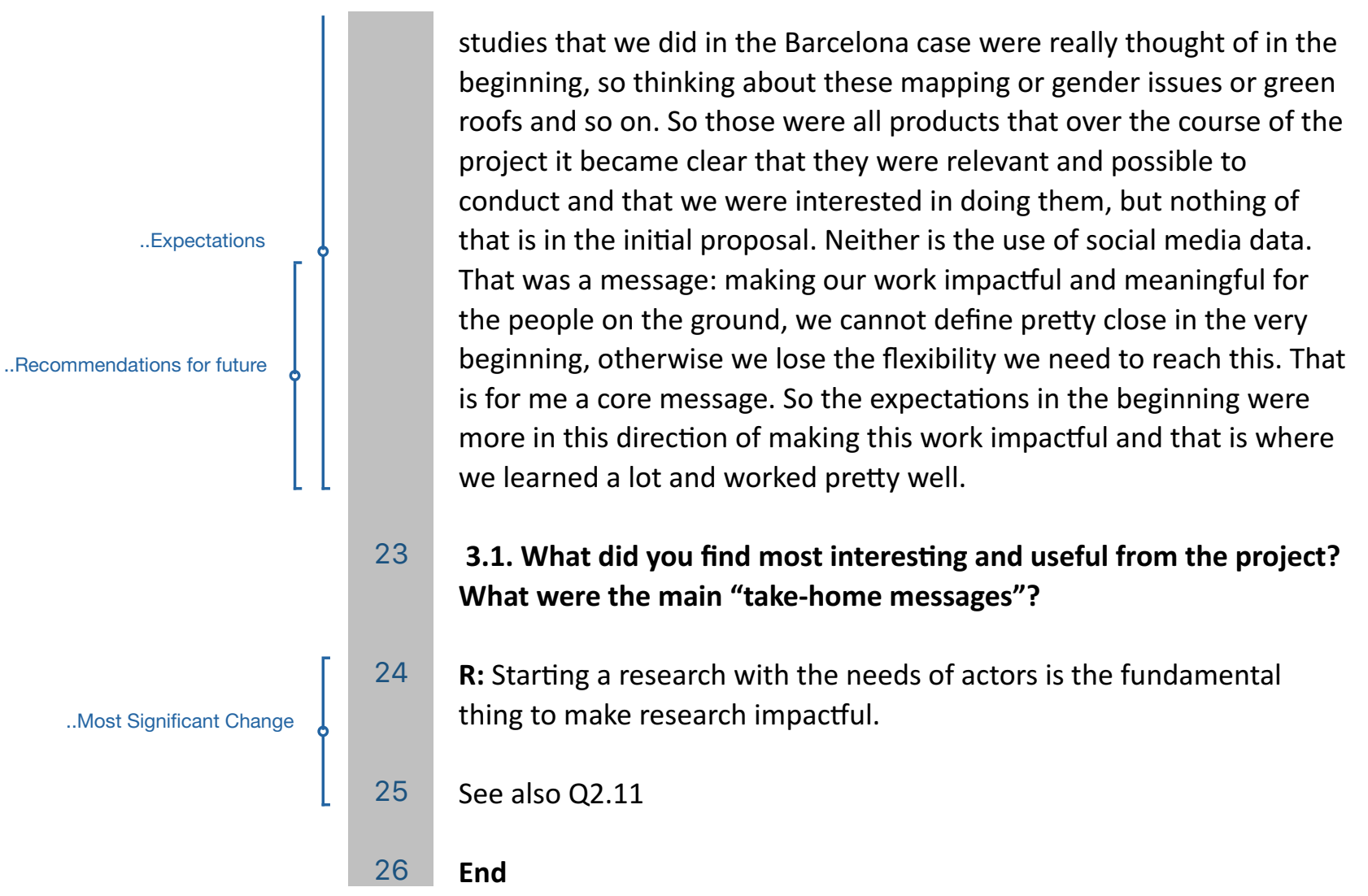


2.2. What events or other opportunities to foster learning did you promote in your ENABLE case study city? In which stages of the project did they take place?

R: We started the stakeholder process in March 2017 in the framework of [other project name] and ENABLE projects. We have done so far about 8 or 9 sessions and the topics have been changing, but we call the process a dialogue on the implementation of naturebased solutions and green and blue infrastructure in the Metropolitan Area of Barcelona. We try to bring together stakeholders from different organizations, both from public authorities like the city council of Barcelona but also the regional council, some departments of the Catalan Government, planning agencies, other research centers, we try also to have social organisations or neighbourhood associations, although it is more difficult for them to come because we organise these in the morning so it is more difficult for people to come. The topics of the meetings have been changing depending on the needs of the project at some point, at the same time we try also to talk about topics that are relevant for the stakeholders. The first one was, for example, on the identification, mapping and prioritization of nature-based solutions, we did a kind of workshop to do this spatialisation exercise. The second was more on the opportunities and barriers to integrate nature-based solutions and green infrastructure in urban planning, so it was more related with ENABLE with this barriers approach. Then the third one was on how can we increase green infrastructure in compact cities like Barcelona and in all of these meetings we have presentations from participants who are working on different initiatives at the policy level or urban planning level or projects related to green space. In this third one the urban green infrastructure program of the city council was presented and discussed. Then in March 2018 the topic was more related to health, so what is the impact of nature-based solutions and green infrastructure on human health and how can we make healthy cities. Here we invited researchers from a center here who are doing a lot of research on this topic, they are environmental epidemiologists. Then in June 2018 we did a more ENABLE-related meeting, related to green roofs. We organised it on a rooftop garden from the city council, they are doing a very interesting project related to social integration of people with mental disabilities and they work in this garden and other gardens in the city - they won a prize recently for this project. In this meeting it was a kind of prioritisation of where green roofs should be implemented in Barcelona based on different criteria, basically based on ecosystem services demand in the city. [BAR1] was more leading this study, which was recently published in a scientific journal. Then in December 2018, because our group is working more on environmental justice, we had a meeting on how can we integrate social and environmental justice and equity in urban greening. We openned that one a bit more than normal, we organised a public event in the 


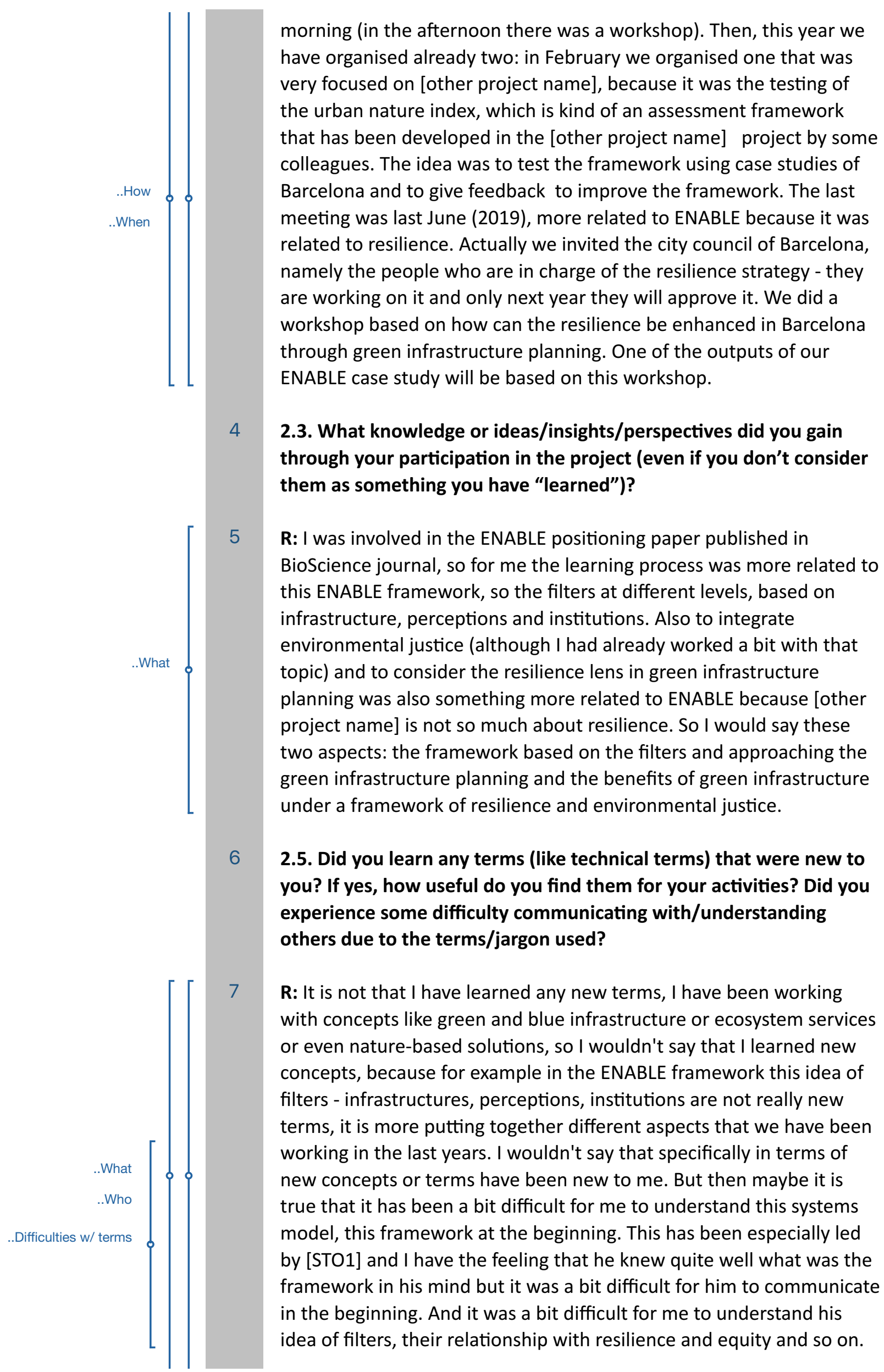




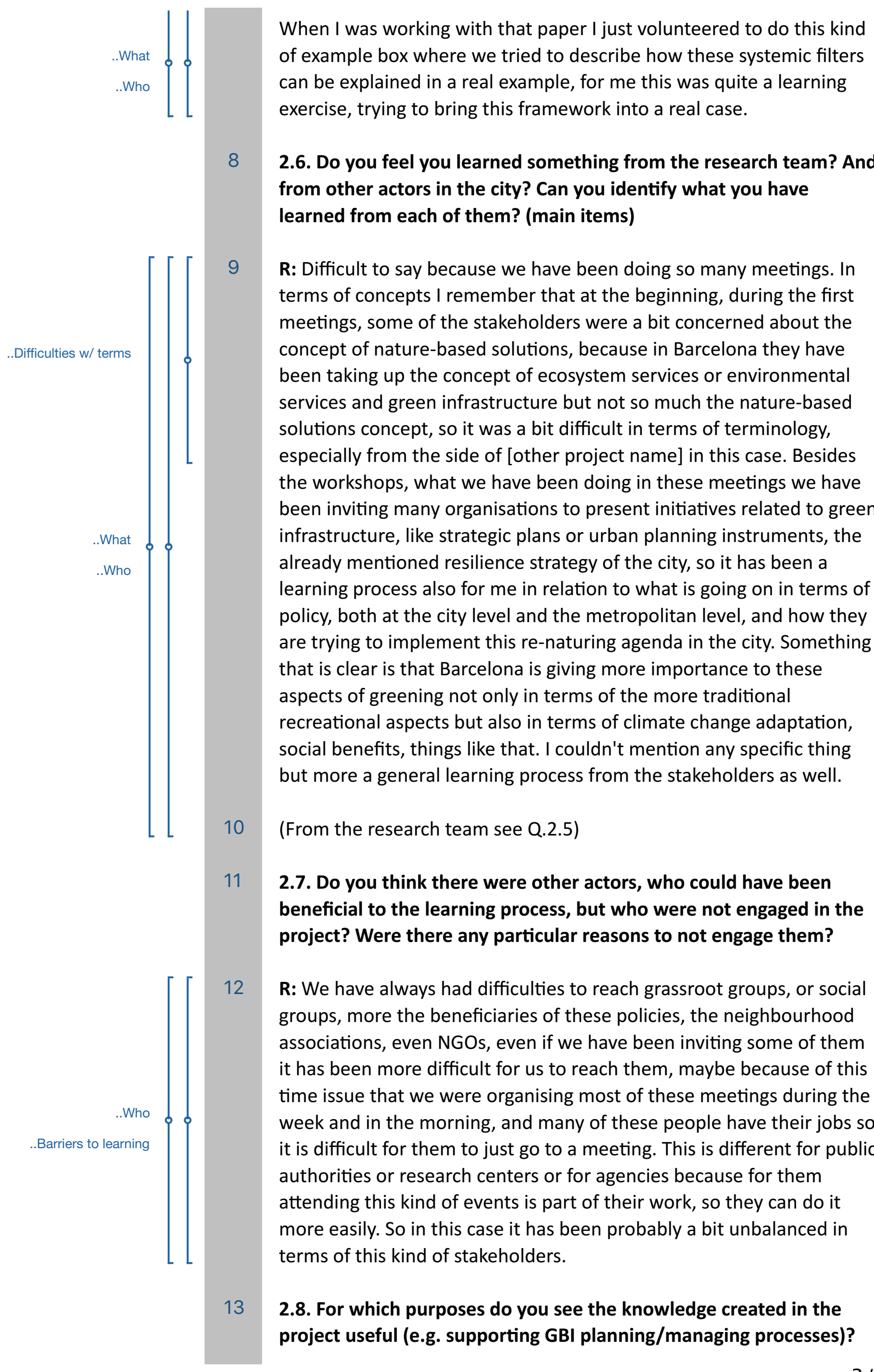


R: These kind of projects are trying to influence at some point the urban policy and urban planning and there are different decisionmaking contexts where this kind of research projects are influential. First would be simply awareness raising about the benefits of green infrastructure, maybe also the narrative aspects but also the benefits. Second, could be more directly influencing policy, priority-setting. Those would be the two levels to which the outputs of the project could be more relevant. Actually in the last meeting in June about resilience we co-organised the workshop with the city council (urban resilience department) so it could be useful for the strategy of the city, because they are now developing this strategy. We always try to organise these meetings together with stakeholders who have a kind of mandate for integrating these concepts in urban policy. Even if sometimes it is more about knowledge transfer only.

\subsection{In which ways is the knowledge produced in the project useful} for you (as support to your activities)?

R: I don't know if it was for specific things, being involved in research projects like ENABLE is more a learning process in general. Gaining knowledge is also useful for teaching. Sometimes I teach at Master level and the knowledge generated in these projects can be used, since it is something relevant and recent. In terms of benefits, the publications are also important for us as reseachers. Then all the networks that we are maintaining in these projects with different research organisations in Europe. I would say these are the most relevant for me.

\subsection{What new knowledge or new insights resulting from the} project do you consider the most relevant for the planning and management of green and blue infrastructure in your case study city?

R: I would say that the ENABLE framework, with this idea of the three filters, is something new, even if it is more difficult to operationalise. At the level of research I think it is important. For me all these aspects related to environmental justice have been useful, the idea of availability, accessibility and attractiveness, because our group here is focussing on environmental justice aspects, so it has been a good synergy with the ENABLE project.

2.11. Did the project meet your expectations regarding what you wanted to learn about? If not, what would you have liked to learn about, which was not possible through the project?

20 R: It is a bit difficult to answer this because I was supposed to be a bit more involved in the project than I could in the end. I do not exactly remember if my expectations were very high or not. I guess something that I was more or less involved in the beginning and I'm not sure 


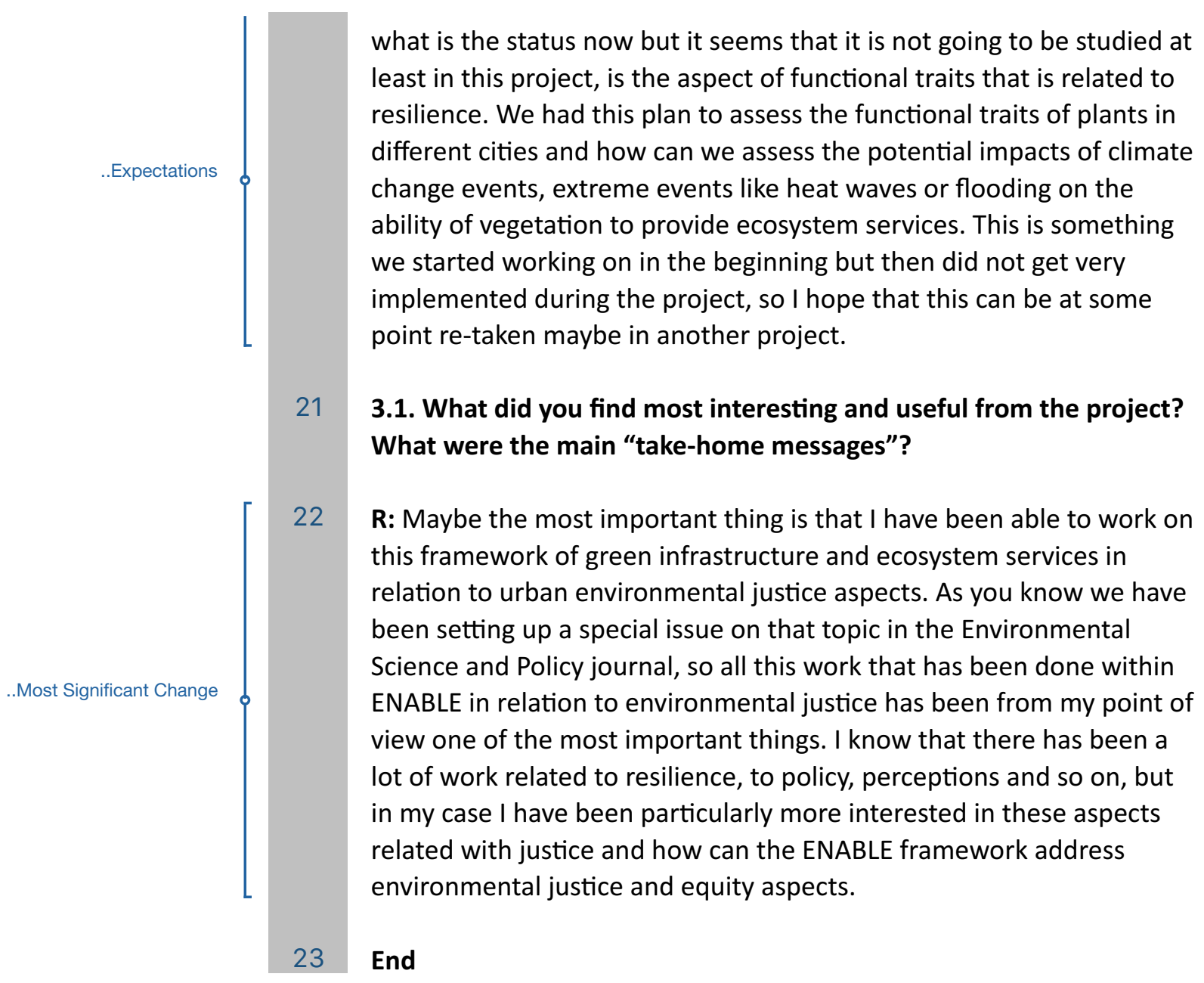




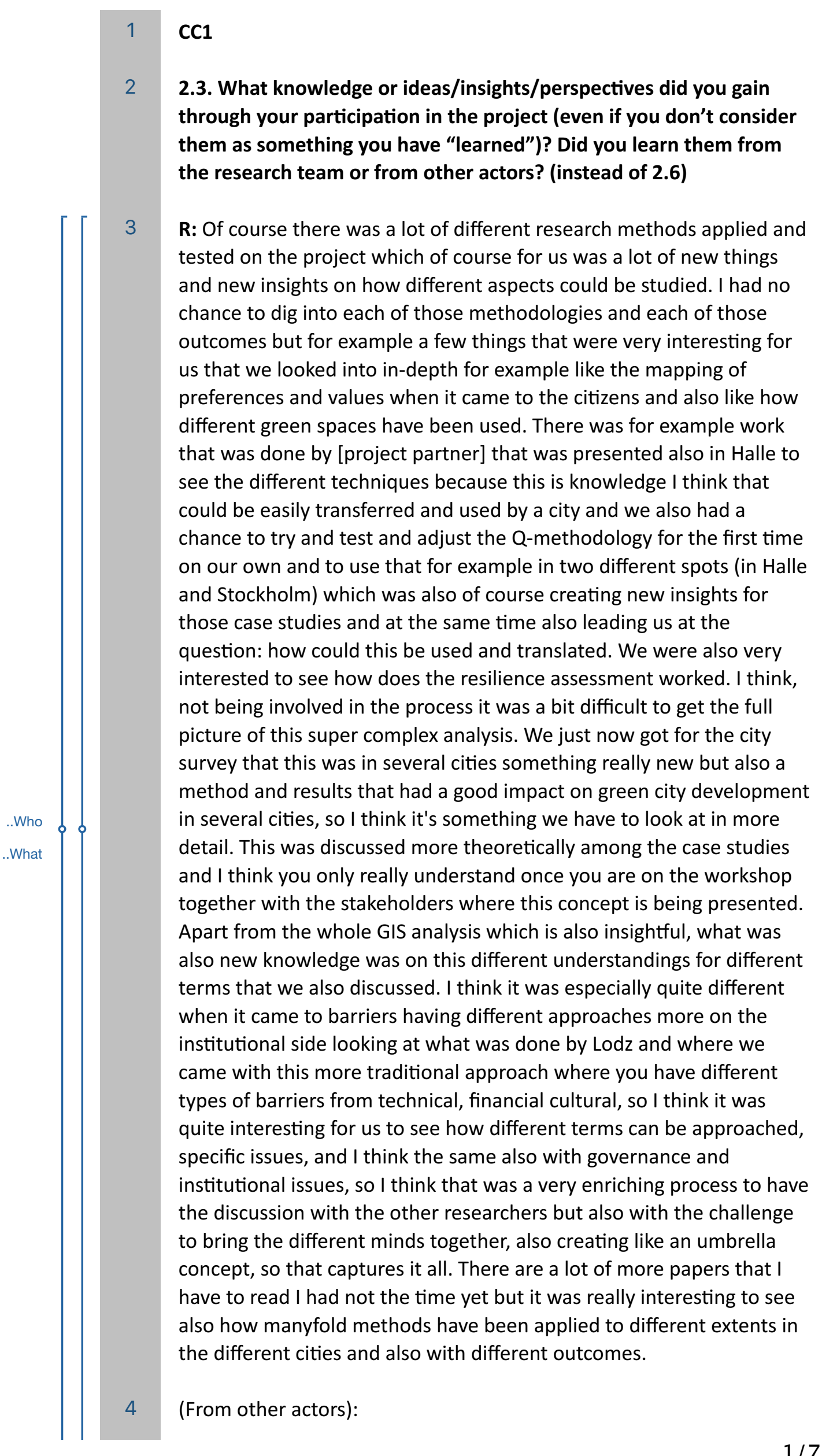


Our contact was rather limited because everything happened through the city research partners. I think the closest contact we had was with the different actors in Halle so with the city administration people and also with the people for example from Neutopia in Halle-Neustadt and I think that was insightful as well. It made us start thinking how can you really like apply a method which is usually super theoretic and super research driven but how can you apply it to a specific context, so that it is still understandable and can also create meaningful results, at least results that could be presented and ideally also feed into ongoing processes, so I think this was something that definitely we learned. Also there was so many different factors from culture, different habits of the people there and different interests and also with the language of course that's where we needed people who speak Arabic which we luckily had, or Russian. For us it was a challenge but it was a really good one to to embrace all those different factors. There was of course also contact with the city but I think they were always so overwhelmed with work, especially in the last workshop as I remember, they were unfortunately not that many people as expected so I think that left us with a question mark: the people who were there were really motivated, but still the question what could be achieved if other people had been involved. That was not fully clear from this contact. Our interaction in Lodz also enlightened us like how for example the term green and blue infrastructure is being perceived and also operationalized which can be super different from technological solutions or just really be regeneration towards really green solutions taking into account multiple benefits. I think this is what we learned when engaging with the stakeholders either through workshops or just for the study site visits.

\subsection{Through which project-related activities (e.g. workshops in other ENABLE cities, stakeholder workshops in own city) do you think you have learned the most?}

R: Maybe because it's fresh but also because I was more strongly involved, were the latest series of workshops that happened in the second half of last year, that was what we call it the co-creation workshops to discuss the policy options. We have been deeply involved also in the design of some of these, to see how we we can really get the messages that we want, so I think we took a lot of it of course. There's a lot of variety of different outcomes but it also made us realize how different processes are and also showed to some extent that each city had a different focus some were regional in focus some had a specific topic to follow up. You cannot just compare those results but I think what was really good for my learning was to see the different approaches in terms of people that they had invited, the discussions they had but also to see how different the outcomes were, like when it came to potential policy options that have been discussed and that have a lower or higher chance also to feed into future policy development. I think this is what I remember the most. I was really amazed that even for cities that were struggling, like Lodz, they were 


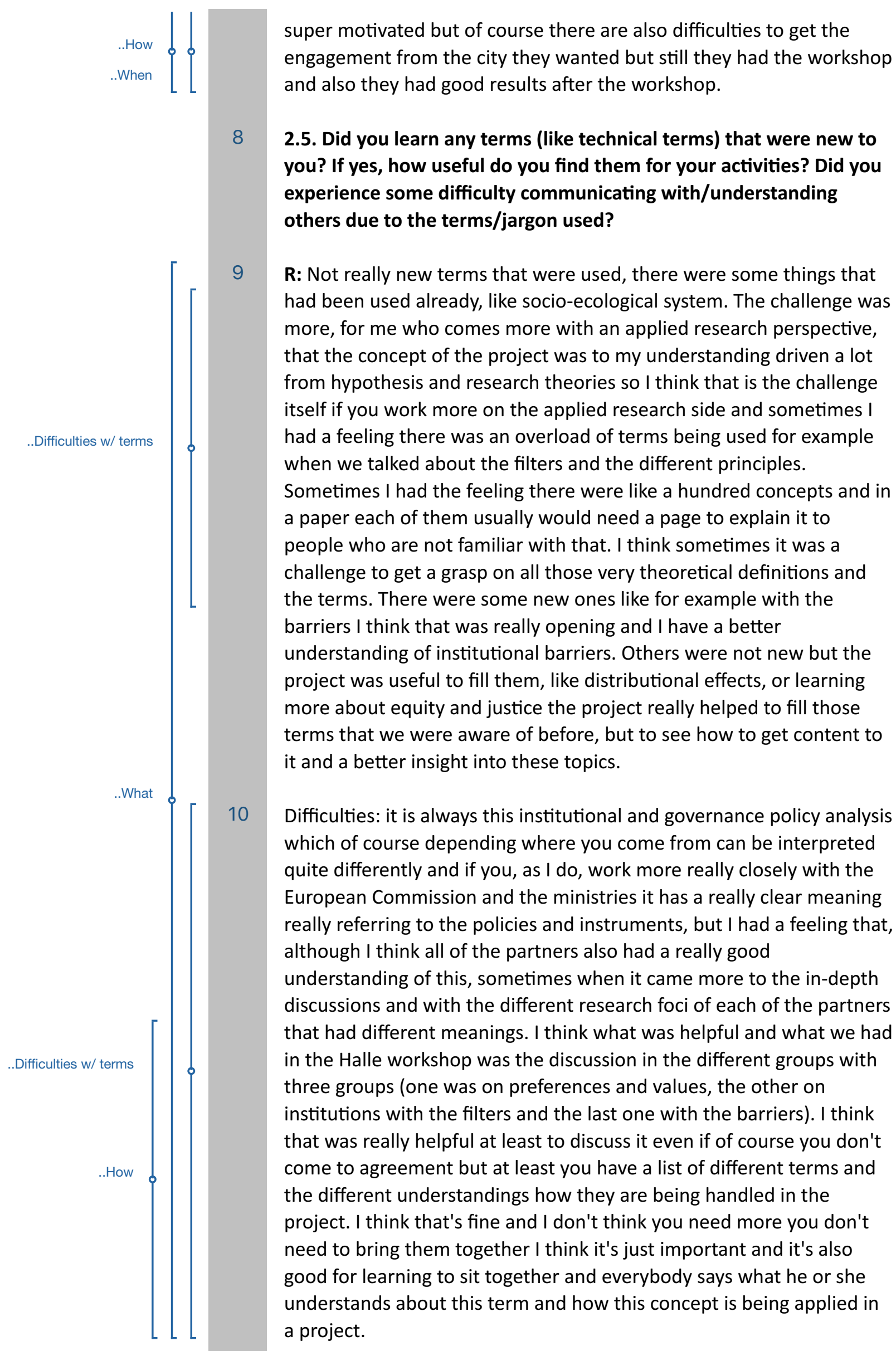


2.7. Do you think there were other actors, who could have been beneficial to the learning process, but who were not engaged in the project? Were there any particular reasons to not engage them?

R: We had an event in Brussels and invited the right people because we had for example DG Environment and DG RTD present and other stakeholders. It would have been interesting to engage, to a certain extent, with one or two other projects that were running under the same funding scheme, to exchange, see what is their research focus and if there may be some some overlaps or similarities. For the cities usually you should always have the people who have a say in these topics - like the city officials from the city development or the environmental department. That was the case in some of our case studies, but you should also engage people who also can have a contribution, maybe people who work in education or in health. What was I think super interesting from the Oslo case, and maybe that was a special case but they were I think quite successful, at least in some areas, because [OSL1] worked really closely with the technicians. That is quite interesting because I think there were no really technicians in the other cases, maybe it wouldn't have made sense but it was interesting to see that depending on what you work on, you might need to engage other people.

2.10. What new knowledge or new insights resulting from the project do you consider the most relevant for the planning and management of green and blue infrastructure in the case study cities?

R: Starting with presenting and discussing a new holistic approach also in terms of a resilience assessment that considers multiple benefits in a really integrated way. That was something new to the cities and to some extent also triggered other perspectives and views on green and blue infrastructure, so that helped in several cities to open their minds. I think that was something, like increasing and handing a more systemic understanding of green and blue infrastructure and what is included, so it's not just climate change but it could be also social aspects or other things that are being addressed. Another thing which is part of that but has been addressed more specifically was having more focus on the social dimension of green and blue infrastructure, for example thinking about how green and blue spaces are distributed, how different people benefit or don't benefit from it and then addressing this issue of equity, which is emerging but I think it's still not something that's in the minds of the people who are planning maybe because they don't have time to think about it. Another thing that was quite beneficial was just improving the evidence for decisionmaking. A lot of those things have been supported also by GIS analysis and providing data and maps (for example in NYC data on stormwater management), so providing planning authorities with analyses that maybe they couldn't do themselves mostly maybe because they don't have the timely capacities or they don't have the technical capacities 
..What ..Why

15

16

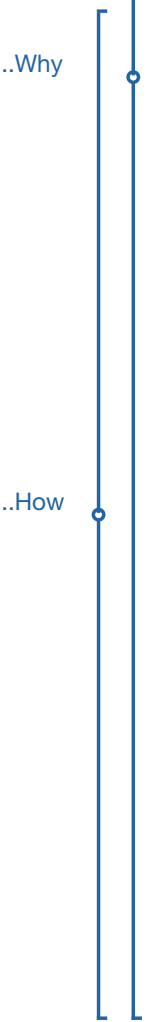

17 so I think these analyses also were a big step to maybe support or to inform future initiatives.

\subsection{In which ways is the knowledge produced in the project useful for you (as support to your activities)?}

R: Mostly from stuff we did ourselves, for the first time we started digging into this topic of preferences and values and perceptions of citizens when it comes to the design of green infrastructure, this was a super good opportunity for us to to try and test a specific method but also learn about other methods that have been applied by other partners in this regard and that is also something that we will follow up in the future and in other projects because we should take into account people's preferences and not presume that we know what they want. This is something that helped us enlarging the focus of our green and blue infrastructure work. Another thing we are super interested in is what is needed to establish and enable a good relationship and a good working basis between researchers and practitioners (and in this case the cities) because maybe compared to others, we are not so much involved in scientific research (testing hypothesis, publishing papers) but we are very interested to look into what the cities have learned here and maybe over many years and helping us elicit the hampering but also success factors, but also showcasing what results have been through processes and why it worked or why it didn't work. I think that was something that's adding new knowledge for our work that is very important also to take into account for future work because you can much better encounter those factors and then adjust again your method as necessary, also when building own processes with cities it's also helpful to know what is really needed or what could be a good approach for example to establish a good relationship and a trusty relationship because that's key to create benefits for both sides and also to work towards a goal. I think this was not explicit in ENABLE so we just had a discussion using transdisciplinary approach but there are different definitions so if you take it easy you could just say it's a good big cooperation between researchers and administrations or citizens but there are also concepts that say no well actually you start already with a joint problem definition and then you create your research agenda and you work towards it. I had the feeling we started with the methods and with the research which was fine because this was the scope of the project but in my understanding it was not a hundred percent transdisciplinary approach because then we would have started with a gap and a problem analysis in each of the cities and would have designed [the research] but of course it was not the purpose because the purpose was a different one.

3.4. Based on your experience with ENABLE, how should knowledge exchange strategies and processes be designed in the future to enhance the learning process? 
19 There are different interests always in such a research project so of course we have to advance with specific methods and different approaches, assessment this has to be advanced so this is one interest. On the other hand we should address societal challenges, seeing what are the key problems and then to see what could be the methods that could be applied. Sometimes I felt the amount of methods we were dealing with was quite overwhelming and the question would be how they fit together, because the idea was to have a complementary implementation of the different methods and I think they all had good results but maybe there could have been a few less methods to apply to a specific target but of course with the freedom of the researcher also to test new things so working with the instruments and having the researcher as a sort of knowledge broker who has knowledge but knowing that there's also knowledge from the city side. There is a lot of local knowledge that does not always necessarily go into our research. So start earlier with a discussion with the cities and then find a concept that fits the interest of the people being involved and that is still of course realistic and maybe also don't commit to too many methods but a good set of methods that could be beneficial for most of the cities and then try if possible to have a more frequent exchange maybe with smaller meetings to establish a small dialogue so that it's not only like once a year or twice a year but so keep the people informed. In the end what you deliver is something that could be really not just informing but ideally something that could already directly feed into ongoing processes. I think that already happened in a few cities but if you even increase the number of dialogues which still works for both in terms of workload I think that could be quite beneficial. And even more exchange between the cities not just between the researchers. I think it would be interesting for the cities if they have not just the role of a research subject but also give them the room to exchange because it's also a learning experience and you learn the most if you go into the cities and see the places and hear the stories.

\subsection{Did the project meet your expectations regarding what you wanted to learn about? If not, what would you have liked to learn about, which was not possible through the project?}

R: First of all we were a newbie to this team, there was a lot of relations already established through I think the URBES project. I think we were lucky to get the opportunity to work with this new group of people, which was a new network for us which is always a new exciting experience for us because we know there's a lot of expertise that this network has and that we can just benefit from, because all partners had a lot of publications. We were really excited to get the opportunity to work with this team. I don't think we had like a specific expectation, I think there was a lot of interest when we had the concept and for example to learn more, from the very beginning, 

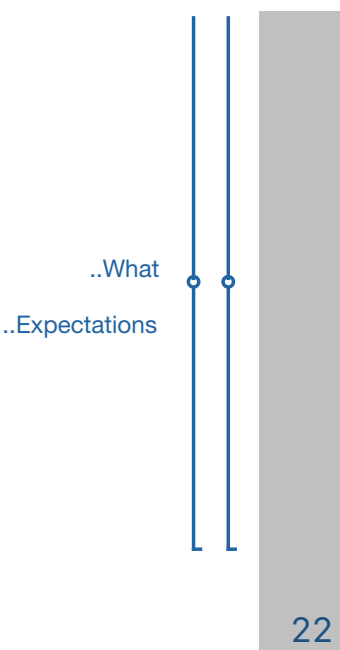

23

R: One of the things that definitely we will take away and take back to our work is this potpourri of possible assessments and methods, that worked really well in practice together with the cities and to take those into account when starting to work with other cities, just to learn what research can contribute to improve the current planning when it comes to green and blue infrastructure, or nature based solutions, having an overview of methods which you can pick from, I think that's really worth having and then trying to implement them in other projects.

24 Thinking about what does it take to create a good cooperation with the city that's beneficial for both sides knowing about all the different factors that could impact such a work and either hamper but also be success drivers, I think that's also very insightful.

25 And then learning from the experiences from the cities, what specific research has made an impact in those cities and taking those also as good examples when going to other cities. It's always good to see what has worked in a given city, what was the result and maybe this is something that we can try, of course adjusting to the local context, and I think that's also helpful with these different different regional cases that we looked at and of course also looking at the things maybe that worked less well that's also like learning from the failures or things that worked out differently than expected, this is quiet a valuable information for other cities for example.

\section{End}

